Rodrigo Telles da Silva Vale

\title{
Localização de Monte Carlo aplicada a robôs submarinos
}

São Paulo

2014 
Rodrigo Telles da Silva Vale

\section{Localização de Monte Carlo aplicada a robôs submarinos}

Dissertação apresentada à Escola Politénica da Universidade de São Paulo para obtenção do título de Mestre em Ciências.

Área de Concentração: Engenharia de Controle e Automação Mecânica

Orientador: Prof. Dr. Thiago de Castro Martins

São Paulo

2014 
Este exemplar foi revisado e corrigido em relação à versão original, sob responsabilidade única do autor e com a anuência de seu orientador.

São Paulo, de novembro de 2014.

Assinatura do autor

Assinatura do orientador

Catalogação-na-publicação

Vale, Rodrigo Telles da Silva Localização de Monte Carlo aplicada a robôs submarinos /

R.T.S. Vale. -- versão corr. -- São Paulo, 2014. $101 \mathrm{p}$.

Dissertação (Mestrado) - Escola Politécnica da Universidade de São Paulo. Departamento de Engenharia Mecatrônica e de Sistemas Mecânicos.

1.Submersíveis não tripulados 2.Navegação em tempo real 3.Filtro de partículas 4.Sonar I.Universidade de São Paulo. Escola Politécnica. Departamento de Engenharia Mecatrônica e de Sistemas Mecânicos II.t. 


\section{Agradecimentos}

Agradeço primeiramente aos meus pais e aos meus irmãos pelo apoio e carinho.

Aos amigos do laboratório de Veículos Não Tripulados (João Dantas, Lucas Machado, William Caetano, Persing Cardenas, Artur Freitas, Rodrigo Diana e Franco Picarelli, Sarah Pérez e Igor Silva ) pelo companheirismo e pela colaboração durante os ensaios.

Aos amigos do laboratório de Geometria Computacional ( Edson Ueda, André Sato e Rogério Takimoto ) pelo companheirismo.

Ao pessoal do laboratório de Engenharia Naval e Oceânica ( João Martins, Marlei Araujo e Carlos Freire ) pelo apoio nos ensaios.

Ao prof. Dr. Eduardo Aoun Tannuri pelo auxílio com o equipamento de rastreio visual. Ao prof. Dr. Ettore Apolonio de Barros pela oportunidade da pesquisa no ramo de navegação.

Ao meu orientador, prof. Dr. Thiago de Castro Martins pela imensa ajuda, apoio e paciência.

À Companhia Energética de São Paulo pelo suporte. 


\section{Resumo}

A tarefa de operar um veículo submarino durante missões de inspeção de ambientes estruturados como, por exemplo, duto de usinas hidrelétricas, é feita principalmente por meio de referências visuais e uma bússola magnética. Porém alguns ambientes desse tipo podem apresentar uma combinação de baixa visibilidade e anomalias ferromagnéticas que inviabilizaria esse tipo de operação. Este trabalho, motivado pelo desenvolvimento de um veículo submarino operado remotamente (ROV) para ser usado em ambientes com essas restrições, propõe um sistema de navegação que utiliza o conhecimento prévio das dimensões do ambiente para corrigir o estado do veículo por meio da correlação dessas dimensões com os dados de um sonar de imageamento 2D. Para fazer essa correlação é utilizado o filtro de partículas, que é uma implementação não paramétrica do filtro Bayesiano. Esse filtro faz a estimação do estado com base nos métodos sequenciais de Monte Carlo e permite trabalhar de uma maneira simples com modelos não lineares. A desvantagem desse tipo de fusão sensorial é o seu alto custo computacional o que geralmente o impede de ser utilizado em aplicações de tempo real. Para que seja possível utilizar esse filtro em tempo real, será proposto neste trabalho uma implementação paralela utilizando uma unidade de processamento gráfico (GPU) da NVIDIA e a arquitetura CUDA. Neste trabalho também será feito um estudo da utilização de duas configurações de sensores no sistema de navegação proposto neste trabalho. 


\section{Abstract}

The task of navigating a Remotely Operated underwater Vehicles (ROV) during inspection of man-made structures is performed mostly by visual references and occasionally a magnetic compass. Yet, some environments present a combination of low visibility and ferromagnetic anomalies that negates this approach. This paper, motivated by the development of a ROV designed to work on such environment, proposes a navigation method for this kind of vehicle. As the modeling of the system is nonlinear, the method proposed uses a particle filter to represent the vehicle state that is a nonparametric implementation of the Bayes filter. This method to work needs a priori knowledge of the environment map and to make the data association with this map, a $2 \mathrm{D}$ image sonar is used. The drawback of the sensor fusion used in this work is its high computational cost which generally prevents it from being used in real time applications. To be possible for this filter to be used in real time application, in this work is proposed a parallel implementation using a graphics processing unit (GPU) from NVIDIA and CUDA architecture. In this work is also made a study of two types of sensors configuration on the navigation system proposed in this work.

Key-words: Unmanned Underwater Vehicle, Real Time Navigation, Particle Filter, Sonar. 


\section{Sumário}

Sumário ......................... 5

Lista de ilustrações . . . . . . . . . . . . . . 7

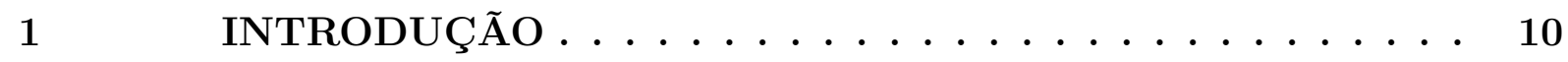

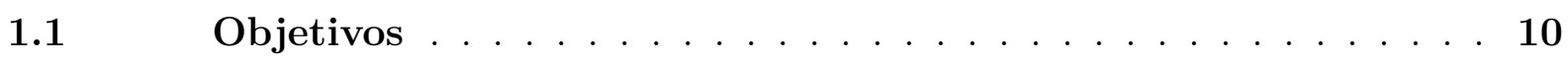

1.2 Revisão Bibliográfica . . . . . . . . . . . . . . . . 11

1.3 Organização da tese . . . . . . . . . . . . . 15

2 ESTUDO DOS SENSORES EMPREGADOS . . . . . . 17

$2.1 \quad$ Sonares de imageamento $2 \mathrm{D}$ de visão frontal . . . . . . . . . . . . 17

2.1.1 Sonar de varredura mecânica . . . . . . . . . . . . . . . . . . . . 19

2.1.2 Sonar de multi elementos . . . . . . . . . . . . . . . . . . . . 20

2.1.3 Comparação entre os sonares . . . . . . . . . . . . . . . . . 21

2.1.4 Perturbações nas imagens dos sonares . . . . . . . . . . . . . . . . 21

$2.2 \quad$ Medidor de velocidades por efeito Doppler . . . . . . . . . . 23

$2.3 \quad$ Giroscópio . . . . . . . . . . . . . . . . 24

2.3.1 Erros característico dos giroscópios . . . . . . . . . . . . . . . . . 24

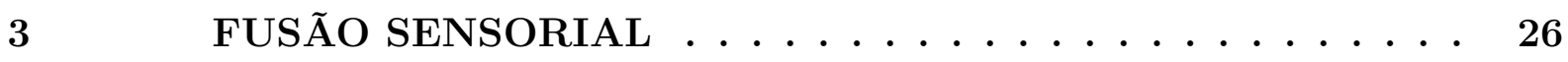

3.1 Estimação Bayesiana . . . . . . . . . . . . . 27

3.2 Filtro de Partículas . . . . . . . . . . . . . . . . . . . 27

3.2.1 Integração de Monte Carlo . . . . . . . . . . . . . . . . . . . 29

3.2.2 Sequential Importance Sampling _ . . . . . . . . . . . . . . . . 30

3.2.3 Sequential Importance Resampling . . . . . . . . . . . . . . . . . . . . 33

3.2.4 Outras variações da etapa de reamostragem . . . . . . . . . . . . . . . 34

3.2.4.1 Reamostragem estratificada . . . . . . . . . . . . . . . . 34

3.2.4.2 Reamostragem sistemática . . . . . . . . . . . . . . . . . . 35

4 LOCALIZAÇÃO DE MONTE CARLO . . . . . . . . 36

$4.1 \quad$ Algoritmo . . . . . . . . . . . . . . 36

4.2 Modelagem do sistema . . . . . . . . . . . . . 38

4.2.1 Modelo de Propagação _ . . . . . . . . . . . . . . . . . . . . . . . 39

4.2.2 Modelos de Medição . . . . . . . . . . . . . . . . . . . 43

4.2.2.1 Modelo do sonar f . . . . . . . . . . . . . . . . . . . . 43

4.2.2.2 Processo de filtragem do sonar . . . . . . . . . . . . . . . . . . . . . . . . 44

4.2.2.3 Modelo . . . . . . . . . . . . . . . . . . . . . . . . . . . . 45 
4.3 Configurações de sensores estudadas $\ldots \ldots \ldots \ldots \ldots \ldots$

$5.1 \quad$ Unidades de processamento gráfico (GPUs) . . . . . . . 51

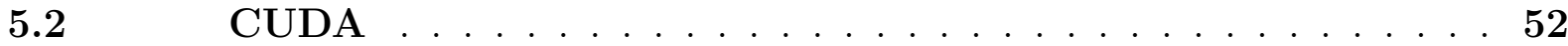

$5.3 \quad$ Estudo da paralelização do filtro de partículas . . . . . . . . 52

5.4 Implementação paralela da localização de Monte Carlo em uma GPU utilizando CUDA . . . . . . . . . . . . . . . . . 56

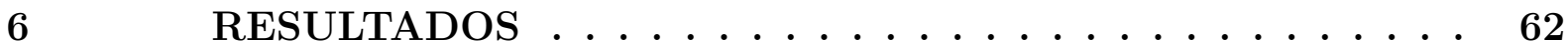

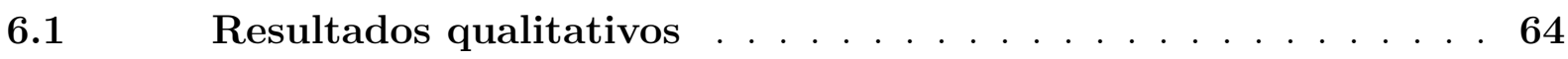

6.2 Resultados quantitativos com referência externa . . . . . . . . 66

6.2.1 Configuração de cada sensor nos testes _ . . . . . . . . . . . . . 67

6.2.2 Resultados com o sonar de varredura mecânica . . . . . . . . . . 67

6.2.3 Resultados com o sonar de multi elementos _ . . . . . . . . . . . 75

6.2.4 Influência do tamanho do conjunto de partículas . . . . . . . . . . . 80

6.2.4.1 Efeito do número de partículas no erro RMS da estimativa de posição . . . . . . . 82

6.2.4.2 Efeito do número de partículas na entropia relativa da posição $\ldots \ldots \ldots$

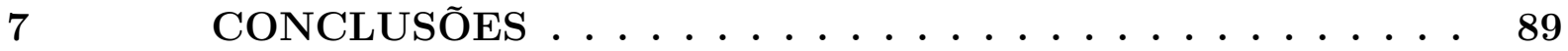

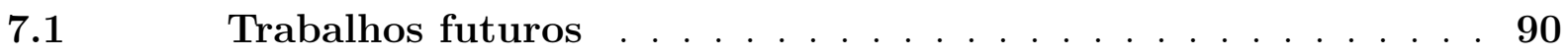

A ESPECIFICAÇÕES DO MEDIDOR DE VELOCIDADE POR EFEITO DOPPLER .................. 92

A.1 Descrição . . . . . . . . . . . . . . . . . 92

B ESPECIFICAÇÕES DO GIROSCÓPIO . . . . . . . . . 93

B.1 Descrição . . . . . . . . . . . . . . . . . . 93

C ESPECIFICAÇÕES DO SONAR DE VARREDURA MECÂ-

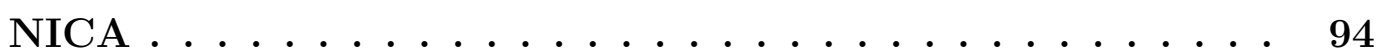

C.1 Descrição . . . . . . . . . . . . . . . . . . . 94

D $\quad$ ESPECIFICAÇÕES DO SONAR DE MULTI ELEMENTOS . 95

D.1 Descrição . . . . . . . . . . . . . . . . . . . 95

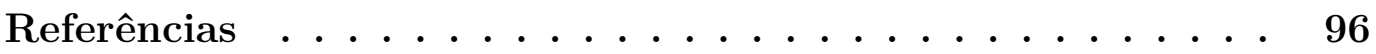




\section{Lista de ilustrações}

Figura 2.1 - Imagem do sonar de varredura mecânica tirada em um tanque retangular 19

Figura 2.2 - Imagem do sonar de multi elementos tirada em um tanque retangular 20

Figura 2.3 - Resultado da imagem de um sonar de uma quina quadrada . . . . . . . 22

Figura 3.4 - A rede bayesiana dinâmica que caracteriza a evolução do estado, das medidas e das entradas de controle . . . . . . . . . . . . . 26

Figura 3.5 - Representação de distribuições por amostragem . . . . . . . . . . . . . 29

Figura 3.6 - Passos do Sequential Importance Resampling . . . . . . . . . . . . . . . 31

Figura 3.7 - Passos do filtro Sequential Importance Resampling . . . . . . . . . . . 33

Figura 4.8 - Representação dos sistemas de coordenadas . . . . . . . . . . . . . . . 40

Figura 4.9 - Imagem de sonar do tanque de testes . . . . . . . . . . . . . . . . . . 44

Figura 4.10-Resultado da filtragem dos dados do sonar . . . . . . . . . . . . . . . . 45

Figura 4.11-Função densidade de probabilidade do modelo do sonar . . . . . . . . . 46

Figura 4.12-Esquema da localização de Monte Carlo para a configuração de sensores do sonar de varredura mecânica . . . . . . . . . . . . . . . . . 49

Figura 4.13-Esquema da localização de Monte Carlo para a configuração de sensores do sonar de multi elementos . . . . . . . . . . . . . . . . . 49

Figura 5.14-Comparação entre o tempo de processamento do algoritmo de localização de Monte Carlo sem a parte de filtragem dos dados do sonar para o caso da configuração de sensor formada pelo sonar de multi elementos entre a CPU e a GPU . . . . . . . . . . . . . . . . . . 60 60

Figura 6.15-Desenho técnico da plataforma flutuante utilizada nos testes . . . . . . 63

Figura 6.16-Foto da plataforma flutuante utilizada nos testes . . . . . . . . . . . 63

Figura 6.17-Primeira forma de validação a localização de Monte Carlo foi verificar a sua convergência utilizando dados dos sensores para o caso em que a plataforma permaneceu parada (iterações do algoritmo estão da esquerda para a direita) . . . . . . . . . . . . . . . . . 64 64

Figura 6.18-Comparação entre o rumo obtido com o sistema de navegação proposto nesse trabalho (vermelho) e o rumo estimado por uma AHRS (azul) no primeiro teste . . . . . . . . . . . . . . 6 65

Figura 6.19-Uma das câmeras utilizadas para validar os resultados deste trabalho . 66

Figura 6.20-Comparação entre a estimativa de rumo pelo sistema de câmeras (preto), pelo sistema de navegação ( vermelho ) e pelo sensor AHRS (azul) para o teste de trajetória retangular com pouca variação de rumo . . . . . . 68

Figura 6.21-Análise do erro da estimativa de rumo pelo sistema de navegação para o teste de trajetória retangular com pouca variação de rumo . . . . . . 69 
Figura 6.22-Comparação entre a estimativa de posição dada pelo sistema de câmeras (preto), pelo sistema de navegação ( vermelho ) e pela navegação estimada (azul) para o teste de trajetória retangular com pouca variação de rumo . . . . . . . . . . . . . . . . . . . .

Figura 6.23-Análise da estimativa de posição pelo sistema de navegação para trajetória retangular com pouca variação de rumo . . . . . . . . . . . . . 7

Figura 6.24-Comparação entre a estimativa de rumo do sistema de câmeras (preto), do sistema de navegação (vermelho) e da AHRS (azul) para o teste em que a plataforma permaneceu em torno da mesma posição mas com oscilação no rumo . . . . . . . . . . . . . . . . . . . . . .

Figura 6.25-Análise da estimativa de posição pelo sistema de navegação para plataforma oscilando em rumo na mesma posição . . . . . . . . . . . . . . . 72

Figura 6.26-Comparação entre a estimativa de rumo do sistema de câmeras (preto), do sistema de navegação ( vermelho ) e da AHRS (azul) para o teste de trajetória retangular com variação de rumo . . . . . . . . . . . . .

Figura 6.27-Análise do erro da estimativa de rumo pelo sistema de navegação para trajetória retangular com variação de rumo . . . . . . . . . . . . . . 73

Figura 6.28-Comparação entre a estimativa de posição do sistema de câmeras (preto), do sistema de navegação ( vermelho ) e da navegação estimada (azul) para o teste de trajetória retangular com variação de rumo . . . . . . 74

Figura 6.29-Análise do erro da estimativa de posição pelo sistema de navegação para o teste de trajetória retangular com variação de rumo . . . . . . . 74

Figura 6.30-Comparação entre a estimativa de rumo do sistema de câmeras (preto) e do sistema de navegação ( vermelho ) para o teste de trajetória retangular com pouca variação de rumo . . . . . . . . . . . . . . .

Figura 6.31-Análise do erro da estimativa de rumo pelo sistema de navegação para o teste de trajetória retangular com pouca variação de rumo . . . . . . 75

Figura 6.32-Comparação entre a estimativa de posição do sistema de câmeras (preto) e do sistema de navegação ( vermelho ) para o teste de trajetória retangular com pouca variação de rumo

Figura 6.33-Análise do erro da estimativa de posição pelo sistema de navegação para o teste de trajetória retangular com pouca variação de rumo . . . 76

Figura 6.34-Comparação entre a estimativa de rumo do sistema de câmeras (preto) e do sistema de navegação (vermelho) para o teste em que a plataforma permaneceu em torno da mesma posição mas com o rumo oscilando

Figura 6.35-Análise do erro da estimativa de rumo pelo sistema de navegação para o teste de trajetória retangular sem variação de rumo 
Figura 6.36-Comparação entre a estimativa de rumo do sistema de câmeras (preto) e do sistema de navegação ( vermelho ) para o teste de trajetória retangular com oscilação no rumo . . . . . . . . . . . . . . 78

Figura 6.37-Análise do erro da estimativa de rumo pelo sistema de navegação para o teste de trajetória retangular com oscilação no rumo $\quad$. . . . . . . . . 79

Figura 6.38-Comparação entre a estimativa de posição do sistema de câmeras (preto) e do sistema de navegação ( vermelho ) para o teste de trajetória retangular com oscilação no rumo . . . . . . . . . . . . . . 79

Figura 6.39-Análise do erro da estimativa de posição pelo sistema de navegação para o teste de trajetória retangular com oscilação no rumo . . . . . . 80

Figura 6.40-Resultado do cálculo do RMS para diferentes números de partículas para a configuração de sensores que utiliza o sonar de varredura mecânica 83

Figura 6.41-Resultado do cálculo do RMS para diferentes números de partículas para a configuração de sensores que utiliza o sonar de multi elementos . 83

Figura 6.42-Método escolhido para extrapolar uma função de densidade de probabilidade de um conjunto de pontos . . . . . . . . . . . . . . . . . . 85

Figura 6.43-Comparação da variância na estimativa de posição dada pelo algoritmo de navegação usando sonar de varredura mecânica o medidor de velocidades por efeito Doppler e o giroscópio para diferentes números de partículas . . . . . . . . . . . . . . . . 886

Figura 6.44-Comparação da variância na estimativa de posição dada pelo algoritmo de navegação para diferentes números departículas . . . . . . . . . . 87

Figura 6.45-Resultado do cálculo da entropia relativa para diferentes números de partículas para a configuração de sensores que utiliza o sonar de varredura

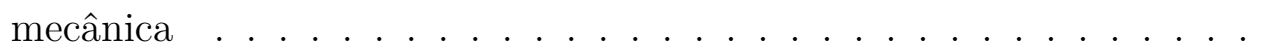

Figura 6.46-Resultado do cálculo da entropia relativa para diferentes números de partículas para a configuração de sensores que utiliza o sonar de multi elementos ........................ 88 


\section{Introdução}

A complexidade e o risco de algumas tarefas tornam cada vez mais necessário substituir o ser humano por robôs. Na área marinha esse fato é mais relevante. Os robôs submarinos passaram a desempenhar um papel fundamental na exploração de recursos marinhos como o petróleo, no estudo e na conservação de ambientes marinhos, em aplicações de segurança de portos e em aplicações de inspeção como inspeção de turbinas hidrelétricas.

Os robôs submarinos são classificados em dois tipos diferentes, os remotamente operados (ROV) [1] e os autônomos (AUV) [2, 3]. Os robôs remotamente operados são robôs que possuem um cabo umbilical que os conectam com uma estação base na superfície que fornece a energia e a comunicação necessárias para o seu funcionamento. Dessa maneira, os operadores podem controlá-los da superfície e receber as informações dos sensores embarcados nele. Já os robôs autônomos não possuem um cabo umbilical ligando-os a uma estação base na superfície, assim eles precisam ser autônomos com relação a energia, utilizando por exemplo baterias, e também com relação a capacidade de tomar decisões com base nas leitura de seus sensores tendo sido dado um plano de missão.

Apesar dessa diferenciação na classificação dos ROVs e dos AUVs com quanto à autonomia, algumas aplicações de ROVs requerem dos mesmos algumas funções semiautônomas. Um exemplo são operações de inspeção nas quais é necessária uma boa exatidão de posicionamento, que requerem sistemas de navegação e de controle de posição ao menos parcialmente autônomos. A vantagem dos ROVs com relação aos AUVs no que se refere a questão da implementação de funções autônomas é que como eles são conectados a uma estação base, potencialmente possuem a sua disposição um poder de processamento muito maior que os AUVs, cujo hardware é limitado pelas restrições impostas por sua condição embarcada.

Com relação aos sistemas de navegação, eles são pré-requisito para quase todas as tarefas realizadas por robôs móveis, sejam eles submarinos, terrestres ou aéreoos. Assim, o problema da localização tornou-se um dos temas mais investigados na robótica. Devido a algumas limitações dos ambientes subaquáticos, a navegação, nessa área ganha muito mais importância $[4,5]$.

\section{$1.1 \quad$ Objetivos}

Com este trabalho pretende-se estudar a aplicação do filtro de partículas para o problema de navegação de ROVs em um ambiente que se conheça a priori as dimensões. O filtro de partículas será utilizado para combinar os dados de alguns sensores do veículo para obter estimativas de posição e orientação. 
Levando em consideração que ROVs tem diferentes aplicações e que uma delas é a de inspeção de ambientes estruturados e que esse tipo de ambiente pode apresenta anomalias ferromagnéticas, devido, por exemplo, a presença de materiais ferromagnéticos nas suas estruturas, assim como pode ter baixa visibilidade, devido a eventual presença de materiais em suspensão, pretende-se desenvolver um sistema de navegação que leve em conta essas restrições, ou seja, não serão utilizadas câmeras de vídeo para auxiliar a navegação e não será utilizado dados de magnetômetros para fazer a estimação do rumo. Com isso pretende-se utilizar duas configurações diferentes de sensores para resolver o problema da navegação, uma configuração que utilizará um sonar de imageamento 2D de varredura mecânica, um medidor de velocidades por efeito Doppler e um giroscópio, e outra configuração que utilizará apenas um sonar de imageamento 2D de multi elementos.

O trabalho também visa investigar os tipos de filtro de partículas que são comumente empregados na localização de robôs, assim como investigar maneiras de melhorar a sua performance. Pretende-se analisar o desempenho do filtro por meio de resultados experimentais validados por meio de um sistema externo.

O filtro de partículas tem um alto custo computacional, o que geralmente o impede de ser utilizado em aplicações de tempo real, porém a sua implementação é altamente paralelizável, por isso outro objetivo desse trabalho é estudar maneiras de utilizar unidades de processamento gráfico para acelerar o processamento desse filtro. Para isso pretende-se usar a unidade de processamento gráfico da estação base que comando o robô.

\subsection{Revisão Bibliográfica}

A função de um sistema de navegação é estimar a posição e a orientação atual do veículo baseando-se nas informações atuais e passadas de alguns sensores, assim o desenvolvimento de um sistema de navegação depende, dentre outros fatores, dos sensores disponíveis em seu sistema. A disponibilidade de sensores para o sistema de navegação no caso de robôs submarinos, além das restrições de custo e tamanho, também sofrem com outras restrições. Pelo fato de alguns sensores utilizados na navegação de robôs terrestres ou aéreos, não funcionarem ou terem seu funcionamento prejudicado em ambientes subaquáticos, a tarefa de desenvolver um sistema de navegação para um robô submarino é mais complicada do que desenvolver para um terrestre ou aéreo. Um exemplo disso é o GPS, que é amplamente utilizado na navegação aérea e terrestre por fornecer uma leitura direta da posição do robô, mas que na navegação submarina não é muito utilizado por não funcionar embaixo d'água já que o seu sinal não propaga nesse meio, tendo a sua utilização restrita a superfície da água. Outro exemplo são as câmaras de vídeo que, devido à falta de visibilidade em ambientes submarinos devido a turbidez da água e a baixa propagação da luz na água, elas geralmente também não são uma opção. Portanto é necessário se ter um conhecimento dos sensores utilizados em ambientes aquáticos [6]. 
Pela versatilidade, os sensores mais utilizados na navegação submarina são os sensores inerciais e o medidor de velocidade por efeito Doppler (DVL). Esses sensores compõem a navegação conhecida como navegação estimada [7]. A navegação estimada é uma navegação que se caracteriza por obter uma estimativa da variação de posição do sistema por meio da integração numérica dos dados de aceleração linear e velocidade angular nos três principais eixos de uma central inercial e das velocidades lineares nos três principais eixos de um medidor de velocidade por efeito Doppler. Para se obter um posicionamento absoluto, utilizando esse tipo de navegação, é necessário conhecer a posição inicial do veículo com relação a um referencial fixo. O problema desse tipo de navegação é que como a estimativa é feita por meio de sucessivas integrações diretas dos dados desses sensores, a estimativa acaba apresentando um erro, que aumenta gradualmente ao longo do tempo, já que os sensores apresentam erros em suas medições. Já a vantagem da navegação estimada é que a estimativa do movimento relativo ocorre com uma frequência maior do que em comparação com a estimativa de outros métodos de navegação. Essas características da navegação estimada tornam necessário que ela seja corrigida por outros tipos de sensores.

Os sensores mais utilizados em ambientes subaquáticos para fazer essa correção da navegação estimada são os sensores acústicos. Um exemplo deste tipo de sensor é o sistema de posicionamento acústico que por meio do cálculo das distâncias entre transmissores, previamente posicionados ao redor da região de navegação, e um receptor dentro do veículo calculadas utilizando o tempo de vôo ( time of flight ) dos sinais acústicos emitidos pelos transmissores, consegue obter a posição do veículo utilizando um princípio análogo ao do GPS ( Global Positioning System ) [8]. Existem vários tipos de sistemas de posicionamento acústico, sendo que a diferença está no número de transmissores usados para fazer a localização [9]. A desvantagem desse tipo de sensor é a necessidade de uma linha de visada entre os transmissores e o receptor que em alguns ambientes, devido a presença de algum obstáculo, pode não acontecer, invalidando este tipo de solução.

Outro exemplo de sensor acústico usado em ambientes aquáticos para fazer a correção da navegação estimada são os sonares. Para ambientes aquáticos existem vários tipos de sonares. Uma primeira classificação dos sonares é com relação a sua largura de feixe, existem sonares que possuem uma grande largura de feixe possibilitando uma maior detecção do ambiente em volta que são os sonares de visão frontal e outros que possuem uma pequena largura de feixe com o objetivo de conseguir uma melhor discretização da região que emitiu a onda que são os sonares utilizados em levantamento batimétricos. Outra classificação é com relação ao número de receptores, existem sonares de apenas um receptor, que ou sempre apontam para um único azimute que são os ecobatímetros ou possuem um motor que o rotaciona que são os sonares de varredura mecânica, existem também os sonares que possuem vários receptores cobrindo um campo de visão fixo que são conhecidos como multi elementos. Por último, existem sonares que fornecem apenas informações de distâncias aos obstáculos ao redor enquanto outros que além da distância 
também fornecem a intensidade com que a onda retorna sendo possível formar uma imagem do ambiente [10, cap.2].

Tendo visto os sensores utilizados na navegação submarina é necessário verificar quais são as técnicas utilizadas para fazer a fusão deles para se ter uma melhora na estimativa do estado do veículo. As técnicas que já foram utilizadas para fazer a navegação de robôs submarinos, são o filtro de Kalman e as suas variações, o filtro de informações e o filtro de partículas, que são filtros que se baseiam no método de Bayes. Em casos em que a modelagem do sistema é linear e os ruídos são Gaussianos, a técnica utilizada é o filtro de Kalman, isso porque para essa situação ele é um estimador ótimo que minimiza a covariância do erro estimado. O filtro de Kalman é uma solução analítica do filtro Bayesiano. No caso de sistemas com ruídos Gaussianos mas com modelos não lineares, não existe uma forma fechada para fazer a estimação do estado. Um tipo de filtro muito utilizado para resolver esse tipo de problema é o filtro de Kalman Extendido. Nesse filtro a modelagem do sistema é linearizada em torno do estado estimado para que o filtro de Kalman possa ser utilizado. Essa aproximação, as vezes pode ser uma distorção grosseira da verdadeira, o que pode fazer com que o filtro divirja. Outra possível solução para a estimação não linear é a utilização de métodos numéricos. Uma técnica que vem sendo bastante utilizada e, que tem esse tipo de abordagem, é o filtro de partículas [11]. O filtro de partícula é uma implementação não paramétrica do filtro Bayesiano baseado no método sequencial de Monte Carlo. Quanto mais a modelagem do sistema é não linear, ou quanto mais os ruídos do sistema são não Gaussianos, mais os filtros de partículas têm potencial com relação ao filtro de Kalman Extendido, especialmente em aplicações onde se tem grandes recursos computacionais e taxa de amostragem moderada, isso porque a desvantagem desse tipo de filtro é que o seu custo computacional maior do que os outros tipos de filtro. O filtro de partículas tem sido extensivamente estudado e hoje em dia existem vários tipos deste filtro [12], assim como diferentes tipos de aplicações [13, 14].

Uma das aplicações do filtro de partículas é a chamada de localização de Monte Carlo [15, cap.8] que consiste no filtro de partículas estimar a posição e a orientação de um robô enquanto ele se move no ambiente e tira medidas desse ambiente comparando-as com algumas informações conhecidas a priori. Nesse tipo de aplicação não é necessário conhecer a posição inicial do robô no ambiente. O filtro de partículas,nesse tipo de aplicação, já foi amplamente utilizado no caso de robôs terrestres com diferentes abordagens em relação aos sensores que compõem o sistema de navegação. O sensor mais utilizado na localização de Monte Carlo em robôs terrestres são os lasers [16], mas também há aplicações com câmeras de vídeo [17], com sonares [18], com wifi [19], entre outros.

Para o caso da robótica submarina, o número de exemplos desse tipo de aplicação do filtro de partículas é bem menor, devido ao fato já comentado acima de que a gama de sensores disponíveis para ambientes subaquáticos é bem menor do que para ambientes terrestres. O sensor mais utilizado na localização de Monte Carlo em ambientes subaquá- 
ticos são os sonares. Alguns casos desse tipo de localização em ambientes subaquáticos já foram citados acima que é a navegação auxiliada pelo terreno [20, 21], a navegação utilizando landmarks [22] e a navegação auxiliada por um mapa das estruturas do ambiente $[23,24]$. Também são encontrados aplicações da localização de Monte Carlo em ambientes subaquáticos com outros tipos de sensores, além dos sonares, que é o caso de [25] que utiliza uma bússola e um mapa do campo magnético da região para fazer a localização de um AUV.

Dando um enfoque para o caso da localização de Monte Carlo que faz a navegação utilizando um mapa das estruturas do ambiente, a seguir serão comentados alguns trabalhos sobre esse tema. [26] propôs uma localização de Monte Carlo para um AUV usando como sensores principais um sonar e um sistema de laser para ambientes estruturados. Para conseguir este tipo de navegação [26] precisa ter conhecimento de um mapa do meio e a forma das estruturas desse ambiente, a priori. [27] também propôs uma localização de Monte Carlo para um AUV para ambientes estruturados utilizando o conhecimento de um mapa do meio a priori, porém utiliza apenas um sonar como sensor principal. Além disso, [27] também propôs uma navegação ativa em que o objetivo é incorporar as ações de controle do robô no processo de localização e, portanto, como é conhecido o mapa do meio a priori, achar o melhor caminho a seguir para reduzir a incerteza na estimativa de posição. Neste trabalho [27] utiliza uma bússola para estimar a orientação do veículo. [28] também propôs uma localização de Monte Carlo para um AUV utilizando o conhecimento de um mapa do meio a priori utilizando como sensor principal apenas um sonar, porém para ambientes estruturados e não estruturados. [28] propõe uma modificação no filtro de partículas do algoritmo para reduzir os custo computacionais e fazer como que ele explore o espaço de estado mais eficientemente. Essa modificação consiste em instanciar a cada estimativa do filtro uma porção de partículas aleatórias [28] valida o sistema de navegação proposto por meio de simulações e também por meio de dados de experimentais.

Apesar do filtro de partículas ter as vantagens de ser facilmente implementado e possibilitar trabalhar com modelos não lineares, a sua desvantagem está no custo computacional de sua execução. Por isso muitos dos trabalhos tanto de navegação terrestre quanto subaquática, fazem uma localização de 3DOF, são poucos os trabalhos que fazem uma localização de 6DOF [29]. Em alguns casos é possível usar uma técnica chamada de Rao-Blackwelization [30] que consegue diminuir o custo computacional do filtro de partículas sem diminuir a complexidade do vetor de estado [31]. Outra maneira de se conseguir um estimativa em tempo real com o filtro de partículas é por meio de sua paralelização. Atualmente existem várias maneiras de se fazer essa paralelização que inclui a utilização de processadores multicores ou de Field-progammable Gate Arrays (FPGAs) [32, 33] ou de clusters de computadores [34] ou Graphics processing units (GPUs) $[35,36]$. Dentre essas maneiras, as GPUs oferecem o mais baixo custo e fácil acesso ao Single Instruction Multiple Data (SIMD). A seguir serão comentados alguns trabalhos que 
paralelizam o filtro de partículas na GPU. [37] apresenta uma implementação paralela do algoritmo de localização de Monte Carlo em GPUs para um robô terrestre em ambientes internos utilizando como sensor principal um sensor laser. A técnica desenvolvida por [37] é processada inteiramente na GPU e foi validada utilizando simulações com a placa de vídeo GPU NVIDIA GeForce 9800 GT. As simulações foram feitas utilizando diferentes números de partículas sendo que o melhor resultado foi um aumento de 30 vezes na velocidade de processamento. Já [38] apresenta uma implementação paralela de uma navegação para um veículo aéreo não tripulado que utiliza o filtro de partículas para comparar as medidas de um altímetro com um mapa do relevo do ambiente de navegação. O algoritmo proposto em [38] foi desenvolvido utilizando a arquitetura CUDA e foi implementado utilizando o MATLAB. O algoritmo foi validado por meio de simulações com a placa de vídeo NVIDIA GeForce GTX 480.

\subsection{Organização da tese}

O capítulo 2 apresenta uma descrição dos sensores utilizados neste trabalho para fazer a navegação do ROV, que são dois sonares de imageamento 2D, um de varredura e o outro de multi elementos, um medidor de velocidades por efeito Doppler e um giroscópio. Este capítulo descreve como cada sensor funciona e os erros que cada um apresenta. O capítulo 3 apresenta a teoria básica do filtro de partículas que é o filtro escolhido neste trabalho para fazer a fusão sensorial dos sensores apresentados no capítulo 2. Além da explicação do funcionamento desse filtro, neste capítulo também serão apresentadas algumas de suas características e algumas das suas variações. Já o capítulo 4 apresenta o algoritmo de navegação conhecido como Localização de Monte Carlo que é uma das aplicações do filtro de partículas e que é o algoritmo utilizado para fazer a navegação do ROV neste trabalho. Além disso, neste capítulo também serão apresentados o modelo de propagação e o modelo de medição, necessários para o funcionamento desse algoritmo. Neste capítulo ainda é feita uma descrição das duas configurações de sensores que serão comparadas neste trabalho no âmbito da localização de Monte Carlo. No capítulo 5, como a localização de Monte Carlo apresenta um grande custo computacional que geralmente inviabiliza a sua utilização em aplicações de tempo real, será mostrado como paralelizar esse tipo de filtro para deixar a sua execução mais rápida e assim ser possível utilizá-lo em tais aplicações. No capítulo 6 são mostrados os resultados do sistema de navegação proposto neste trabalho para duas configurações de sensores estudadas neste trabalho. Os resultados do capítulo 6 foram obtidos por meio de testes experimentais e as duas configurações de sensores foram validados utilizando um sistema externo bem preciso. Como a performance desse algoritmo de localização está fortemente relacionado com a quantidade de partículas utilizada por ele, o capítulo 6 também apresenta uma análise sobre a influência desse parâmetro sobre o resultado desse algoritmo. O texto termina com o capítulo 7 que contém as conclusões 
dos estudos realizados e algumas sugestões para o prosseguimentos desta pesquisa. 


\section{Estudo dos sensores empregados}

Como foi dito na seção 1.2, a performance de uma sistema de navegação depende da qualidade dos sensores que o compõe e também de como é feita o tratamento dos dados desses sensores. Por isso neste capítulo será feita uma descrição do funcionamento de todos os sensores que serão utilizados no sistema de navegação proposto neste trabalho e também será feito um levantamento dos tipos de erros que cada um desses sensores apresenta.

\subsection{Sonares de imageamento 2D de visão frontal}

Em ambientes subaquáticos, a utilização de sensores a laser é impraticável devido a atenuação e dispersão da luz na água, assim como, a utilização de câmeras é limitada a aplicações onde a água é transparente. Já uma onda acústica consegue viajar milhares de metros pela água, sem que haja uma perda significativa de energia. Portanto, é usual encontrar sonares capazes de medir longas distâncias mesmo em condições de água turva. Devido a isso, os sensores acústicos são a melhor opção para a detecção submarina. Geralmente, os sonares utilizados em veículos submarinos são dispositivos tecnologicamente mais avanços do que aqueles utilizados em veículos terrestres ou aéreos, o desenvolvimento de transdutores sofisticados junto com a utilização de técnicas de formação de feixe permite que feixes estreitos sejam emitidos proporcionando medições mais precisas no azimute de transmissão do feixe.

Existem dois tipos de sonares, os passivos e os ativos. Os sonares passivos são sonares que apenas captam a presença de fontes emissoras de sinais acústicos presentes no ambiente, utilizando apenas um transdutor que serve como receptor. Já os sonares ativos são sonares que possuem tanto um transmissor quanto um receptor, servindo para captar regiões de interesse do ambiente. Este trabalho envolve apenas sonares ativos. Os sonares ativos funcionam da seguinte maneira, o sonar emite um pulso de som que ao encontrar um obstaćulo retorna para o seu emissor. O sonar cronometra o tempo que a onda acústica levou para retornar e utilizando o valor da velocidade do som na água determina a distância do obstáculo a ele. O funcionamento do sonar depende do valor da velocidade do som na água e esse valor depende da salinidade, da temperatura e da pressão. Existem alguns sensores acústicos que calculam automaticamente o valor da velocidade do som na água utilizando informações de outros sensores, mas em geral a velocidade tem que ser configurada no sonar manualmente. Como a velocidade do som na água depende da pressão, os sonares são mais afetados quando estão operando na vertical. Outra cuidado a ser tomado com relação ao cálculo da velocidade do som na água é que o som é mais devagar na água doce do que na água salgada. 
Os sonares ativos podem ser classificados de três formas diferentes. A primeira forma é com relação as informações que eles fornecem, existem sonares que fornecem apenas a informação da distância ao objeto mais próximo no azimute em que a onda foi emitida e sonares que além da distância conseguem medir a intensidade com que a onda retorna sendo possível formar uma imagem do ambiente. Os tipos de sonares que conseguem formar uma imagem acústica fazem várias detecções de retorno de ondas ao longo de um período, assim eles conseguem produzir não um, mas uma série de intensidades de ecos com as respectivas distâncias, podendo assim formar uma imagem. Outra forma com que eles podem ser classificados é com relação a largura do feixe que eles emitem, os sonares de visão frontal possuem uma largura de feixe grande para facilitar a detecção de obstáculos, já os sonares utilizados em levantamento batimétricos possuem uma largura de feixe pequena para conseguir uma melhor precisão da região que refletiu a onda. A última forma de classificação é com relação ao número de receptores, existem sonares que possuem apenas um único receptor assim como sonares que possuem mais de um. Com relação aos que possuem apenas um receptor, existem dois tipos: os ecobatímetros que apontam sempre para um único azimute e os de varredura mecânica que possuem um motor que rotaciona tanto o receptor como o transdutor, possibilitando ao sonar apontar para diversos azimutes. Já com relação aos sonares que possuem mais de um receptor, cada um deles aponta sempre para um mesmo azimute e assim o campo de visão desses sonares depende do número de receptores que o sonar apresenta. Diferentemente dos sonares de varredura mecânica, esses sonares tiram uma imagem completa do ambiente a cada instante, com isso, as imagens não sofrem deformações como os de varredura mecânica quando submetidos a movimentação. Neste trabalho serão utilizados dois tipos diferentes de sonares de imageamento 2D de visão frontal, um de varredura mecânica e outro de multi elementos.

Existem vários tipos de formato de feixe da onda acústica que os sonares podem trabalhar, mas os que serão utilizados neste trabalho usam o formato de feixe do tipo leque com uma grande abertura vertical e uma estreita abertura horizontal. O formato do feixe estreito no plano horizontal, serve para medir distâncias nesse plano. Contudo, a grande abertura na vertical do feixe de formato leque dos sonares pode introduzir um pequeno erro nas medições horizontais. Isso porque qualquer objeto tridimensional presente no campo de visão dos sonares irá ser reproduzido em uma imagem acústica 2D, assim com esse formato de leque não é possível determinar a posição do objeto com relação ao plano vertical. Como a frente de onda do pulso é um arco, essa indeterminação com relação a posição vertical do objeto induz uma perda de resolução nas medições dos sonares. Quanto mais a onda tiver propagado no ambiente, maior será esse erro. A vantagem desse tipo de formato de feixe é o aumento da capacidade do sonar de detectar objetos. Esse sonar é geralmente utilizado em aplicações de desvio de obstáculos. 


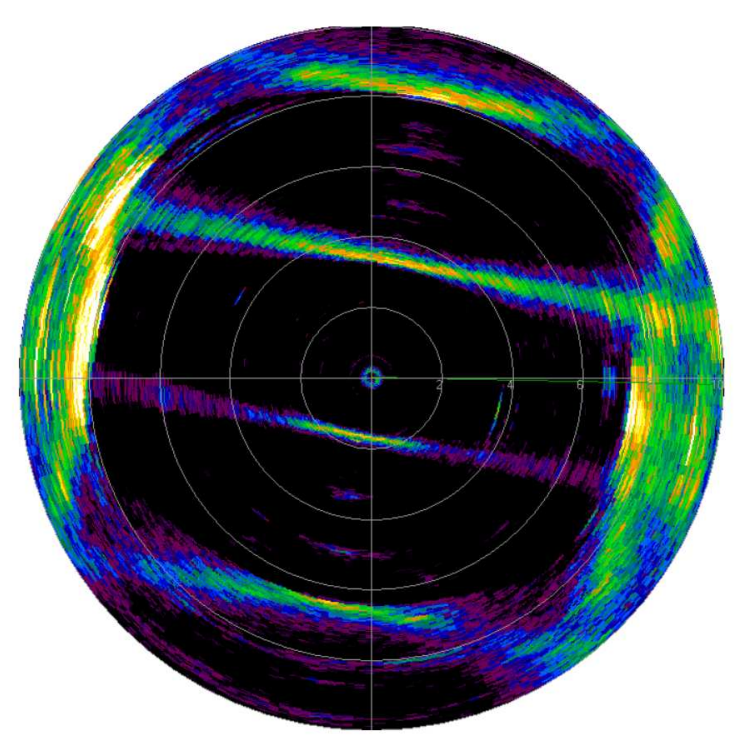

Figura 2.1 - Imagem do sonar de varredura mecânica tirada em um tanque retangular

\subsubsection{Sonar de varredura mecânica}

O sonar de varredura mecânica é um sonar de um único transdutor, que faz uma varredura horizontal com um campo de visão de $360^{\circ}$. Com um único transdutor, esse sonar consegue fazer essa varredura de $360^{\circ}$ utilizando um motor que o rotaciona em incrementos angulares pré-definidos. Para cada uma das posições angulares, um pulso de onda é emitido. Este pulso percorre o ambiente e colide com qualquer objeto que esteja em seu caminho. Quando o pulso colide com um objeto, parte da sua energia retorna para o transdutor. Medindo o tempo de voo da onda retornada e assumindo um valor para a velocidade do som na água, é possível determinar a distância ao obstáculo. Como esse sonar é um sonar de imageamento ele também obtém a intensidade com que a onda retorna ao transdutor. $\mathrm{O}$ sonar capta os retornos obtidos de um único pulso durante um certo período, com isso, para cada azimute, o sonar obtém uma série de intensidades correlacionada com uma certa distância. A figura 2.1 mostra um exemplo de imagem do sonar de varredura. Essa imagem foi tirada em um tanque retangular.

No sonar de varredura, a imagem completa de $360^{\circ}$ não é gerada instantaneamente, já que o motor necessita de um tempo considerável para girar o transdutor em uma volta completa, como resultado, quando o veículo se movimento, a imagem acústica gerada pode eventualmente apresentar descontinuidades consequentes da combinação dos movimentos de translação e rotação. Essas descontinuidades acabam atrapalhando a interpretação das imagens desse sonar. O tempo total que o sonar leva para fazer uma varredura de $360^{\circ}$ depende da configuração de alcance e de discretização do feixe. Para um alcance de 15 metros e uma discretização de feixe de 200 , o sonar leva 9 segundos para completar uma varredura. 


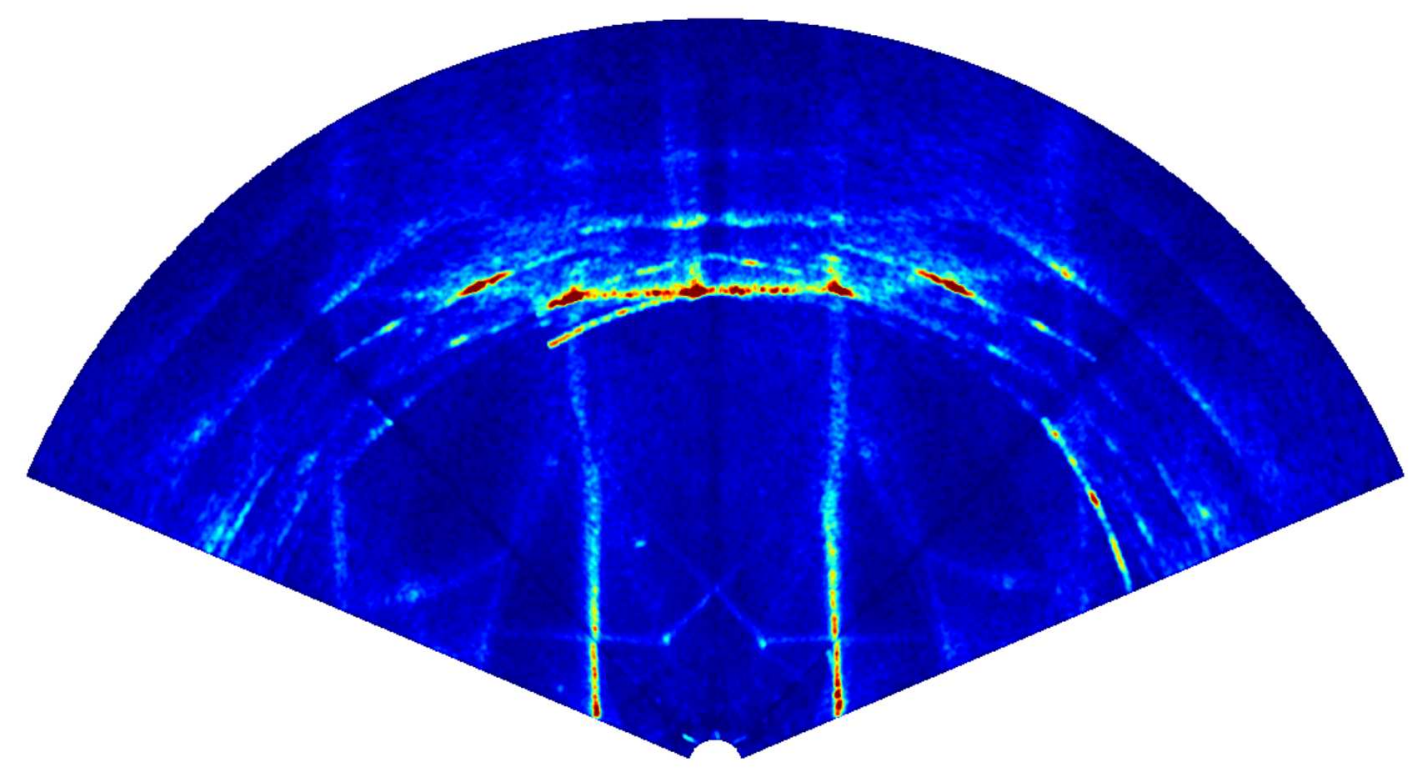

Figura 2.2 - Imagem do sonar de multi elementos tirada em um tanque retangular

\subsubsection{Sonar de multi elementos}

O sonar de multi elementos é um sonar que possui um conjunto de receptores que permite que ele consiga visualizar mais de uma região do ambiente com apenas um único pulso. $\mathrm{O}$ número de elementos vária de sonar para sonar, podendo chegar a mais de 800 elementos. Os elementos são montados no sonar em linha com um espaçamento específico que depende da frequência da onda emitida pelo sonar. Esse conjunto de elementos além de possibilitar um número maior de medições, também possibilita que o sonar identifique a quantidade de energia recebida para diferentes valores de azimutes. Os sonares de multi elementos conseguem fazer isso utilizando um princípio de adição de pulsos para diferentes valores de azimutes, obtido através da detecção precisa dos atrasos na chegada do som em cada um dos receptores. De modo que, as imagens dos sonares de multi elementos possuem uma melhor resolução do que as dos sonares que possuem apenas um. Ainda em comparação aos sonares que possuem apenas um receptor, apesar dos sonares de multi elementos levarem mais tempo para fazer o processamento de um único pulso, esse único pulso consegue visualizar uma região maior. Diferentemente do receptor rotativo do sonar de varredura, os receptores dos sonares multi elementos estão fixos, assim a imagem deles fica limitada a um pequeno setor a sua frente, além disso a imagem é formada com taxas mais elevadas do que a imagem do de varredura. A figura 2.2 mostra um exemplo de imagem do sonar de multi elementos. Essa imagem foi tirada em um tanque retangular.

O sonar de multi elementos utilizado neste trabalho possui um campo de visão de $130^{\circ}$ que é discretizado em 768 partes pelo sonar e ele trabalha em um frequência de aquisição de $15 \mathrm{~Hz}$. 


\subsubsection{Comparação entre os sonares}

Tendo sido visto o princípio de funcionamento do sonar de varredura mecânica e do multi elementos é possível listar as vantagens e desvantagens de cada um dos sistemas.

Uma vantagem do sonar de multi elementos é que como as suas imagens são geradas com um campo de visão de $130^{\circ}$, como se tivesse tirando uma sequência de fotos do ambiente, o sonar de multi elemento não apresenta o problema de distorção da imagem que o sonar de varredura apresenta. Ainda com relação a essa característica dos sonares de multi elementos, as operações de processamento de suas imagens podem ser realizadas levando em consideração a imagem inteira, o que não é possível de ser feito com o sonar de varredura mecânica, porque seria necessário que o veículo ficasse parado durante o tempo inteiro de varredura para que a imagem não ficasse distorcida o que não condiz com a operação do veículo. Outra vantagem desse sonar sobre o de varredura mecânica é que as imagens geradas pelo primeiro apresentam uma resolução angular melhor do que o outro. Como desvantagem, o sonar de multi elementos apresenta um maior consumo de potência.

Apesar do sonar de varredura mecânica ser lento e sofrer distorções em sua imagem devido à movimentação do veículo, sua vantagem se dá principalmente na navegação em ambientes desconhecidos devido ao seu amplo campo de visão de $360^{\circ}$ em comparação ao limitado campo de $130^{\circ}$ dos sonares de multi elementos. Uma última diferença entre esses sonares é com relação ao preço, os sonares de varredura mecânica geralmente são mais baratos do que os sonares de multi elementos.

\subsubsection{Perturbações nas imagens dos sonares}

Nessa seção será feita uma descrição das possíveis pertubações que podem ocorrer no processo de formação da imagem acústica pelos sonares utilizados neste trabalho, com intuito de estudar um processo de filtragem adequado para elas.

Perda de energia na propagação da onda Como a onda acústica ao se propagar no meio sofre perdas de energia, dois obstáculos iguais serão identificados pelo sonar com intensidades diferentes se eles não estiverem equidistante ao sonar. Para corrigir essa perda, alguns sonares possuem um ganho sobre a intensidade recebida variável no tempo.

Grande largura do feixe de formato de leque na vertical Como a frente da onda que o sonar emite tem formato de um arco, a onda acústica acaba tendo uma região, correspondente a flecha do arco, em que o sonar não consegue distinguir a posição do obstáculo dentro dela. Quanto maior for a largura do feixe na vertical, maior será a região da flecha e menor será a discretização do sonar com relação a posição dos obstáculos na horizontal. 


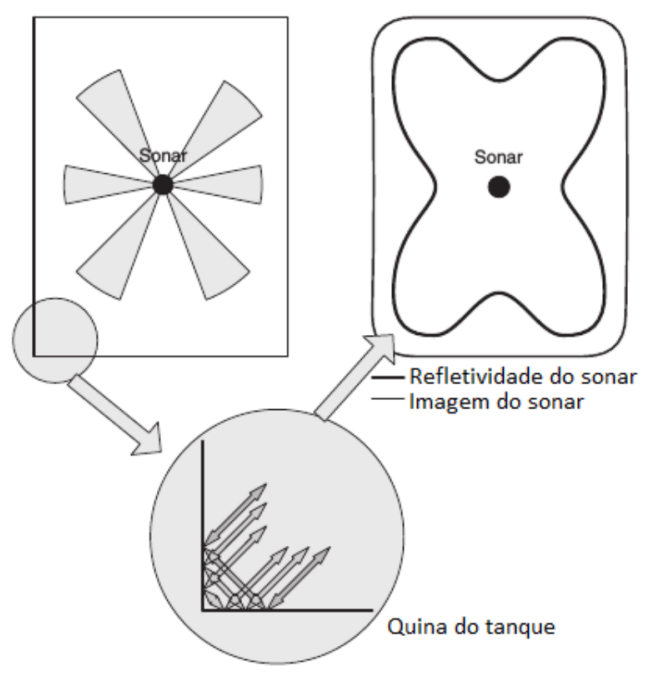

Figura 2.3 - Resultado da imagem de um sonar de uma quina quadrada (imagem retirada de [1])

Reflexões Quando o ambiente, onde o sonar está sendo utilizado, apresenta grandes obstáculos como, por exemplo, paredes, eles acabam funcionando como um espelho para o pulso acústico e, como resultado, podem formar na imagem reflexões que não correspondem a objetos reais do ambiente. Com relação a ambientes que são formados por paredes, as reflexões da onda acústica podem gerar vários tipos de comportamento na imagem do sonar. Um exemplo é o comportamento que a imagem do sonar tem ao visualizar uma quina quadrada do ambiente. Como a onda será refletida diversas vezes na quina quadrada, na imagem do sonar ela aparecerá arredondada, a figura 2.3 ilustra esse exemplo. Outros comportamentos relacionados a essa situação são encontrados em [39].

Ângulo de incidência da onda acústica emitida pelo sonar no obstáculo Se o ângulo de incidência no obstáculo é baixo, boa parte da energia da onda acústica é refletida de volta, mas se o ângulo de incidência da onda é alto, apenas uma parte pequena da energia da onda acústica é refletida de volta. Assim em alguns casos, alguns obstáculos não apareceram na imagem do sonar porque a onda chegou com um ângulo muito alto nesse obstáculo.

Ruídos A imagem acústica do sonar pode ser afetada por diversos tipos de ruídos acústicos como, por exemplo, ruídos gerados pela vibração dos propulsores, ruídos a reflexões do próprio encapsulamento do sonar e ruídos devido a reflexões da onda acústica na superfície da água ou no fundo do ambiente. Como os sonares são projetados para captarem uma certa frequência, alguns desses ruídos podem ser filtrados pela baixa sensibilidade do sonar fora dela. 


\subsection{Medidor de velocidades por efeito Doppler}

Em ambientes subaquáticos o sensor mais utilizado para medir velocidades lineares é o medidor de velocidades por efeito Doppler, ou DVL (Doppler Velocity Log), devido a sua alta exatidão. Como o próprio nome já diz esse sensor utiliza o efeito Doppler para medir as velocidades, ou seja, esse sensor, usa o princípio de que um sinal acústico transmitido ou recebido por um objeto em movimento terá sua frequência modificada por um valor proporcional à velocidade do objeto em movimento [40]. O DVL possui três ou quatro transdutores sendo que cada um deles forma um ângulo de $60^{\circ} \mathrm{com}$ a horizontal. No caso do DVL com três transdutores, eles ficam espaçados igualmente de $120^{\circ}$ entre si, no caso do com quatro transdutores o espaçamento é de $90^{\circ}$. Nenhum dos transdutores têm direção igual a um dos eixos do sistema de coordenadas do veículo. Cada transdutor emite um sinal acústico e calcula uma velocidade, que tem direção paralela a direção de propagação do sinal acústico, por meio do efeito Doppler. Utilizando cada uma das velocidades medidas pelos transdutores é obtido as velocidades dos três eixos em relação ao referencial do corpo. Conhecendo a orientação do veículo a cada instante, essas velocidades podem ser convertidas para um referencial fixo utilizando a matriz de transformação de coordenadas.

O DVL consegue medir dois tipos de velocidades com relação ao referencial do corpo, uma com relação ao fundo do ambiente e outra com relação a água. A velocidade com relação ao fundo fornece a velocidade do veículo direta, porém para conseguir medir essas velocidades, o fundo precisar estar no alcance do DVL. Caso isso não aconteça ele conseguirá medir apenas as velocidades com relação a água e essa medida apresenta um bias que é a medida da correnteza, assim para utilizá-la é necessário um estimador em tempo real da correnteza.

A exatidão do medidor de velocidade por efeito Doppler depende da especificação da frequência do som em que ele trabalha, quanto maior essa frequência melhor será a exatidão, só que menor será o alcance de trabalho do sensor [7]. A especificação do erro do DVL é geralmente feita por meio de um fator de escala e um viés, no caso do DVl utilizado neste trabalho essa especificação é de $\pm 0.2 \% \pm 1 \mathrm{~mm} / \mathrm{s}$. Os DVLs apresentam uma taxa de amostragem baixa, o DVL utilizado neste trabalho apresenta uma taxa máxima de amostragem de $5 \mathrm{~Hz}$.

Em [7] são comentados alguns dos erros característicos do DVL. O primeiro é com relação a importância da exatidão da velocidade do som na água utilizada pelo DVL. Como a velocidade do som na água depende de variáveis como salinidade, temperatura e profundidade, os DVLs possibilitam que a velocidade do som na água utilizada em seu processamento seja alterada. Outro erro comentado é o causado devido a rotações angulares. Como o DVL funciona por meio do cálculo da diferença de frequência da onda acústica transmitida e da onda acústica recebida para medir a velocidade em cada um dos seus transdutores e como essas velocidades precisam ser transformadas para o sistema de 
coordenadas do corpo, quando o DVL é submetido a uma rotação, o ângulo da direção da velocidade de cada transdutor muda e isso acarreta em um erro de fator de escala nas medidas de velocidade do DVL.

\subsection{Giroscópio}

Os giroscópios são sensores que detectam a variação angular de um corpo com relação a um referencial inercial e são utilizados em diferentes aplicações, sendo utilizados, por exemplo, na navegação para estimar a orientação do veículo. Existem vários tipos deste sensor [41], mas neste trabalho foi estudado apenas o tipo MEMS ( Microelectromechanical systems ). A diferença entre os giroscópios do tipo MEMS para os outros tipos é que os giroscópios do tipo MEMS são atualmente muito menos precisos do que os outros, porém os MEMS possuem uma série de vantagens: tamanho reduzido, menor peso, menor custo, uma construção robusta e consumo menor de energia. Também necessitam de menos manutenção e a sua inicialização é mais rápida [41].

O funcionamento dos giroscópios do tipo MEMS é baseado no efeito de Coriolis, que consiste na força induzida em uma massa $m$ movendo a uma velocidade $v$ em um referencial girando com velocidade angular $w$, que é expressa segundo a equação 2.1 [41].

$$
F_{c}=-2 m(w \times v)
$$

Como a Terra gira em torno do seu eixo com uma velocidade angular significativa, qualquer referencial ligado a superfície da Terra é na melhor das hipóteses apenas uma aproximação de um sistema de coordenadas inercial. Assim em aplicações de navegação que exigem alta precisão é necessário levar em consideração a rotação da Terra na medição dos giroscópios.

Os giroscópios do tipo MEMS contêm elementos vibratórios para medir o efeito Coriolis que podem ser de diferentes geometrias, como uma roda ou um diapasão. A geometria mais simples de funcionamento de um giroscópio do tipo MEMS consiste de uma simples massa que é colocada em vibração ao longo de um eixo de acionamento. Quando o giroscópio é rotacionado, uma segunda vibração é induzida ao longo do eixo perpendicular ao de acionamento, devido à força de Coriolis. A velocidade angular é obtida medindo essa segunda vibração.

\subsubsection{Erros característico dos giroscópios}

A performance de um giroscópio é afetada por uma série de erros, assim para um melhor aproveitamento da leitura desse sensor nessa seção será feito uma descrição deles.

Os erros dos giroscópios podem ser classificados de duas formas diferentes, ou o erro é determinístico ou o erro é estocástico. Os erros determinísticos podem ser eliminados por 
meio de processos de calibração, já os estocástico precisam ser modelados corretamento no algoritmo de navegação segundo a teoria de processos estocásticos.

Bias é um offset na leitura do giroscópio quando este se encontra estático. O bias de um giroscópio pode ser estimado tirando uma média de um conjunto de dados coletados do giroscópio parado durante um longo período. Uma vez que o bias é estimado, ele pode ser corrigido simplesmente subtraindo o seu valor da saída do giroscópio. Esse procedimento tem que ser repetido toda vez que o sensor é ligado, porque o valor de bias muda a cada vez que o sensor é ligado.

Random Walk É o erro resultante devido à integração do ruído aleatório presente nos sinais do giroscópios. Uma analogia feita para esse erro é a saída de um integrador forçado por um ruído branco. Tomando um requisito adicional nessa analogia de que o ruído também é Gaussiano, o random walk é conhecido como processo de Wiener.

Fator de escala é um erro proporcional a saída do giroscópio. Quanto maior for a saída do giroscópio maior será a imprecisão provocado pelo erro de fator de escala.

Não-linearidade é o erro da medida de quão perto a saída emitida pelo giroscópio é linear com relação ao proporcional da velocidade angular real.

Efeitos da temperatura são erros causados pela variação de temperatura nos giroscópios. A forma como isso ocorre é de difícil modelagem, assim eles devem ser modelados como um processo aleatório. A maioria dos giroscópios possuem sensores de temperatura para compensar o efeito de variação de temperatura, mas apesar disso a maioria não consegue compensar os erros causado por grandes variações, devido a alta não linearidade da relação entre temperatura e bias.

G-sensibilidade é o erro causado pela influência da aceleração na saída do giroscópio 


\section{Fusão Sensorial}

O problema da estimação de estado de um sistema dinâmico aborda o problema de estimar quantidades, que não são diretamente observáveis, mas que podem ser inferidas a partir de dados ruidosos de sensores. Assim em problemas como esse, as equações que descrevem a evolução desse sistema e as suas medições são modeladas por leis probabilísticas. A lei probabilística que caracteriza a evolução do estado é $p\left(x_{t} \mid x_{0: t-1}, z_{1: t-1}, u_{1: t}\right)$. Se for levado em consideração a condição de Markov, que diz que os dados do passado e do presente são independentes se é conhecido o estado atual $x_{t}$, no caso de $p\left(x_{t} \mid x_{0: t-1}, z_{1: t-1}, u_{1: t}\right)$, sendo conhecido $x_{t-1}$, o conhecimento de $x_{0: t-2}, z_{1: t-1}$ e $u_{1: t-1}$ não traz nenhuma informação adicional que ajudaria a prever o futuro com mais precisão, assim a evolução do estado passa a ser descrita como na equação 3.1 .

$$
p\left(x_{t} \mid x_{0: t-1}, z_{1: t-1}, u_{1: t}\right) \stackrel{\text { Markov }}{=} p\left(x_{t} \mid x_{t-1}, u_{t}\right)
$$

Já o processo pelo qual as medições são geradas é representado pela função densidade de probabilidade mostrada na equação 3.2 .

$$
p\left(z_{t} \mid x_{0: t}, z_{1: t-1}, u_{1: t}\right) \stackrel{\text { Markov }}{=} p\left(z_{t} \mid x_{t}\right)
$$

A densidade $p\left(x_{t} \mid x_{t-1}, u_{t}\right)$ da equação 3.1 é a densidade de transição de estado que especifica como o estado evolui ao longo do tempo em função das entradas de controle. Já a densidade $p\left(z_{t} \mid x_{t}\right)$ da equação 3.2 é a densidade de medição que especifica a probabilidade da medição ter sido feita dado o estado $x_{t}$. As densidades $p\left(x_{t} \mid x_{t-1}, u_{t}\right)$ e $p\left(z_{t} \mid x_{t}\right)$ juntas descrevem a evolução de um sistema estocástico dinâmico, em que o estado no instante $t$ é estocasticamente dependente do estado no instante $t-1$ e da entrada de controle $u_{t}$ e em que a medição $z_{t}$ depende estocasticamente do estado no instante $t$. Tal modelo é conhecido como modelo oculto de Markov ou rede Bayesiana dinâmica, a figura 3.4 ilustra esse tipo de modelo.

Existem várias formas de se fazer a estimação de estados e essas formas podem ser divididos em dois grupos, os estimadores Bayesianos [15, cap.2] e os estimadores não Bayesianos. Este trabalho envolve um estimador Bayesiano.

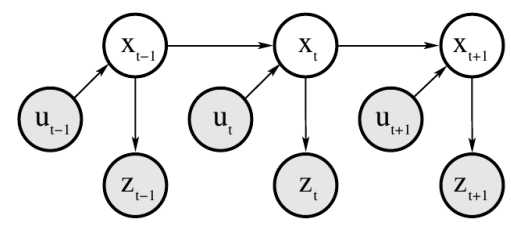

Figura 3.4 - A rede bayesiana dinâmica que caracteriza a evolução do estado, das medidas e das entradas de controle (imagem retirada de [15]) 


\subsection{Estimação Bayesiana}

O objetivo da estimação é encontrar uma função densidade de probabilidade $p\left(x_{t} \mid z_{1: t}, u_{1: t}\right)$ que especifica a probabilidade do estado ser $x_{t}$ dadas todas as medições $z$ e todas as entradas de controle $u$ até o instante atual. O filtro Bayesiano é um filtro recursivo, isso porque, a densidade $p\left(x_{t} \mid z_{1: t}, u_{1: t}\right)$ do instante $t$ é calculada a partir da densidade $p\left(x_{t-1} \mid z_{1: t-1}, u_{1: t-1}\right)$ do instante $t-1$. Isso implica que o filtro Bayesiano necessita de uma densidade inicial $p\left(x_{0}\right)$ no instante $t=0$. O filtro Bayesiano possui duas etapas principais, a primeira chamada de propagação na qual o estado $x_{t}$ é propagado baseado no estado $x_{t-1}$ e na ação de controle ruidoso $u_{t}$. As equações 3.3 e 3.4 mostram a derivação dessa etapa do filtro.

$$
\begin{aligned}
& p\left(x_{t} \mid z_{1: t-1}, u_{1: t}\right) \stackrel{\text { Probabilidade }}{\stackrel{\text { Total }}{=}} \int p\left(x_{t} \mid x_{t-1}, z_{1: t-1}, u_{1: t}\right) p\left(x_{t-1} \mid z_{1: t-1}, u_{1: t}\right) \mathrm{d} x_{t-1} \\
& p\left(x_{t} \mid z_{1: t-1}, u_{1: t}\right) \stackrel{\text { Markov }}{=} \int p\left(x_{t} \mid x_{t-1}, u_{t}\right) p\left(x_{t-1} \mid z_{1: t-1}, u_{1: t}\right) \mathrm{d} x_{t-1}
\end{aligned}
$$

Já a segunda etapa é chamada de correção na qual se calcula o valor da função densidade de probabilidade posteriori por meio da multiplicação da função densidade de probabilidade $p\left(x_{t} \mid z_{1: t-1}, u_{1: t}\right)$, resultante da etapa de propagação, pela probabilidade da medição $z_{t}$ ter sido feita considerado cada estado hipotético posterior. As equações 3.5, 3.6 e 3.6 mostram a derivação dessa etapa do filtro.

$$
\begin{gathered}
p\left(x_{t} \mid z_{1: t}, u_{1: t}\right) \stackrel{\text { Bayes }}{=} \frac{p\left(z_{t} \mid x_{t}, z_{1: t-1}, u_{1: t}\right) p\left(x_{t} \mid z_{1: t-1}, u_{1: t}\right)}{p\left(z_{t} \mid z_{1: t-1}, u_{1: t}\right)} \\
p\left(x_{t} \mid z_{1: t}, u_{1: t}\right)=\eta p\left(z_{t} \mid x_{t}, z_{1: t-1}, u_{1: t}\right) p\left(x_{t} \mid z_{1: t-1}, u_{1: t}\right) \\
p\left(x_{t} \mid z_{1: t}, u_{1: t}\right) \stackrel{\text { Markov }}{=} \eta p\left(z_{t} \mid x_{t}\right) p\left(x_{t} \mid z_{1: t-1}, u_{1: t}\right)
\end{gathered}
$$

Portanto para implementar o filtro Bayesiano é necessário conhecer três funções de densidade de probabilidade, a probabilidade inicial do estado $p\left(x_{0}\right)$, a probabilidade de transição de estado $p\left(x_{t} \mid u_{t}, x_{t-1}\right)$ e a probabilidade de medição $p\left(z_{t} \mid x_{t}\right)$. Esse tipo de filtro só pode ser implementado para alguns casos, em que ou é possível calcular a integral em 3.4, como a multiplicação em 3.7 em forma fechada (quando $p\left(z_{t} \mid x_{t}, z_{1: t-1}, u_{1: t}\right)$ e $p\left(x_{t} \mid z_{1: t-1}, u_{1: t}\right)$ são conjugados), ou em casos que se utilizam métodos numéricos.

\subsection{Filtro de Partículas}

O filtro de partículas é uma implementação não paramétrica do filtro Bayesiano baseado no método sequencial de Monte Carlo [11, 42, 43]. A ideia principal é representar a função 
densidade de probabilidade $p\left(x_{t} \mid z_{1: t}, u_{1: t}\right)$ por meio de um conjunto de amostras dessa densidade. Essas amostras são chamadas de partículas e cada uma delas representa uma hipótese para o valor real do estado do sistema, assim quanto maior o número de partículas concentradas em uma região do espaço de estado, maior é a probabilidade dessa região ser o valor real do estado. Para esse tipo de filtro quanto maior o número de partículas utilizado para fazer a estimação do estado, melhor será a estimativa, porém maior será o custo computacional para fazê-la.

O filtro de partículas apresenta algumas vantagens sobre o filtro de Kalman [44], que é um filtro estocástico muito utilizado na navegação de robôs. Uma vantagem é que a formulação do filtro de partículas permite utilizar, além da distribuição Gaussiana, funções densidade de probabilidade não Gaussianas e multi modais, diferentemente do filtro de Kalman que trabalha apenas com funções Gaussianas. Como o filtro de Kalman é uma implementação paramétrica do filtro de Bayes que faz a estimativa do estado por meio do cálculo da média e da variância de uma distribuição Gaussiana, esse tipo de filtro fica restrito a esse tipo de distribuição. Como o filtro de partículas representa a função densidade de probabilidade por meio de um conjunto de amostras dessa densidade, esse tipo de filtro permite trabalhar com funções mais complexas. Um exemplo da representação do filtro de partículas de uma caso complexo de distribuição é mostrado na figura 3.5. Outra vantagem é que utilizando essa forma de representação das funções densidade de probabilidade, o filtro de partículas é capaz de trabalhar com transformações não lineares, sem a necessidade de fazer a linearização do modelo que é uma imposição para se utilizar o filtro de Kalman. Além disso, o filtro de partículas permite que o seu tempo de execução seja adaptável aos requisitos de tempo do software do robô já que o número de partículas a ser utilizado no filtro não é fixo [45]. Uma ressalva a ser feita com relação a essa vantagem é que quanto menor o número de partículas a ser utilizado, menor o tempo de execução, no entanto menor será a acurácia do filtro. Uma última vantagem do filtro de partículas é sua simples implementação [45].

Com relação as desvantagens, o filtro de partículas apresenta duas desvantagens em relação ao filtro de Kalman. A primeira é a falta de uma prova consistente de convergência sob condições específicas, da mesma forma como é encontrada para o filtro de Kalman. Outra desvantagem é que o número de partículas necessárias para se fazer a estimação cresce exponencialmente com o número de dimensões do espaço [45], assim para vetores de estado de grandes dimensões é necessário um número bem maior de partículas deixando o custo computacional do filtro inviável para algumas aplicações de tempo real. Por isso aplicações mais bem sucedidas da utilização do filtro de partículas limitaram-se a vetores de estado de baixa dimensão.

Nesse trabalho foi escolhido o filtro de partículas para fazer a fusão sensorial por causa da não linearidade dos modelos de medição e propagação do sistema, que serão vistos posteriormente, e também por causa da possibilidade de explorar a paralelização desse 


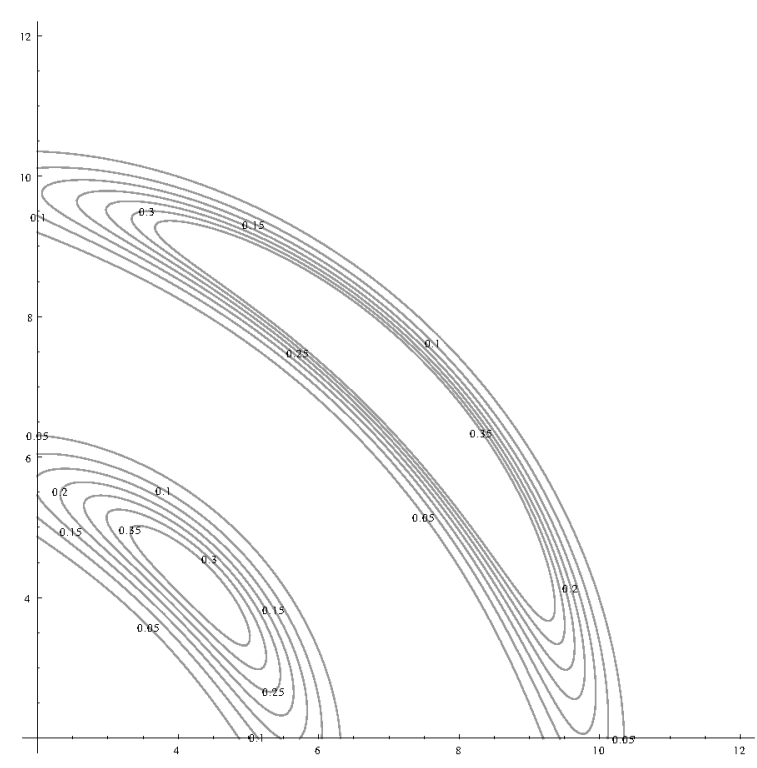

(a) Curvas de nível da função densidade de probabilidade de uma distribuição multimodal

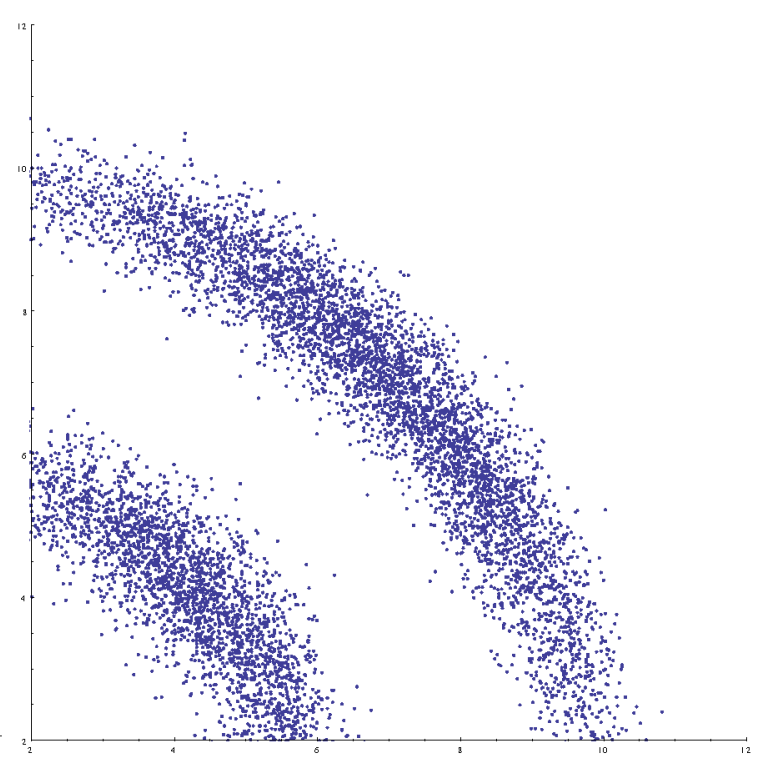

(b) Amostra da mesma distribuição

Figura 3.5 - Representação de distribuições por amostragem

tipo de filtro.

Neste capítulo será feita uma revisão da teoria básica do filtro de partículas e serão vistas as diferentes formas de se implementar esse tipo de filtro [12].

\subsubsection{Integração de Monte Carlo}

A interação de Monte Carlo é a base dos métodos sequenciais de Monte Carlo que por sua vez é a base do filtro de partículas. Os algoritmos de integração numérica normalmente utilizados calculam a integral avaliando iterativamente grades regular do espaço, em um procedimento determinístico como, por exemplo a integração trapezoidal. A integração de Monte Carlo, por outro lado, utiliza uma abordagem não determinística, os pontos em que a integração é avaliada são escolhidos aleatoriamente.

A integração de Monte Carlo funciona da seguinte maneira, suponha que queremos avaliar numericamente uma integral multidimensional dada pela equação 3.8 .

$$
I=\int g(x) \mathrm{d} x
$$

O método de monte Carlo para integração numérica fatoriza $g(x)=f(x) \cdot \pi(x)$ de tal forma que $\pi(x)$ é interpretada como uma função densidade de probabilidade que satisfaz $\pi(x) \geq 0$ e $\int \pi(x) \mathrm{d} x=1$. Assumindo que é possível amostrar $N \gg 1$ amostras distribuídas de acordo $\operatorname{com} \pi(x)$ a estimativa da integral passa a ser:

$$
I=\int f(x) \pi(x) \mathrm{d} x
$$


que pode ser calculada a partir da média da amostra:

$$
I_{N}=\frac{1}{N} \sum_{i=1}^{N} f\left(x^{i}\right)
$$

onde $x^{i}$ são as amostras de $\pi(x)$. Se as amostras $x^{i}$ são independentes então $I_{N}$ é uma estimativa não viesada e de acordo com a lei dos grande números [46], $I_{N}$ convergirá quase certamente para o valor de $I$. Se a variância de $f(x)$

$$
\sigma^{2}=\int(f(x)-I)^{2} \pi(x) \mathrm{d} x
$$

é finita, então o teorema do limite central pode ser utilizado e o erro de estimativa converge na distribuição:

$$
\lim _{N \rightarrow \infty} \sqrt{N}\left(I_{N}-I\right) \sim \mathcal{N}\left(0, \sigma^{2}\right)
$$

O erro da estimativa de Monte Carlo, $e=I_{N}-I$ é da ordem $O\left(N^{-\frac{1}{2}}\right)$, mostrando que a velocidade de convergência da estimativa da integral é independente da dimensão do integrando. Qualquer método de integração numérica determinística, tem uma velocidade de convergência que diminui à medida que a dimensão do integrando aumenta. Devido a isso, a integração de Monte Carlo é particularmente útil para integrais de grandes dimensões.

\subsubsection{Sequential Importance Sampling}

O filtro Sequential Importance Sampling (SIS) é simplesmente a aplicação da integração de Monte Carlo para executar a filtragem não-linear. O filtro SIS é a forma de implementação mais básica do filtro de partículas. A ideia principal do SIS é a amostragem por importância, que é um método para se obter amostras de uma função densidade de probabilidade de difícil amostragem ( $f$, distribuição alvo ) a partir de amostras de outra função de fácil amostragem ( $g$, distribuição proposta). Isso acontece nos problemas de filtragem de sistemas dinâmicos quando se deseja calcular a expectância da função densidade de probabilidade $p\left(x_{t} \mid z_{1: t}, u_{1: t}\right)$, mas só se tem disponível dados amostrados a partir de uma função densidade de probabilidade $p\left(x_{t} \mid u_{t}, x_{t-1}\right) p\left(x_{t-1} \mid z_{1: t-1}, u_{1: t-1}\right)$. Para ajudar a explicação da amostragem por importância será utilizado um exemplo [15, cap.4]. A expectância de $x \in A$ pode ser expressa como uma expectância sobre $g$, da seguinte forma: 


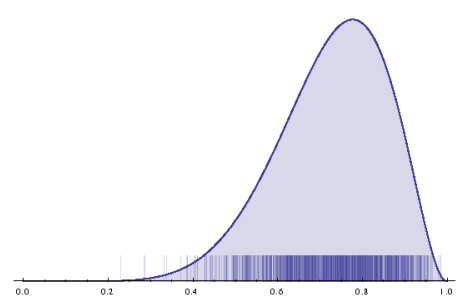

(a)

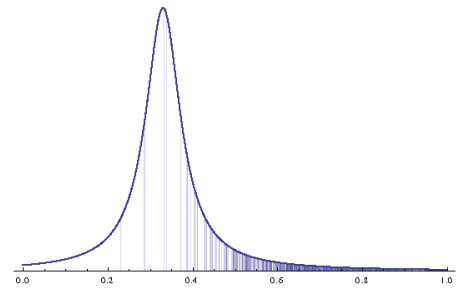

(b)

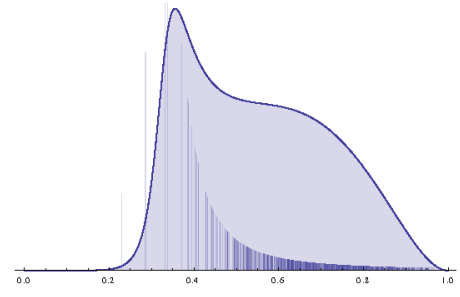

(c)

Figura 3.6 - Passos do Sequential Importance Resampling: (a) Distribuição $f$ amostrada. (b) Amostra com pesos ponderados pela distribuição g. (c) Resultado: Amostra ponderada da distribuição $f \cdot g$

$$
\begin{aligned}
E_{f}[I(x \in A)] & =\int f(x) I(x \in A) \mathrm{d} x \\
& =\int \frac{f(x)}{g(x)} g(x) I(x \in A) \mathrm{d} x \\
& =\int w(x) g(x) I(x \in A) \mathrm{d} x \\
& =E_{g}[w(x) I(x \in A)]
\end{aligned}
$$

Nesse exemplo, $w(x)=\frac{f(x)}{g(x)}$ é um fator de ponderação que representa o descompasso entre $f$ e $g$. A distribuição proposta deve ser tal que $f(x)>0$ implica $g(x)>0$ de modo que não haja uma probabilidade nula de gerar uma amostra de $f$ a partir de $g$. A eficiência da amostragem por importância depende da similaridade entre a distribuição alvo e a proposta. A figura 3.6 ilustra a amostragem por importância.

Tendo sido visto a ideia principal do filtro Sequential Importance Sampling, a seguir será dada uma breve explicação dos passos desse algoritmo. Pelo fato do filtro de partículas ser uma derivação do filtro Bayesiano, o filtro de partículas é recursivo, assim, a estimativa de estado fornecido pelo conjunto de partículas $X_{t}$ é originada a partir do conjunto de 
partícula do passo anterior $X_{t-1}$, das entradas conhecidas do sistema e das saídas do sistema. Também como parte dos filtros Bayesianos, cada iteração do filtro de partículas pode ser dividida em dois ciclos, o ciclo de propagação e o ciclo de correção. O ciclo de propagação é responsável por projetar para a frente o valor do estado usando a probabilidade de transição do estado $p\left(x_{t} \mid u_{t}, x_{t-1}\right)$ e o ciclo de correção é responsável por incorporar as medidas do sistema para melhorar a estimativa do estado obtido no ciclo de propagação, utilizando a probabilidade de medição $p\left(z_{t} \mid x_{t}\right)$. Assim, para a sua implementação, é necessário saber três funções de densidade de probabilidade, a probabilidade do estado inicial $p\left(x_{0}\right)$, a probabilidade de transição de estado $p\left(x_{t} \mid u_{t}, x_{t-1}\right)$ e a probabilidade de medição $p\left(z_{t} \mid x_{t}\right)$.

As entradas para o algoritmo são: o conjunto de partículas da etapa anterior $X_{t-1}$, a ação de controle $u_{t}$ e as medições dos sensores $z_{t}$. Já a saída é o conjunto de partículas posterior $X_{t}$. O primeiro passo do algoritmo é gerar um conjunto de partículas $\bar{X}$ em que cada uma de suas partículas é gerada a partir de uma respectiva partícula do conjunto $X_{t-1}\left(x_{t-1}^{[n]}\right)$ levando em consideração a influência da ação de controle $u_{t}$ com seus respectivos erros nessa partícula, ou seja, cada partícula de $\bar{X}\left(x_{t}^{[n]}\right)$ é gerada de acordo com $p\left(x_{t}^{[n]} \mid u_{t}, x_{t-1}^{[n]}\right)$. Depois para cada partícula $x_{t}^{[n]}$ de $\bar{X}$ é calculado um peso de importância $w_{t}^{[n]}$. O cálculo desses pesos é feito seguindo o conceito de que as partículas propagadas $x_{t}^{[n]}$ que apresentarem uma maior coerência com a medição $z_{t}$ receberão valores maiores, indicando que essas partículas tem maior probabilidade de serem o valor real do estado. Assim os valores dos pesos de importância $w_{t}^{[n]}$ são baseados na probabilidade de medição $p\left(z_{t} \mid x_{t}^{[n]}\right)$. Essa é a forma como o filtro de partículas incorpora as medições $z_{t}$ na sua estimação do estado. A última etapa do SIS se refere a atualização dos pesos de importância de cada partícula que é dada por $w_{t}^{[n]}=w_{t}^{[n]} w_{t-1}^{[n]}$, onde $w_{t-1}^{[n]}$ é o peso de importância da partícula no período anterior. Para exemplificar a explicação do filtro Sequential Importance Sampling a seguir é mostrado um pseudo código desse algoritmo.

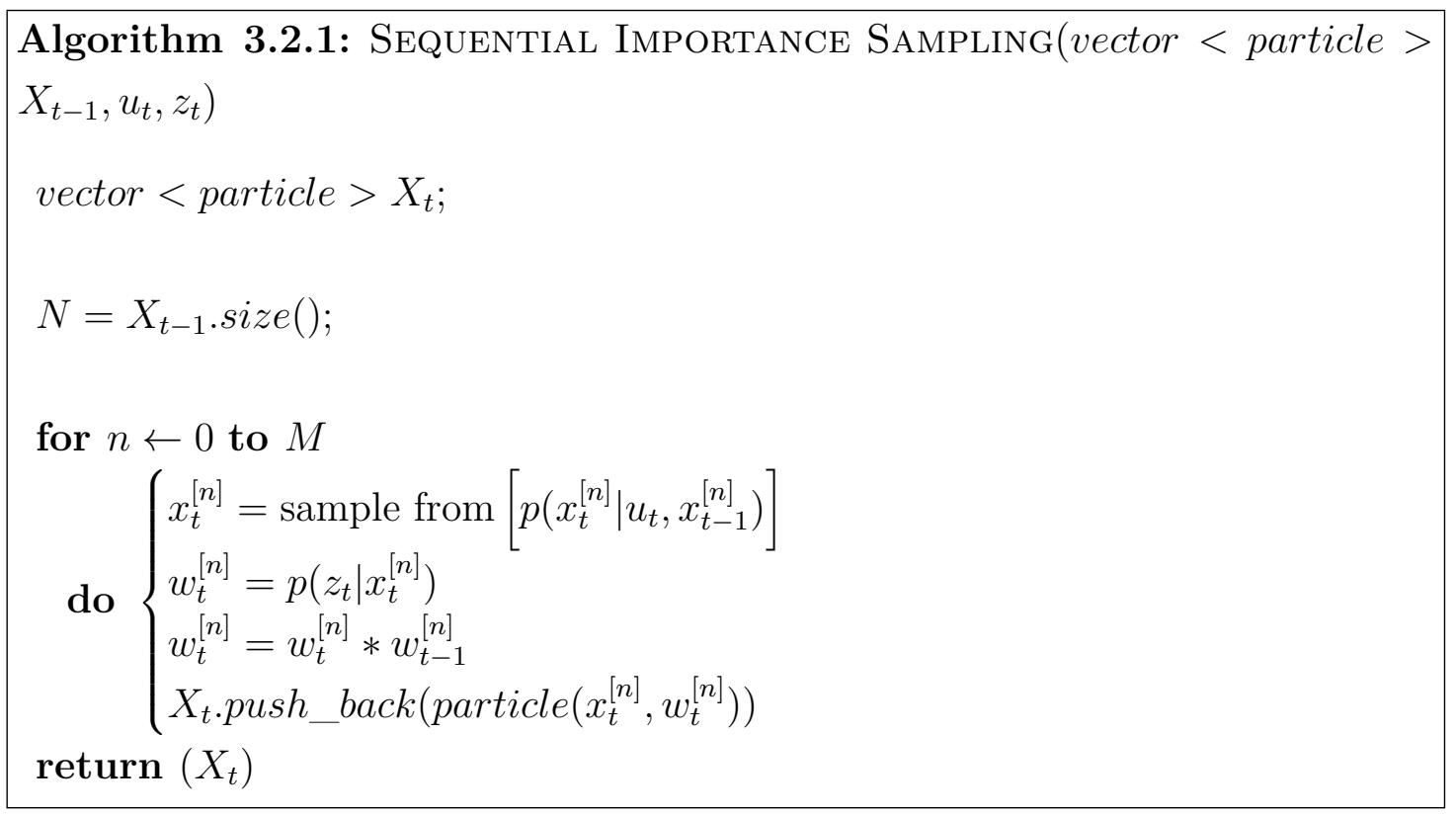


Essa forma de funcionamento do SIS faz com que ele apresente uma ineficiência. Como o filtro estima o estado por meio de um processamento envolvendo todas as partículas e, além disso, a cada iteração do filtro mais e mais partículas acabam indo para as regiões mais longes do valor real do estado, a estimativa do estado acaba por ter um desperdício de recursos computacionais, porque perde tempo fazendo o processamento dessas partículas que estão distantes do valor real do estado. Devido a essa ineficiência desse tipo de filtro de partícula, esse não foi muito utilizada, porém o seu princípio de funcionamento serviu como base para as outras formas de implementação do filtro de partículas.

\subsubsection{Sequential Importance Resampling}

O Sequential Importance Resampling (SIR) é outra forma de implementação do filtro de partículas. Baseado no SIS, o SIR consiste em sua junção com uma etapa a mais chamada de reamostragem. A adição dessa etapa no SIS tem como objetivo eliminar o problema de degeneração apresentado pelo SIS.

Essa etapa consiste em uma amostragem com reposição do conjunto de partículas em que a amostragem é baseada no peso de importância das partículas, ou seja, quanto maior o peso da partícula maior será a chance dela ser amostrada. Como a etapa de reamostragem é uma amostragem com reposição, o conjunto de partículas final é do mesmo tamanho do conjunto inicial e como a amostragem leva em consideração os pesos das partículas, o conjunto final pode apresentar partículas repetidas. Então o objetivo da etapa de reamostragem é focar o conjunto de partículas na região do espaço de estado de maior relevância. Isso faz com que o número de partículas necessárias para fazer a estimação do estado seja menor se comparado com o SIS, o que também faz com que o custo computacional para executar o SIR seja menor. A etapa de reamostragem é uma implementação probabilística da ideia darwinista da sobrevivência do mais apto. Para complementar a explicação a figura 3.7 mostra os passos do SIR.
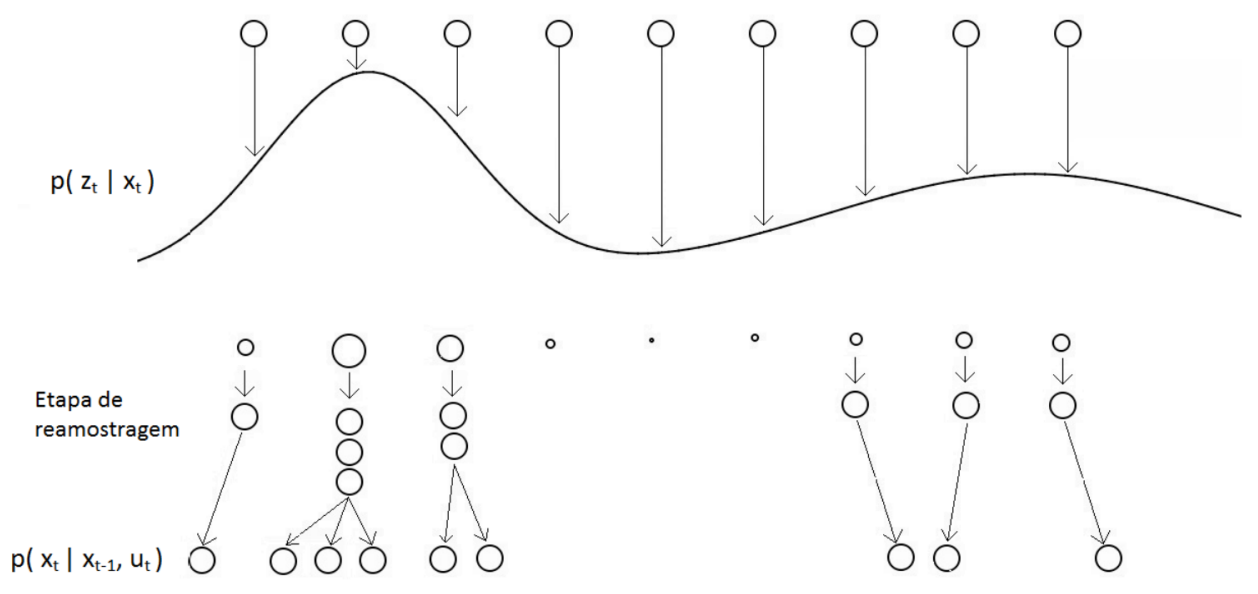

Figura 3.7 - Passos do filtro Sequential Importance Resampling 
Embora a reamostragem reduza os efeitos da degeneração, ela introduz um outro problema conhecido como empobrecimento amostral, já que estatisticamente apenas as partículas que têm grandes pesos são selecionadas muitas vezes. Assim, haverá muitas partículas repetidas o que acarreta numa perda de diversidade. Num caso limite isso pode conduzir a um colapso das partículas, onde todas as partículas ocupam o mesmo ponto no espaço de estado. Esta situação corresponde a uma representação muito baixa da densidade posterior e normalmente faz com que o filtro divirja. Para resolver esse problema do SIR, outras variações da etapa de reamostragem são utilizadas. A etapa de reamostragem usada no SIR é chamada de reamostragem multinomial.

\subsubsection{Outras variações da etapa de reamostragem}

$\mathrm{Na}$ literatura são encontrados vários tipos de etapas de reamostragem [47, 48]. Essa etapa tem como o objetivo focar o conjunto de partículas na região do espaço de estado de maior relevância levando em consideração o peso de importância que cada partículas possui. Assim, a etapa de reamostragem é uma parte crucial para o funcionamento do filtro de partículas e por isso é importante fazer uma escolha bem fundamentada do método de reamostragem a ser utilizado. Na literatura podem ser encontrados alguns métodos de reamostragem, cada um com suas vantagens e desvantagens. Um fator importante na escolha do tipo da etapa de reamostragem é com relação a possibilidade da implementação em paralelo dessa etapa. Como o filtro de partículas apresenta um alto custo computacional, uma solução para a sua utilização em aplicações de tempo real e fazer uma implementação paralela e de todos os passos do filtro de partículas, a etapa de reamostragem é a mais difícil de ser implementada paralelamente porque envolve uma interação entre as partículas. O grau de interação entre as partículas varia entre as etapas de reamostragem existentes, assim pode-se ter uma preferência maior pelo grau de paralelização da implementação da etapa de reamostragem do que pelo seu desempenho.

\subsubsection{Reamostragem estratificada}

Nessa variação da etapa de reamostragem, as partículas são agrupadas em subconjuntos. O processo de amostragem desses subconjuntos é realizadas em duas etapas. Na primeira etapa, a quantidade de amostras de cada subconjunto é determinado com base no peso total das partículas contidas no subconjunto. Na segunda etapa, amostras individuais são tiradas randomicamente de cada subconjunto usando, por exemplo a reamostragem multinomial. Essa variação da etapa de reamostragem apresenta uma menor variância amostral e tende a ter um bom desempenho quando um robô rastreia várias hipóteses distintas, com um único filtro de partículas. 


\subsubsection{Reamostragem sistemática}

A ideia básica dessa variação da etapa de reamostragem é que ao invés de selecionar as amostras de forma independente umas das outras, como é feito na reamostragem multinomial, a escolha envolve um processo estocástico sequencial. Ou seja, ao invés de se amostrar $\mathrm{N}$ números aleatórios entre [0,1] e utilizar o conjunto de partículas normalizadas para selecionar as partículas correspondentes a esses números aleatórios amostrados, como é feito na reamostragem multinomial, essa variação amostra um único número aleatório e a partir dele seleciona as partículas. Essa seleção ainda é proporcional ao peso de importância da partícula. A amostragem desse único número aleatório é feita no intervalo $\left[0 ; N^{-1}\right]$, onde $\mathrm{N}$ é o número de partículas a serem amostradas na etapa de reamostragem. Com esse número, as partículas são selecionadas adicionando várias vezes o montante fixo $N^{-1}$ ao valor do número aleatório amostrado e escolhendo a partícula que corresponde ao número resultante.

Essa variação da etapa de reamostragem também é chamada de Low variance sampling e ela apresenta duas vantagens. A primeira vantagem é que ela cobre o espaço de estado de uma forma mais sistemática do que a reamostragem multinomial evitando o empobrecimento amostral. Isso é óbvio já que os ciclos de amostras dependentes percorrem todas as partículas de forma sistemática, ao invés de escolhê-las de forma independente ao acaso. A segunda vantagem é que se todas as amostras tiverem os mesmos fatores de importância, o conjunto de amostras resultante é equivalente ao conjunto de amostras de entrada, de modo que nenhuma amostra é perdida se for realizada a reamostragem sem ter sido integrada uma observação, o que não acontece com a reamostragem multinomial, na qual a execução da reamostragem sem a incorporação de uma observação, gera um problema de empobrecimento amostral, deixando o conjunto de amostras resultante com um número maior de partículas repetidas. 


\section{Localização de Monte Carlo}

A localização de Monte Carlo é um algoritmo de localização baseado no filtro de partículas que a partir do conhecimento prévio do mapeamento de alguma característica do ambiente, estima a posição e a orientação do robô enquanto ele se movimenta nesse ambiente e faz medições dessa característica do ambiente. Como ele é baseado no filtro de partículas, a função densidade de probabilidade do estado do robô é estimada por meio de um conjunto partículas sendo que cada partícula representa uma possível posição e orientação do robô. Quanto mais partículas acumuladas em torno de uma região do espaço de estado, maior a probabilidade dessa região ser o valor real do estado do robô e quanto maior o número de partículas utilizadas melhor será a estimativa, porém maior será o custo computacional. Nesse algoritmo, quando o robô se movimenta, as partículas são espalhadas pelo espaço de estado conforme um modelo e quando o robô faz uma medição de alguma característica do ambiente, as partículas que apresentarem melhor associação dessa medição com o mapeamento dessa informação no ambiente conhecido a priori são as partículas que terão maior probabilidade de sobreviver para a próxima iteração do filtro. Esse algoritmo é aplicado tanto para o caso de localização global como para o caso de rastreamento de posição. A sua implementação é fácil e já foi bastante testado em robôs terrestres $[16,17,18,19]$.

\subsection{Algoritmo}

A explicação do funcionamento da localização de Monte Carlo será feita utilizando o algoritmo 4.1.1. Esse algoritmo mostra a forma mais simples de se implementar a localização de Monte Carlo. Como a localização de Monte Carlo é baseada no filtro de partículas do tipo SIR explicado na seção 3.2.3, o algoritmo 4.1.1 também serve como uma explicação 
desse tipo de filtro.

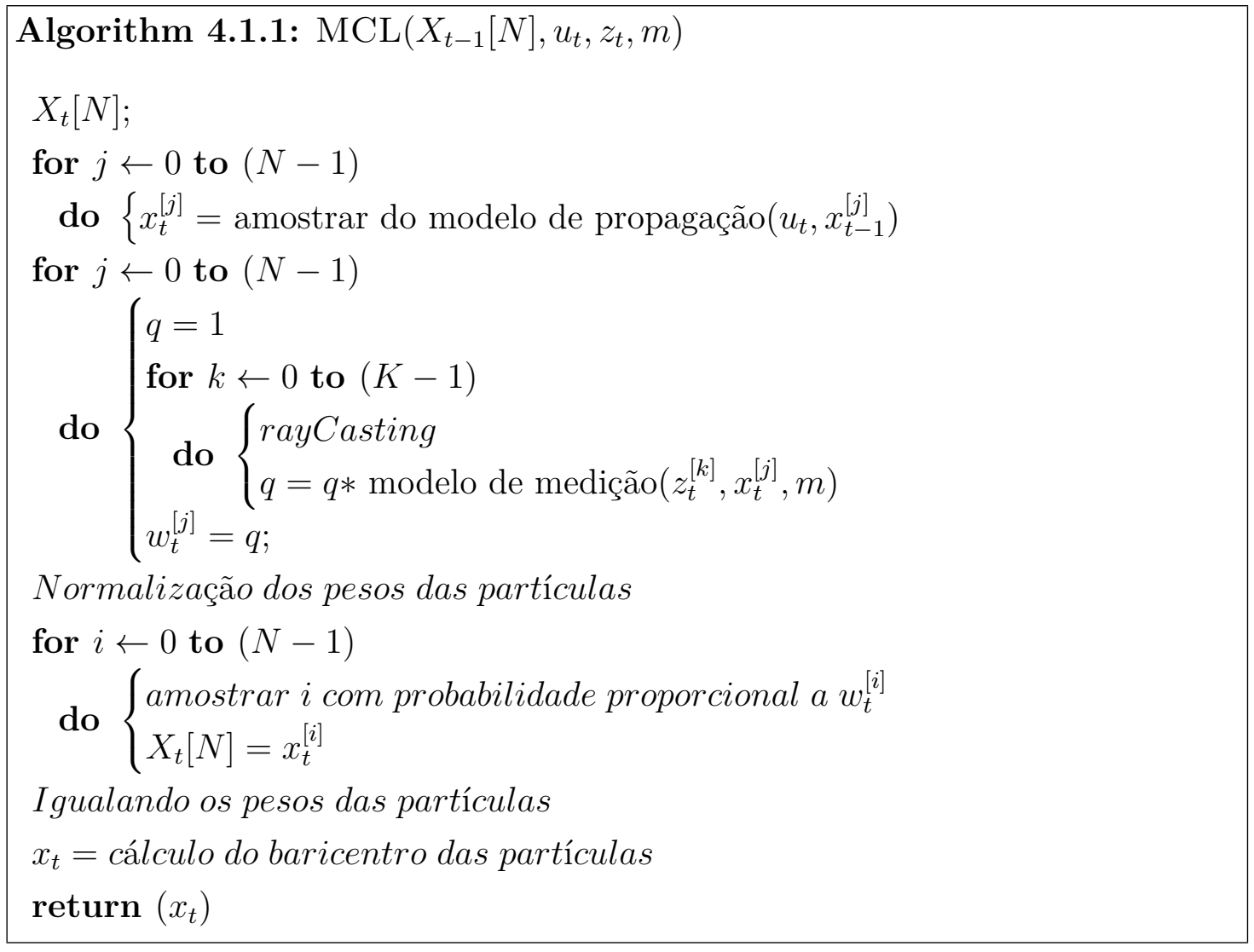

O algoritmo 4.1.1 produz uma nova estimativa do estado a partir das ações de controle e das medições em um instante de tempo. Pelo fato da localização de Monte Carlo ser uma aplicação do filtro de partículas, que por sua vez, é uma derivação do filtro Bayesiano, a localização de Monte Carlo é recursivo, assim, a estimativa de estado é originado a partir da estimativa anterior o que pode ser observado no algoritmo 4.1.1. O algoritmo 4.1.1 é formado por três laços. No primeiro laço é realizado o ciclo de propagação que consiste em formar um novo conjunto de partículas do mesmo tamanho que o anterior levando em consideração o conjunto de partículas anterior, as ações de controle e o modelo de propagação. No segundo laço é realizado o ciclo de atualização em que são calculados pesos de importância para cada partícula gerada no ciclo de propagação. O cálculo desses pesos é feito levando em consideração as medições, o modelo de medição e o mapeamento de alguma informação do ambiente conhecido a priori. No terceiro laço é feita a etapa de reamostragem, já comentada em 3.2.3, que consiste na etapa em que é feita uma amostragem ponderada com repetição das partículas sendo que a ponderação é feita com base nos pesos de importância das partículas. Nesse terceiro laço, um novo conjunto de partículas é formado com base no conjunto formado no primeiro laço. As partículas que formam esse novo conjunto são escolhidas com base nos pesos de importância calculadas no segundo laço, quanto maior o peso da partícula maior a probabilidade dela continuar no novo conjunto de partículas. Assim ao final desse laço, como a seleção é feita com repetição, algumas partículas acabam sendo repetidas e algumas acabam sendo descartadas 
para formar o novo conjunto. O algoritmo mostrado em 4.1.1 utiliza a reamostragem do tipo Multinomial mas qualquer um dos tipos visto na seção 3.2.4 podem ser utilizado.

A escolha do modelo de propagação e do modelo de medição utilizados na localização de Monte Carlo dependem da aplicação. Os modelos que serão utilizados neste trabalhos serão apresentados na seção 4.2. Neste trabalho serão estudadas duas configurações de sensores, uma configuração baseada no sonar de varredura mecânica e a outra baseada no sonar de multi elementos, portanto na seção 4.2 serão apresentados um modelo de propagação e um modelo de medição para cada uma das configurações de sensores. No segundo laço do algoritmo 4.1.1 é mostrado o ciclo de atualização para o caso da configuração de sensor baseado no sonar de multi elementos. A diferença desse laço para essas duas configurações de sensores é que como o sonar de multi elementos retorna a cada medição vários valores de distância e o sonar de varredura a cada medição retorna apenas um, o segundo laço para o sonar de multi elementos possui um laço interno enquanto que para o sonar de varredura esse laço interno é executado apenas uma vez. Outra diferença no algoritmo 4.1.1 para as duas configurações de sensores é que no primeiro laço apenas a configuração baseada no sonar de varredura mecânica utiliza ações de controle no ciclo de propagação, no caso da configuração baseada no sonar de multi elementos o ciclo de propagação utilizada apenas o conjunto de partículas da última estimativa.

A diferença da localização de Monte Carlo para as outras aplicações do filtro de partículas está no fato dela depender do mapeamento de alguma característica do ambiente feito a priori como, por exemplo, o levantamento do campo magnético do ambiente [49]. No caso estudado neste trabalho é necessário se conhecer um mapa das dimensões do ambiente. Esse mapa serve para fazer uma associação entre o dado do sensor que está detectando a informação presente no mapa e a informação que cada partícula com a sua posição e orientação está detectando do mapa. Essa associação é utilizada na etapa em que se calcula os pesos para cada uma das partículas. Assim no exemplo do levantamento do campo magnético do ambiente, é utilizado um magnetômetro para obter a informação do campo magnético e essa informação é utilizado para decidir quais partículas estão mais coerentes com ele sendo que cada partícula possui uma posição dentro do mapa e cada posição do mapa possui um valor de campo magnético.

\subsection{Modelagem do sistema}

Como a localização de Monte Carlo é uma aplicação do filtro de partículas que pertence à classe de filtros Bayesianos, para a sua implementação são necessárias três funções de densidade de probabilidade, a probabilidade inicial do estado $p\left(x_{0}\right)$, a probabilidade de transição do estado $p\left(x_{t} \mid u_{t}, x_{t-1}\right)$ e a probabilidade de medição $p\left(z_{t} \mid x_{t}, m\right)$. A probabilidade inicial do estado $p\left(x_{0}\right)$ depende do conhecimento sobre o estado inicial. Existem alguns casos para $p\left(x_{0}\right)$, no qual se o estado inicial pode ser estimado a partir da medida de 
alguns sensores, $p\left(x_{0}\right)$ pode ser considerada uma distribuição Gaussiana com média igual a essa estimava e com variância igual a variância desses sensores. Outro caso de $p\left(x_{0}\right)$ é que quando não se tem nenhum conhecimento sobre o estado inicial, ela é descrita por uma distribuição uniforme ao logo de todo o espaço de estado. As probabilidades de transição de estado e de medição, exigem uma maior explicação e assim o resto dessa seção será utilizado para descrevê-las. A probabilidade de transição de estado também recebe o nome de probabilidade de propagação de estado.

Este trabalho irá investigar a localização de Monte Carlo para duas configurações de sensores diferentes, assim serão utilizados um modelo de propagação e um modelo de medição para cada uma das configurações. Porém os modelos de medição são parecidos, apresentando apenas uma pequena distinção. Como os sensores responsáveis pelo modelo de medição são os sonares, a diferença do modelo de medição para as duas configurações de sensores está na diferença entre os sonares utilizados em cada uma. Como o sonar de varredura mecânica capta apenas um feixe por vez, o modelo de medição é executado apenas uma vez para cada partícula, já o sonar de multi elementos capta 768 feixes por vez, sendo executado 768 vezes para cada partícula.

\subsubsection{Modelo de Propagação}

Nessa parte do trabalho será feita a descrição do modelo usado para representar a probabilidade de transição do estado $p\left(x_{t} \mid u_{t}, x_{t-1}\right)$ que na localização de Monte Carlo é responsável por espalhar as partículas pelo espaço de estado em cada período de tempo.

A modelagem utilizada no sistema de navegação deste trabalho será feita utilizando apenas equações cinemáticas que tratam apenas dos aspectos geométricos do movimento não se preocupando com as causas dele. Para descrever essa modelagem, neste trabalho serão utilizadas as nomenclaturas de movimento navais sugeridas por SNAME [50], que são mostradas na tabela 1.

Tabela 1 - Nomenclatura utilizada neste trabalho

\begin{tabular}{ccc}
\hline \hline & Velocidades lineares e angulares & Posições e ângulos de Euler \\
\hline movimentos na direção x (avanço) & $\mathrm{u}$ & $\mathrm{x}$ \\
movimentos na direção y (deriva) & $\mathrm{v}$ & $\mathrm{y}$ \\
movimentos na direção z (afundamento) & $\mathrm{w}$ & $\mathrm{z}$ \\
rotações sobre o eixo x (rolagem) & $\mathrm{p}$ & $\phi$ \\
rotações sobre o eixo y (arfagem) & $\mathrm{q}$ & $\theta$ \\
rotações sobre o eixo z (guinada) & $\mathrm{r}$ & $\psi$ \\
\hline \hline
\end{tabular}

Como para referenciar a posição e a orientação de um veículo no espaço é necessário definir um sistema de coordenadas, antes de explicar a modelagem utilizada neste trabalho é necessário antes fazer uma breve explicação dos sistemas de coordenadas utilizados [51, cap. 2]:

- Sistema de Coordenadas NED - O sistema de coordenadas North-East-Down NED é um sistema de coordenadas em que seu centro pode ser colocado em qualquer 


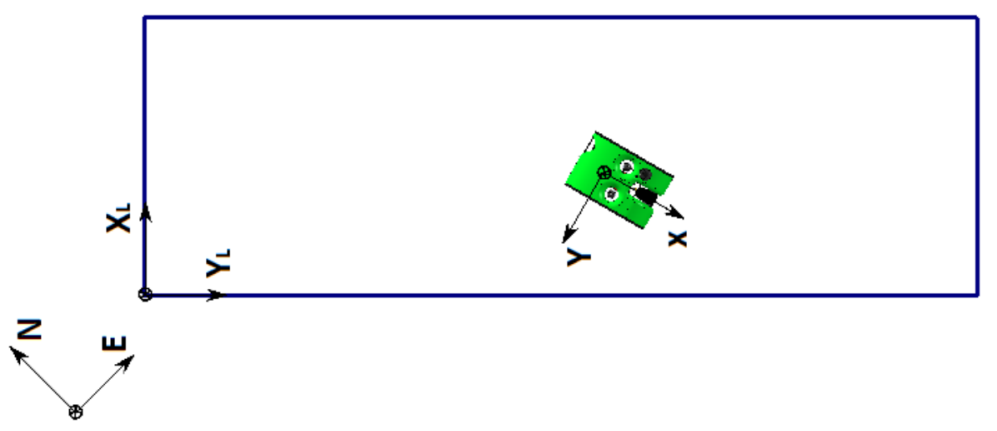

Figura 4.8 - Representação dos sistemas de coordenadas

ponto do globo terrestre em um plano tangente à superfície da Terra. Nesse sistema o eixo $x$ aponta para o norte verdadeiro, o eixo $y$ aponta para o Leste enquanto que o eixo $z$ aponta para baixo na direção normal à superfície da Terra, seguindo a regra da mão direita.

- Sistema de Coordenadas Local - O sistema de coordenadas Local $X_{L} Y_{L} Z_{L}$ é um sistema que tem as mesmas característica do sistema de coordenadas NED porém a orientação do eixo $x$ não aponta para o norte verdadeiro e sim para um rumo mais conveniente para a navegação. Esse sistema de coordenadas é utilizado quando se deseja fazer a localização do veículo com relação a um ambiente conhecido.

- Sistema de Coordenadas do Corpo - O sistema de coordenadas fixo no corpo $X Y Z$ é um sistema de coordenadas cujos eixos estão fixos ao veículo. A origem $O$ do sistema de coordenadas fixo ao corpo é geralmente escolhida para coincidir com o centro de gravidade do veículo. Nesse sistema o eixo $x$ aponta para a direção nominal de movimento do veículo, o eixo $y$ aponta para uma direção ortogonal e a direta do eixo $x$ e o eixo $z$ aponta para baixo seguindo a regra da mão direita.

A figura 4.8 ilustra os sistemas de coordenas utilizados. Como o equacionamento do problema deste trabalho envolverá esses sistemas de coordenadas é necessário verificar o cálculo necessário para fazer a transformação de coordenadas de um vetor representado em um sistema para o outro. Essa transformação é representada pela equação 4.1.

$$
v^{n}=R_{b}^{n} v^{b}
$$

A matriz de transformação de coordenadas $R_{b}^{n}$ pode ser calculada de diferentes modos, ela pode ser calculada utilizando cossenos diretores ou ângulos de Euler ou quaternions [51]. Neste trabalho, a modelagem será feita utilizando os ângulos de Euler por ser uma representação mais intuitiva e pelo fato de que as desvantagens de sua utilização não serem relevantes para o caso da aplicação deste trabalho. A representação por ângulos de Euler apresenta duas desvantagens, uma devido ao alto custo computacional para se fazer a 
transformação de coordenadas, que neste trabalho, por não ser realizado em componentes embarcados, não trará limitações e a outra porque essa representação apresenta uma singularidade para ângulos de arfagem iguais a \pm 90 , mas como este trabalho envolve a modelagem de um robô submarino do tipo ROV que são, geralmente, passivamente estáveis em arfagem, isso também não será problema.

Os ângulos de Euler descrevem a orientação de um corpo por meio de três ângulos, a matriz de rotação representadas por esses ângulos é obtida pela rotação independente e consecutiva ao redor de cada eixo do sistemas de coordenadas não inercial. Por essas rotações não serem acumulativas, é necessário estabelecer uma ordem para sequência de rotações e a ordem utilizada nesse trabalho foi a Z, Y e X. A equação 4.2, mostra a forma da matriz de transformação de coordenadas entre o sistema NED e o sistema fixo ao corpo.

$$
R_{n}^{b}=\left(\begin{array}{ccc}
\cos (\psi) \cos (\theta) & -\sin (\psi) \cos (\phi)+\cos (\psi) \sin (\theta) \sin (\phi) & \sin (\psi) \sin (\phi)+\cos (\psi) \cos (\phi) \sin (\theta) \\
\sin (\psi) \cos (\theta) & \cos (\psi) \cos (\phi)+\sin (\phi) \sin (\theta) \sin (\psi) & -\cos (\psi) \sin (\phi)+\sin (\theta) \sin (\psi) \cos (\phi) \\
-\sin (\theta) & \cos (\theta) \sin (\phi) & \cos (\theta) \cos (\phi)
\end{array}\right)
$$

Para calcular a matriz de transformação de coordenadas do sistema fixo ao corpo para o sistema NED basta apenas calcular a transposta de $R_{n}^{b}$ [51, cap. 2]. Essa mesma matriz não pode ser utilizada para fazer a transformação de coordenadas das velocidades angulares fixas ao corpo $\omega_{n b}^{b}=[p, q, r]^{T}$, isso porque as rotações dos ângulos de Euler não são aplicados às coordenadas ortogonais do referencial não inercial e sim aos eixos no quais eles são definidos durante o processo de rotação. Assim as velocidades angulares se integradas diretamente não resultarão na orientação verdadeira do veículo, ou seja, a integração $\int_{0}^{t} \omega_{n b}^{b}(\tau) \mathrm{d} \tau$ não tem nenhum sentido físico imediato. Assim o vetor de velocidades angulares fixa ao corpo $[p, q, r]$ e o vetor da taxa de Euler $[\dot{\phi}, \dot{\theta}, \dot{\psi}]$ estão relacionados por meio de uma matriz de transformação [51, cap. 2]. Essa transformação é mostrada na equação 4.3 .

$$
\left(\begin{array}{c}
\dot{\phi} \\
\dot{\theta} \\
\dot{\psi}
\end{array}\right)=\left(\begin{array}{ccc}
1 & \sin (\phi) \tan (\theta) & \cos (\phi) \tan (\theta) \\
0 & \cos (\phi) & -\sin (\phi) \\
0 & \sin (\phi) \sec (\theta) & \cos (\phi) \sec (\theta)
\end{array}\right)\left(\begin{array}{l}
p \\
q \\
r
\end{array}\right)
$$

Assim, a equação 4.3 pode ser utilizada para se determinar a orientação do veículo em ângulos de Euler a partir das velocidades angulares do veículos obtidas por meio de giroscópios fixos a ele. Para ângulos de arfagem de $\theta= \pm 90, T_{\Theta}$ é indefinida e com isso não é possível utilizar esse tipo de modelagem para os casos em que esses valores de arfagem são atingidos. Nesses casos é necessário utilizar a representação de quaternions [51, cap. 2].

Tendo sido visto como é feita as transformações dos vetores de velocidade linear e angular do sistema NED para o sistema fixo ao corpo a seguir será descrito os modelos de propagação utilizado neste trabalho. Para veículos submarinos do tipo ROV pode ser feita uma aproximação de que o veículo tem um controle passivo de rolagem e arfagem porque 
esses controle são decorrentes de um certo posicionamento do centro de gravidade e do centro de flutuabilidade que podem ser facilmente controlados por meio da utilização de flutuadores e lastros. Assim os ângulos $\phi$ e $\theta$ podem ser considerados pequenos. Com isso a modelagem do sistema será de três graus de liberdade sendo formado pelas posições $x \mathrm{e}$ $y$ e pela guinada $\psi$. Na modelagem não foi considerada a posição $z$ porque em ambiente subaquáticos utilizando um sensor de pressão calibrado é possível obter uma estimativa direta da profundidade do veículo.

Por ser mais simples, será feito primeiro a explicação do modelo de propagação da configuração de sensores formada apenas pelo sonar de multi elementos. A grande diferença entre os dois modelos de propagação é que o modelo de propagação da configuração formada apenas pelo sonar de multi elementos não utiliza informação de sensores nesta etapa enquanto que a outra utiliza. Como a configuração de sensores formada apenas pelo sonar de multi elementos não utiliza dados de sensores a propagação do estado é feita com base apenas no estado anterior. Como o vetor de estado também não possui nenhum de seus estados sendo uma derivada do outro, a propagação de cada elemento do vetor de estado é feita com relação ao seu valor anterior ( modelo de ordem zero ). Com isso a propagação de estado dessa configuração só depende da covariância do ruído da dinâmica. O modelo de propagação dessa configuração de sensores é mostrado na equação 4.4, o qual $n_{x}, n_{y}$ e $n_{\psi}$ correspondem aos ruídos da dinâmica de cada estado.

$$
\left[\begin{array}{c}
x_{k+1} \\
y_{k+1} \\
\psi_{k+1}
\end{array}\right]=\left[\begin{array}{c}
x_{k}+n_{x} \Delta t \\
y_{k}+n_{y} \Delta t \\
\psi_{k}+n_{p s i} \Delta t
\end{array}\right]
$$

Já o modelo de propagação da configuração de sensores que utiliza um sonar de imageamento 2D de varredura, um medidor de velocidades por efeito Doppler e um giroscópio é mostrado na equação 4.5, o qual $u$ e $v$ correspondem respectivamente as velocidades lineares do medidor de velocidades por efeito Doppler nos eixos $x$ e $y, r$ corresponde a velocidade angular do eixo $z$ dada pelo giroscópio e $n_{u}, n_{v}$ e $n_{r}$ correspondem aos ruídos dos sensores.

$$
\left[\begin{array}{l}
x_{k+1} \\
y_{k+1} \\
\psi_{k+1}
\end{array}\right]=\left[\begin{array}{c}
x_{k}+\left(u \Delta t+n_{u} \frac{\Delta t^{2}}{2}\right) \cos \left(\psi_{k}\right)-\left(v \Delta t+n_{v} \frac{\Delta t^{2}}{2}\right) \sin \left(\psi_{k}\right) \\
y_{k}+\left(u \Delta t+n_{u} \frac{\Delta t^{2}}{2}\right) \sin \left(\psi_{k}\right)+\left(v \Delta t+n_{v} \frac{\Delta t^{2}}{2}\right) \cos \left(\psi_{k}\right) \\
\psi_{k}+r \Delta t+n_{r} \Delta t^{2} / 2
\end{array}\right]
$$

O modelo de propagação dessa configuração de sensores utiliza os dados de um giroscópios do tipo MEMS [52] para estimar o rumo e para propagar a posição $(x, y)$ da plataforma será utilizado um medidor de velocidades por efeito Doppler (DVL). Tanto as medições de velocidades lineares obtidas pelo DVL, como as angulares obtidas pelo giroscópios serão usadas como se fossem ações de controle e não como medições realmente, com intuito de deixar o vetor de estado menor possível e assim diminuir o número de 
partículas necessário para fazer a estimação do estado. Os erros existentes nas medições dos sensores utilizados nesse modelo são modelados como Gaussianos.

Uma característica relevante dos dois modelos de propagação que serão utilizados neste trabalho é que apesar do rumo do veículo ser um dos graus de liberdade do vetor de estado, optou-se por não utilizar bússolas para fazer a correção do rumo pelo fato de que como algumas aplicações de ROVs são realizadas em lugares que possam apresentar anomalias ferromagnéticas, o funcionamento desse tipo de sensor pode ficar muito prejudicado.

\subsubsection{Modelos de Medição}

Nessa parte do trabalho será feita a descrição do modelo de medição utilizado na localização de Monte Carlo para as duas configurações de sensores testadas neste trabalho. Esse modelo representa a probabilidade de medição $p\left(z_{t} \mid x_{t}, m\right)$ que, na localização de Monte Carlo, é responsável por atribuir pesos às partículas. O cálculo dos pesos para cada partícula é a forma como a localização de Monte Carlo incorpora as medições em suas estimativas. Esses pesos são usados na etapa de reamostragem que corresponde a uma amostragem ponderada com reposição, assim quanto maior o peso da partícula maior a chance dela continuar no conjunto de partículas. Para ambas as configurações de sensores testadas neste trabalho, os sensores utilizados nessa modelagem são os sonares, o que significa que eles são os responsáveis por eliminar as partículas com relação as posições $x$ e $y$ e a guinada $\psi$. No modelo de medição está a característica principal da localização de Monte Carlo que é a necessidade de se conhecer previamente o mapa de alguma característica do ambiente ( representada pelo $m$ na probabilidade de medição ) para realizar essa modelagem. No caso deste trabalho é necessário o conhecimento previu das dimensões do ambiente para a sua execução.

\subsubsection{Modelo do sonar}

Nesta seção será feita a descrição do modelo de sonar utilizado. Neste trabalho, serão testados dois tipos de sonares, ambos de imageamento 2D porém um de varredura mecânica e o outro de multi elementos [10, cap.2]. A diferença entre eles é que o de varredura mecânica apresenta apenas um transdutor que é rotacionado por um motor de passo, assim ele capta os retornos em uma direção de cada vez, já o multi elementos, por ter vários transdutores consegue captar os retornos em mais de uma direção por vez, no caso do sonar de multi elementos utilizado neste trabalho são 768 direções. A vantagem do sonar de varredura é que ele possui um campo de visão de $360^{\circ}$ já o do multi elementos é de apenas $130^{\circ}$, porém a desvantagem é que a sua varredura é bem mais lenta do que o de multi elementos. Apesar da utilização desses dois tipos de sonares, o modelo de sonar que será mostrado nesta seção pode ser usado para os dois. 


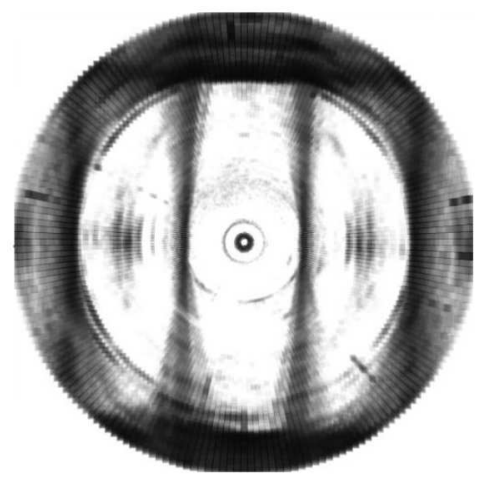

(a)

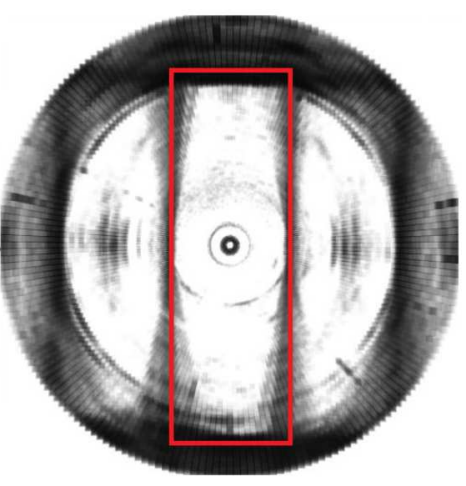

(b)

Figura 4.9 - Imagem de sonar do tanque de testes. (a) Imagem bruta do sonar obtida em um tanque retangular. (b) Contornos do tanque destacados em meio às reflexões

\subsubsection{Processo de filtragem do sonar}

Os sonares de imageamento 2D, diferentemente dos sonares utilizados na robótica terrestre [39], não fornecem informações de distância diretamente e sim informação sobre a intensidade com que a onda retorna do obstáculo. Esses sonares dependendo do alcance em que são configurados e das dimensões do ambiente, eles captam mais de um retorno por onda emitida em uma única direção, assim para cada onda emitida em uma única direção, eles fornecem um perfil de intensidades de retornos. Assim, em termos de modelo, eles possibilitam trabalhar de duas formas diferentes, uma utilizando os perfis de intensidades de seus retornos e a outra processando esses perfis para obter a distância ao obstáculo mais próximos em cada direção. Por ser uma abordagem mais simples, nesse trabalho será utilizado a abordagem da distância, só que para isso é necessário fazer uma filtragem nos perfis de intensidades dos retornos para eliminar os ruídos existentes nesses perfis. Com essa filtragem será possível identificar os contornos do ambiente. Uma imagem acústica de sonar pode possuir diversos ruídos como, reflexões, retornos correspondentes ao fundo do ambiente ou à superfície da água devido a grande largura vertical do feixe, retornos do próprio robô e ruídos gerados pelas vibrações dos propulsores do robô. Para identificar os ruídos existentes na imagem gerada pelo sonar utilizado nesse trabalho, a figura 4.9 mostra uma imagem gerada por ele em um tanque de formato retangular.

Da figura 4.9 é possível identificar os seguintes ruídos:

- Há casos de reflexões de uma mesma parede do tanque, provocando falsos obstáculos na imagem.

- Há retornos de obstáculos que não pertencem ao plano de varredura do sonar, como o fundo do tanque, que embora tenham uma intensidade menor, acabam tornando a imagem mais confusa. 


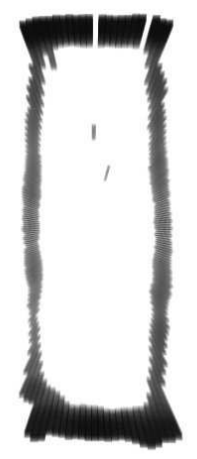

Figura 4.10 - Resultado da filtragem dos dados do sonar

- Há uma grande quantidade de ruído de alta frequência na imagem, tornando difícil identificar picos no perfil de intensidades dos ecos do sonar obtido em cada rotação de seu transdutor.

Assim, para obter uma aproximação do contorno do ambiente, é necessário fazer uma filtragem que elimine esses ruídos [53]. A escolha da filtragem a ser realizada nos dados do sonar ficou restrita aos filtros lineares para não haver distorções na imagem e assim não prejudicar a estimativa de posição pelo sistema de navegação. Por isso para eliminar esses ruídos foram utilizados um filtro Gaussiano [54], um eliminador de ecos e uma limiarização. O resultado da filtragem da figura 4.9 é mostrado na figura 4.10.

Uma falha dessa filtragem é que não considerada a influência do ângulo de incidência da onda emitida pelo sonar no contorno do ambiente. A quantidade de energia da onda, emitida pelo sonar, que volta para ele depende do ângulo que a onda incide no contorno do ambiente, se o ângulo de incidência é baixo, a quantidade de energia que volta para o sonar é alta, mas quando o ângulo de incidência é alto pouca energia desse contorno volta para o sonar. Assim, quando a onda emitida pelo sonar incide no contorno do ambiente com um ângulo grande, a intensidade desse retorno será muito baixa e com isso a reflexão dessa onda em outro contorno do ambiente terá uma intensidade maior do que a primeira, assim, a filtragem acaba descartando o valor do contorno mais próximo pegando ao invés dele o retorno de uma reflexão, ou seja, o filtro falha em detectar o obstáculo mais próximo, o que é um requisito para o funcionamento do filtro de partículas proposto neste trabalho. Apesar dessa falha da filtragem, não é possível resolver esse problema apenas com os dados do sonar já que para o cálculo do ângulo de incidência é necessário saber a posição do sonar, assim essa falha da filtragem tem que ser resolvido na modelagem do sonar 4.2.2.3.

\subsubsection{Modelo}

Agora que é possível extrair medições de distância do sonar, é possível discutir o modelo do sonar que será baseado no modelo proposto em [15, cap.6] que faz a modelagem baseada no comportamento físico do feixe dele. 


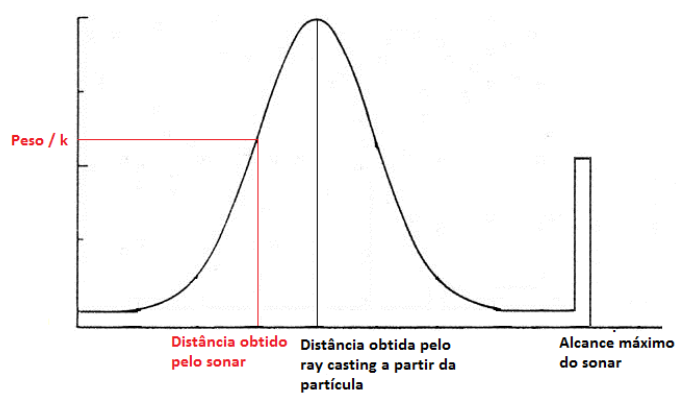

Figura 4.11 - Função densidade de probabilidade do modelo do sonar

Nesse modelo proposto em [15, cap.6] são considerados quatro classes de erros, sendo eles, o erro devido a objetos não previsto no ambiente, o erro devido a limitação da precisão do sonar, o erro devido a falha do sonar em detectar objeto a sua frente e o erro devido a ruídos de difícil modelagem. Como sistema de navegação será testado em ambientes sem vida marinha, o erro devido a objetos não previsto no ambiente não será considerado. O erro devido a limitação da precisão do sonar modela o fato do sonar sempre medir a distância aos objetos mais próximos com um erro resultante da sua limitação de resolução. Esse erro pode ser modelado como uma Gaussiana $p_{\text {hit }}$. O erro devido a ruídos de difícil modelagem serve para modelar como, por exemplo, retornos fantasmas e a influência de ondas acústicas emitidas anteriormente na atual medição. Esse tipo de erro é modelado por meio de uma distribuição uniforme espalhada por todo o alcance do sonar $p_{\text {rand }}$. E por último, o erro devido a falha do sonar em detectar objeto a sua frente incorpora dois tipos de situações, a situação em que o alcance do sonar é menor do que a distância até o obstáculo mais próximo, então o sonar não detecta nada e como resultado fornece o seu valor de alcance máximo. A outra situação é que quando o ângulo de incidência da onda acústica é pequeno, a intensidade do seu retorno também é pequeno, o que faz com que a filtragem elimine esse retorno e pareça com que o sonar não tenha detectado nada e com isso a medição de distância obtido pelo sonar é igual ao seu valor de alcance máximo. Esse tipo de erro é modelado por meio de uma distribuição de massa pontual centrada no valor máximo do alcance do sonar $p_{\max }$. A função densidade de probabilidade resultante dessa modelagem é mostrada na figura 4.11.

Como já comentando em 4.2.2, a característica principal da localização de Monte Carlo é a necessidade de se conhecer previamente o mapa de alguma característica do ambiente para o processamento do modelo de medição. No caso deste trabalho é necessário conhecer a priori as dimensões do ambiente. A necessidade de se conhecer previamente as dimensões do ambiente nesse modelo de sonar proposto em [15, cap.6] está na construção da Gaussiana responsável por modelar o erro do sonar devido a sua limitação de precisão $p_{\text {hit }}$. Na modelagem desse erro, a parte central da Gaussiana corresponde a distância do contorno do ambiente mais próximo de cada partícula levando em consideração a posição e a orientação da partícula e o azimute do sonar. Para obter essa distância é utilizado 
o algoritmo de ray casting [55]. Esse algoritmo consiste em enviar um raio ( em inglês, ray ) que começa na localização da partículas e com uma direção que depende tanto da orientação da partícula como do azimute do sonar. Esse raio é deslocado com essa direção pelo mapa até ele atingir um contorno do ambiente. Com a posição do contorno do ambiente em que o raio atingiu e a posição da partícula é calculada a distância. Para executar o algoritmo de ray casting é necessário um mapa das dimensões do ambientes e isso acaba sendo uma restrição para utilizar o algoritmo de localização proposto neste trabalho que é o conhecimento previu desse mapa. A representação desse mapa, que tem que ser conhecido a priori, irá depender da implementação do ray casting. Existem várias maneiras de representação de mapas métricos [56], as mais conhecidas são a representação geométrica e a representação por grade.

Tendo um modelo para o sonar é possível descrever como são calculados os pesos das partículas no algoritmo de localização de Monte Carlo. Para cada partícula do algoritmo é executado o algoritmo de ray casting, usando o mapa do ambiente conhecido a priori e o valor de azimute do sonar para obter o valor de distância do obstáculo mais próximo à partícula. Com essa distância, a distância fornecida pelo sonar e o modelo do sonar mostrado na figura 4.11 é possível calcular o peso da partícula pela equação 4.6.

$$
w=z_{\text {hit }} p_{\text {hit }}\left(z_{t} \mid x_{t}, m\right)+z_{\text {rand }} p_{\text {rand }}\left(z_{t} \mid x_{t}, m\right)+z_{\max } p_{\max }\left(z_{t} \mid x_{t}, m\right)
$$

Os valores $z_{h i t}$, $z_{\text {rand }}$ e $z_{\text {max }}$ são pesos para fazer a ponderação da influência de cada um dos erros no modelo do sonar assim $z_{\text {hit }}+z_{\text {rand }}+z_{\text {max }}=1$. [15, cap.6] apresenta um algoritmo para ajustar esse ganhos. A diferença da modelagem de medição entre as duas configurações de sensores estudadas neste trabalho está no cálculo mostrado em 4.6. Para o caso da configuração do sonar de varredura, o cálculo do peso de cada partícula é o mostrado em 4.6, isso porque em cada iteração do algoritmo esse sonar fornece apenas um valor de distância, já o sonar de multi elementos, em cada iteração do algoritmo, fornece 768 distâncias, assim o cálculo dos pesos de cada partícula tem que ser feito segundo a equação 4.7 .

$$
w=\prod_{k}^{768}\left(z_{\text {hit }} p_{\text {hit }}\left(z_{t}^{k} \mid x_{t}, m\right)+z_{\text {rand }} p_{\text {rand }}\left(z_{t}^{k} \mid x_{t}, m\right)+z_{\text {max }} p_{\text {max }}\left(z_{t}^{k} \mid x_{t}, m\right)\right)
$$

Um último aspecto a ser ressaltado sobre o modelo de medição do sonar no algoritmo de localização proposto neste trabalho é que o mapa do ambiente tem de ser conhecido a priori para ser possível executar o algoritmo de ray casting, assim é possível identificar as partículas que, devido ao modelo de propagação, foram além dos limites do mapa e assim atribuir um peso zero para estas partículas para que elas possam ser descartadas na etapa de reamostragem, já que representam estimativas inconsistentes. 


\subsection{Configurações de sensores estudadas}

Neste trabalho serão estudadas duas configurações de sensores para o caso da localização de Monte Carlo, uma configuração formada por um sonar de varredura mecânica, um medidor de velocidades por efeito Doppler e um giroscópio e outra formada apenas por um sonar de multi elementos.

Como o sonar de varredura mecânica é muito mais lento para formar uma imagem do ambiente do que o sonar de multi elementos, o algoritmo de localização de Monte Carlo com esse sonar precisa de informações de outros sensores para manter a estimativa de estado. Por isso, além do sonar, essa configuração utiliza um medidor de velocidades por efeito Doppler e um giroscópio. A necessidade da utilização de três sensores para essa configuração torna sua implementação mais difícil do que a do sonar de multi elementos já que é necessário modelar uma quantidade maior de erros. Outra desvantagem desse tipo de configuração é uma possível influência do desalinhamento físico entre os sensores no resultado da localização. Já uma desvantagem da configuração formada apenas pelo sonar de multi elementos é o maior fluxo de dados envolvido nessa configuração devido as características desse tipo de sonar o que resulta em um maior custo computacional no processamento da localização. Outra desvantagem dessa configuração é a sua dependência com relação ao mapa do ambiente conhecido a priori necessário na localização de Monte Carlo. Como essa configuração de sensores é formada apenas por um sonar, se o mapa do ambiente não for preciso, a correlação entre os dados do sonar e o mapa será prejudicada e como não há nenhum outro sensor para corrigir isso, a localização será afetada.

Como as duas configurações de sensores são bem diferentes, o intuito de estudá-las é verificar a influência de cada configuração no algoritmo de localização de Monte Carlo. A figura 4.12 mostra um esquema da implementação da localização de Monte Carlo para a configuração de sensores formada pelo o sonar de varredura mecânica, o medidor de velocidades por efeito Doppler e o giroscópio e a figura 4.13 mostra um esquema da implementação da localização de Monte Carlo para a configuração de sensores formada pelo o sonar de multi elementos.

Uma característica da configuração que utiliza o sonar de varredura e que pode ser observada na figura 4.12 é que o medidor de velocidade por efeito Doppler e o giroscópio são utilizados como ações de controle no algoritmo apesar de serem medições. A configuração que utiliza o sonar de multi elementos não utiliza nenhum sensor no seu modelo de propagação, assim nessa etapa as partículas são propagadas utilizados apenas a última estimação do estado. Das figuras 4.12 e 4.13 pode ser observada a diferença do fluxo de dados entre as configurações devido a diferença entre os sonares. Apesar do maior fluxo de dados da configuração do sonar de multi elementos resultar em uma maior custo computacional para a localização, ele permite uma maior discretização do espaço do que o sonar de varredura e isso pode resultar em uma melhor estimativa do rumo. Como essa discretização é muito pequena, cerca de 0.17 graus, optou-se por aumentá-la para 0.85 


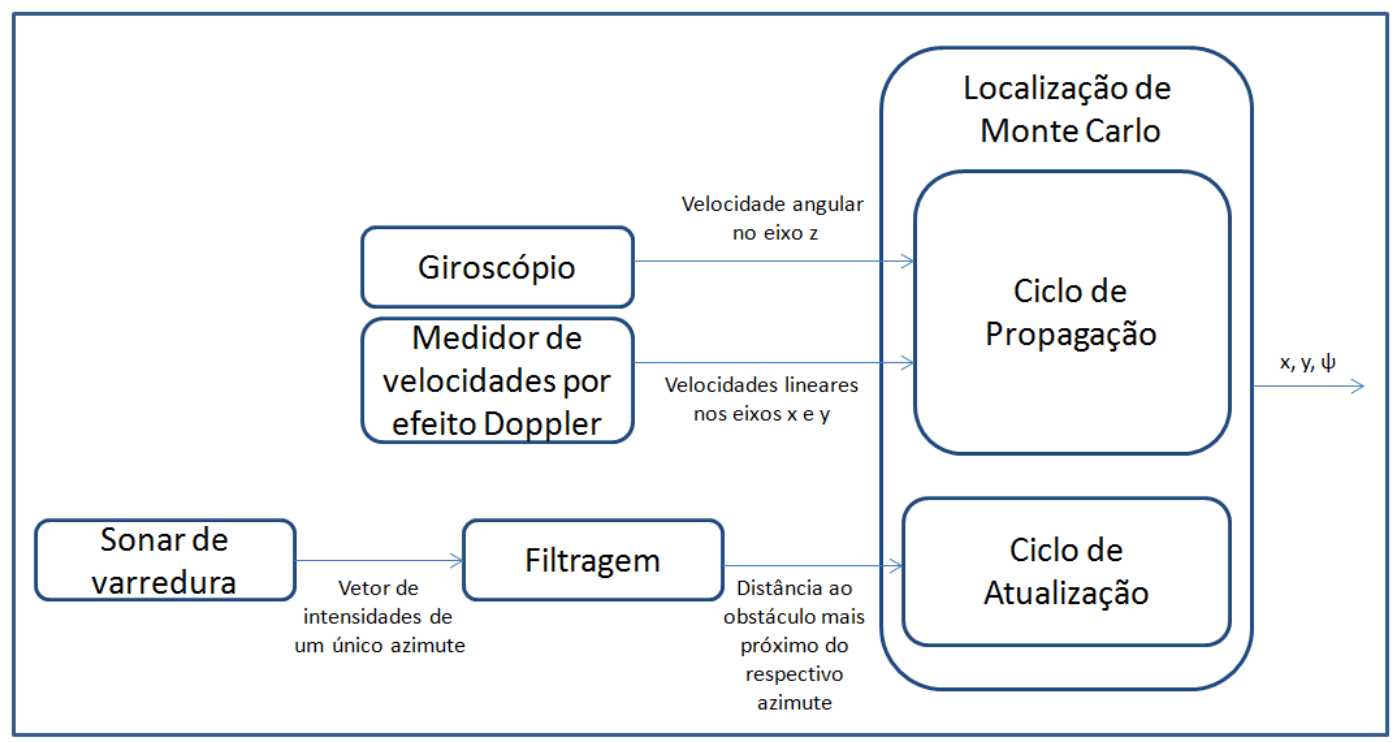

Figura 4.12 - Esquema da localização de Monte Carlo para a configuração de sensores do sonar de varredura mecânica

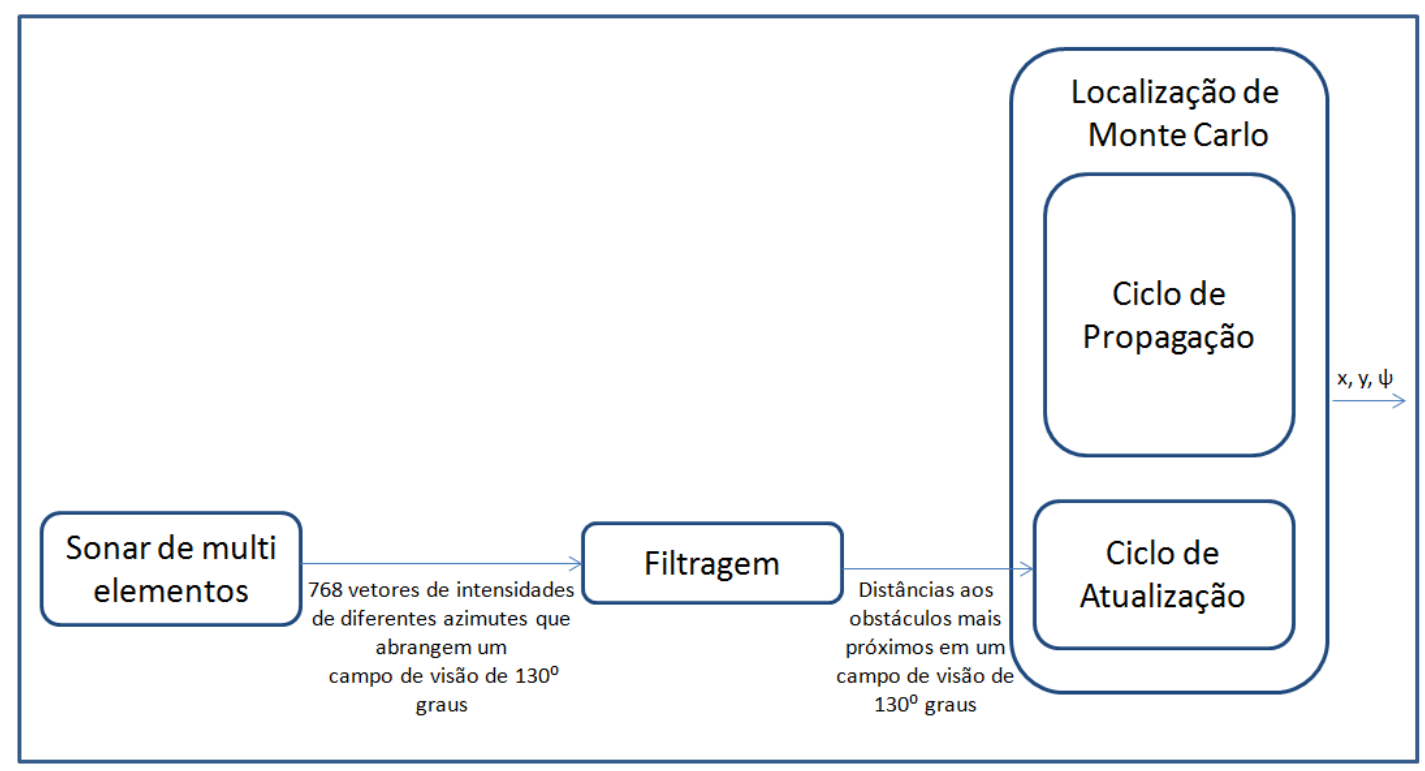

Figura 4.13 - Esquema da localização de Monte Carlo para a configuração de sensores do sonar de multi elementos 
graus, uma vez que análises empíricas não mostraram perdas significativas da qualidade do resultado. Apesar desse aumento, a discretização do sonar de multi elementos ainda fica abaixo da discretização do sonar de varredura que é de 1.8 graus.

A implementação da configuração de sensores que utiliza o sonar de varredura foi feita de forma assíncrona, ou seja, cada operação do algoritmo é realizada na frequência de operação do sensor, assim o ciclo de propagação dessa configuração de sensores trabalha com duas frequências, uma do medidor de velocidades por efeito Doppler e a outra do giroscópio. 


\section{Paralelização da localização de Monte Carlo}

O sistema de navegação proposto neste trabalho se baseia na localização de Monte Carlo que, como foi visto no capítulo 4, é uma aplicação do filtro de partículas em que a ponderação das partículas é feita por meio da correlação entre os dados de um sensor que mede alguma característica do ambiente com um mapeamento conhecido a priori dessa informação nesse ambiente. O filtro de partículas vem sendo muito utilizado atualmente por ser um algoritmo que permite trabalhar com modelos não lineares por meio de uma implementação simples. A desvantagem desse filtro é o seu alto custo computacional que o impede de ser amplamente adotado em aplicações de tempo real. Assim para se utilizar o algoritmo de localização de Monte Carlo na navegação de robôs, é necessário resolver essa adversidade do filtro de partículas. Como o filtro de partículas é altamente paralelizável, uma solução para torná-lo viável para aplicações de tempo real é fazer uma implementação paralela. Atualmente existem vários hardwares que possibilitam fazer essa paralelização como, processadores multicores [57], as Field-progammable Gate Arrays (FPGAs) [32], os clusters de computadores [34] e as unidades de processamento gráfico (GPUs) [36]. Dentre essas possibilidades, as GPUs oferecem o mais baixo custo e fácil acesso ao Single Instruction Multiple Data (SIMD). Como este trabalho trata da implementação de um sistema de navegação para um robô submarino do tipo ROV, que é comandado por meio de um computador na superfície, é possível utilizar a placa de vídeo desse computador para paralelizar o filtro de partículas.

Neste capítulo será feito um estudo da paralelização de cada etapa do filtro de partículas, evidenciando as partes mais complicadas de serem implementadas paralelamente. Neste capítulo também será feita uma explicação da implementação paralela na GPU da localização de Monte Carlo realizada, assim como uma comparação de desempenho dessa implementação com a implementação sequencial processada na CPU.

\subsection{Unidades de processamento gráfico (GPUs)}

As placas de vídeo são projetadas com o intuito de otimizarem o processamento gráfico, assim a concepção de processamento é diferente dos da CPU ( unidade central de processamento ). A diferença é que as GPUs são projetadas para lidar com grandes quantidades de dados em um curto espaço de tempo. Para conseguir isso, a GPU é equipada com uma arquitetura SIMD ( Single Instruction, Multiple Data ). As GPUs oferecem o mais baixo custo e fácil acesso a esse tipo de arquitetura. Atualmente as GPUs chegam a uma execução da ordem de TeraFlops [58] o que ultrapassa muito o poder de processamento das CPUs o 
que torna cada vez mais atraente a utilização de GPUs para a computação de propósito geral. Para algoritmos altamente paralelizáveis a GPU pode superar a performance da CPU. Existem várias maneiras de acessar os recursos da GPU por meio da programação como o OpenGL e o CUDA [35]. Neste trabalho será utilizado a programação CUDA.

\section{$5.2 \quad$ CUDA}

Compute Unified Device Architecture (CUDA) [59, 60] é uma arquitetura de computação paralela desenvolvida pela NVIDIA de padrão aberto. Como a NVIDIA é a única que atualmente implementa essa arquitetura, o CUDA só pode ser utilizado em hardwares da NVIDIA. A arquitetura CUDA integra o vertex shader e o pixel shader em um processador unificado chamado streaming processor (SP). Cada GPU da NVIDIA tem um número de streaming multiprocessors (SM) e cada SM tem oito streaming processors. A arquitetura CUDA tem o recurso de single instruction multiple data (SIMD) em que uma mesma instrução é executada por 32 threads, cada conjunto de 32 threads é chamado de warps. O mesmo tipo de instrução dentro de um warp pode ser paralelizado perfeitamente, porém instruções diferentes dentro de uma warp pode levar a ineficiente execução sequencial.

A programação na arquitetura CUDA é uma extensão da linguagem C, que tem uma sintaxe semelhante ao padrão da linguagem $\mathrm{C}$, mas com algumas extensões para chamar funções para serem executadas na GPU e para acessar alguns dados da GPU em tempo de execução como os índices de threads e blocos em que o kernel está sendo utilizado. A execução do código pode ser dividido entre um programa sequencial executado na CPU e procedimentos paralelos chamados kernels que são executados na GPU, ou seja, a CPU e a GPU podem realizar tarefas diferentes ao mesmo tempo. A GPU não pode usar as funções das bibliotecas criadas para a CPU.

A arquitetura CUDA possui cinco tipos diferentes de memória, memória global, memória constante, memória compartilhada, memória de textura e memória de registro [59]. A memória global é compartilhada por todas as threads e a memória compartilhada é compartilhada por todas as threads do mesmo SM. O tempo de acesso para cada tipo de memória varia e quanto mais rápido for o acesso ao tipo de memória menor é a região disponível para ela, por exemplo, a memória global é a memória de acesso mais lento e possui a maior região de memória.

\subsection{Estudo da paralelização do filtro de partículas}

A diferença da implementação de um algoritmo de localização de Monte Carlo para a implementação de um filtro de partículas está no cálculo dos pesos das partículas no ciclo de atualização. No caso do filtro de partículas, esse cálculo é feito por meio de uma correlação entre o estado propagado e as medidas dos sensores. No caso da localização de 
Monte Carlo, esse cálculo é feito por meio de uma correlação entre o estado propagado, as medidas dos sensores e o mapeamento de alguma informação do ambiente conhecida a priori. No caso deste trabalho, essa correlação consiste em executar um algoritmo de ray casting para identificar a distância da partícula ao contorno do ambiente mais próximo levando em consideração o azimute em que o sonar estaria apontando nessa partícula com a distância fornecida pelo sonar no azimute em que realmente se encontra. Assim o que diferencia o algoritmo do filtro de partículas para a localização de Monte Carlo é que a localização de Monte Carlo precisa executar um algoritmo adicional ( ray casting, no caso deste trabalho ) para fazer a correlação entre o estado propagado e as medidas dos sensores utilizando o conhecimento a priori de alguma informação do ambiente ( no caso deste trabalho, a informação conhecida a priori do ambiente é um mapa de suas dimensões ). Essa etapa que diferencia a localização de Monte Carlo com o filtro de partícula é altamente paralelizável, assim o problema da implementação paralela da localização de Monte Carlo pode ser resumida no problema da paralelização do filtro de partículas. Assim nesta seção será feito um estudo da implementação paralela desse filtro. Para um melhor entendimento da forma como fazer essa implementação, a seguir seŕa feita uma revisão de todas as etapas desse filtro.

- Inicialização do filtro: Cada partícula do filtro é amostrada a partir de uma distribuição inicial e os pesos de importância dessas partículas são inicializados com $1 / N$, onde $N$ é o número de partículas utilizadas no filtro.

- Modelo de Propagação: Cada partícula do filtro é propagada através de uma mesma distribuição chamada de distribuição proposta.

- Modelo de Medição: É calculado o peso de importância de cada partícula do filtro usando a probabilidade de medição.

- Etapa de reamostragem: Substitui partículas improváveis por partículas mais prováveis. Realiza uma amostragem ponderada com reposição das partículas do filtro com relação ao seus pesos de importância. Existem diferentes maneiras de se implementar essa etapa. Para essa etapa é necessário que os pesos de importância estejam normalizados.

- Estimação: É calculado a estimação do estado feita pelo filtro de partículas por meio de uma média ponderada das partículas usando os seus pesos de importância.

O filtro de partículas é conhecido pelo seu alto nível de paralelização, uma vez que cada processador pode ser responsável pelas operações associadas a uma ou mais partículas. Isto é verdadeiro para as etapas mais características desse filtro, mas não para todos os seus passos. Assim para se implementar paralelamente o filtro de partículas na GPU existem vários pontos que requerem uma atenção especial. A etapa de reamostragem e as 
suas variações é o passo mais difícil de se implementar paralelamente, uma vez que em algumas variações dessa etapa as partículas interagem umas com as outras. Outro ponto importante é com relação as etapas de redução presentes no filtro de partículas nas etapas de modelo de medição, na etapa de reamostragem e na estimação. O processo de redução consiste nos cálculos que requerem o cálculo de um fluxo menor ( geralmente apenas um elemento como saída ) a partir de um fluxo maior. Geralmente uma redução pode ser realizada em vários passos. Os resultados da etapa anterior são usados como a entrada para a etapa atual e o intervalo no qual a operação é aplicada é reduzida até que apenas um elemento do fluxo continue. Os exemplos de redução presente no filtro de partículas são: soma dos elementos de um vetor, multiplicação dos elementos de um vetor e soma acumulada dos elementos de um vetor. Outro ponto importante é com relação a geração de números aleatórios, uma vez que esta etapa pode consumir uma parte substancial do tempo gasto no filtro de partículas. As etapas restantes do filtro de partícula não serão discutidas por serem paralelas em sua natureza.

Tendo visto os pontos mais complicados de se paralelizar do filtro de partículas, a seguir será dada uma descrição das maneiras de como é feito a paralelização para cada etapa. Começando pela etapa de reamostragem que é responsável por solucionar o problema de degeneração presente no filtro SIS por meio da substituição de partículas mais improváveis pela mais prováveis. Essa etapa possui algumas variações. A variação mais básica dessa etapa é a reamostragem multinomial, mostrada na subseção 3.2.3. Essa variação consiste em uma amostragem ponderada com reposição do conjunto de partículas sendo que a probabilidade da partícula ser amostrada é proporcional ao seu peso de importância. O algoritmo da reamostragem multinomial seleciona as partículas usando números aleatórios uniformemente distribuídos como entrada para a função distribuição acumulada inversa [61] dada pelos pesos das partículas. Essa variação da etapa de reamostragem é em sua natureza paralelizável porém ela apresenta um problema que é o empobrecimento amostral que pode afetar o desempenho do filtro de partículas. Outra variação da etapa de reamostragem utilizada e que resolve o problema do empobrecimento amostral é a amostragem sistemática, mostrada na subseção 3.2.4. Essa variação da etapa da reamostragem é, na sua essência, sequencial já que possui uma interação entre as partículas e por isso é mais complicada de ser implementada paralelamente. Apesar de ser de difícil paralelização, [62] apresenta uma forma paralelizada da reamostragem sistemática. Outra variação da etapa de reamostragem vista na subseção 3.2.4 que também soluciona o problema do empobrecimento amostral foi a reamostragem estratificada. Essa variação apresenta um solução intermediária entre a multinomial e a sistemática porque ela soluciona de maneira mais simples o problema do empobrecimento amostral, dividindo o espaço de estado em grades sendo que de cada grade ela amostra uma quantidade de partículas que depende do valor dos pesos de importância das partículas presentes nela e por fazer essa divisão do espaço permite que cada partição do espaço seja executado por um processo em paralelo. 
Com relação a geração dos números aleatórios, no filtro de partículas eles são necessários na inicialização quando as partículas são uniformemente distribuídas ao longo de todo o espaço de estado, na etapa de reamostragem para fazer a seleção das partículas de maior relevância e também no ciclo de propagação do filtro para propagar as partículas que é feita adicionando as ações de controle no estado de cada partícula mais um erro que é amostrado da distribuição probabilística que representa o erro dessas ações de controle. Essa amostragem do erro da ação de controle é feita para cada partícula. Para fazer a geração de números aleatórios para a implementação paralela do filtro de partículas foram encontradas três possíveis maneiras. Uma primeira maneira é fazer a geração de número aleatórios na CPU e passá-los para a GPU. Como são necessários vários números aleatórios por partícula em cada iteração do filtro, essa maneira envolve uma grande transferência de dados entre a CPU e a GPU, o que é uma desvantagem já que essa transferência é lenta. Outra maneira é a utilização de uma biblioteca pronta específica para a GPU como a CuRand [63] que é uma biblioteca de geração de números pseudoaleatórios ( PRNG ) em que não envolve transferência de dados entre a CPU e a GPU. O gerador padrão dessa biblioteca é baseada no algoritmo XORWOW que é um exemplo da classe dos geradores xorshift. Esse algoritmo é simples quando comparado com outros geradores o que resulta em geradores simples que são muito rápidos, mas ainda apresentam um bom desempenho em testes estatísticos de aleatoriedade [64]. A última maneira é fazer a implementação na própria GPU de um algoritmo que gera esses números [65, 66]. Essa maneira é a mais complexa de todas mas é a mais completa já que se pode escolher o algoritmo de geração de números aleatórios que tenha o melhor desempenho com relação à aplicação e ao algoritmo que será executado na GPU $[65,66]$ sem ter o problema da lenta transferência de dados entre a GPU e a CPU.

O último ponto importante para paralelização do filtro de partículas são as partes que envolvem redução que correspondem as somatórias que fazem parte da normalização do peso na etapa de correção, no cálculo dos pesos de importância de cada partícula que corresponde a uma sequência de multiplicações, no cálculo do peso acumulado durante a etapa de reamostragem e no cálculo da média ponderada das partículas na etapa de estimação. De todos os casos listados acima, menos a soma cumulativa são resolvidos de uma forma simples de redução que pode ser encontrada em [60]. Já a soma cumulativa pode ser implementada usando um esquema de passagem múltipla, onde uma árvore de somas é percorrida para baixo e depois para cima. Este esquema de passagem múltipla é um método padrão para paralelização de algoritmos sequenciais similares baseados no princípio de dispersão e reunir. Nesse algoritmo na primeira passagem que corresponde a direção de descida, algumas somas parciais são efetuadas, na passagem de subida essas somas parciais são usadas para calcular as somas parciais restantes e assim completar a soma cumulativa [35]. 
Feita a análise dos pontos mais importantes da paralelização do filtro de partículas pode-se concluir que essa paralelização não é trivial sendo necessário fazer uma análise de desempenho para descobrir quais partes serão executadas na GPU e quais serão executadas na CPU e também qual método de reamostragem que garante um bom desempenho do filtro e que permite uma paralelização eficiente.

\subsection{Implementação paralela da localização de Monte Carlo em uma GPU utilizando CUDA}

Nesta seção será feita uma explicação da implementação paralela da localização de Monte Carlo feita neste trabalho e também será feita uma comparação entre o tempo de execução do algoritmo paralelizado executado na GPU e o tempo de execução do algoritmo na forma sequencial executado na CPU.

A ideia de se fazer uma implementação paralela da localização de Monte Carlo está no fato desse algoritmo ser altamente paralelizável, e assim sua implementação na GPU com relação a sua implementação na CPU pode ser muito mais eficiente. Além disso para o caso de uma das duas configurações de sensores estudadas neste trabalho que corresponde a formada pelo sonar de multi elementos, a localização de Monte Carlo é ainda mais paralelizável ( como mostrado na seção 4.1 ) já que o sonar utilizado nessa configuração possui um fluxo de dados muito grande. Além de tornar a localização de Monte Carlo ainda mais paralelizável, a filtragem do alto fluxo de dados desse sonar também por ser feita de forma paralela aumentando ainda mais a importância da implementação na GPU.

A implementação paralela da localização de Monte Carlo feita neste trabalho é uma implementação que é executada inteiramente na GPU. Como a implementação do filtro está inteiramente na GPU, o fluxo de dados entre a GPU e a CPU fica reduzido aos dados dos sensores e ao valor da estimativa do vetor de estado, deixando o tempo de carga baixo. Para que a implementação do filtro esteja inteiramente na GPU, a forma escolhida para gerar os números aleatórios foi utilizar a biblioteca cuRand [63].

Para fazer essa implementação paralela da localização de Monte Carlo foi necessário implementar 10 kernels sendo que alguns kernels são utilizados mais de uma vez. Kernel é o nome dado no CUDA às subrotinas que podem ser chamadas de um programa escrito em linguagem de computação mas que é executado na GPU. Geralmente os kernel são subrotinas que podem ser executadas de forma paralela.

A explicação da forma como foi feita a implementação será dada a seguir e ela será feita com base nas etapas do filtro de partículas como foi feito em 5.3. Para cada etapa do filtro de partículas será feita uma explicação dos kernels necessários.

- Filtragem dos dados do sonar: essa etapa possui o processamento de apenas um kernel que é responsável por fazer a filtragem dos dados dos sonares, ou seja, transforma o 
vetor de intensidades do sonar em informação de distância. Nesse kernel o número de blocos lançados é igual ao número de azimutes que o sonar retorna a cada medição e o número de threads lançadas para cada bloco é igual ao tamanho do vetor de intensidade do sonar que é igual para todos os azimutes.

- Ciclo de Propagação: essa etapa possui o processamento de apenas um kernel que é responsável por propagar as partículas. Nesse kernel o número de blocos lançados é igual ao número de partículas utilizadas no algoritmo e é lançada apenas um thread para cada bloco.

- Ciclo de Medição: essa etapa possui o processamento de apenas um kernel que é responsável pelo cálculo do peso de cada partícula. Nesse kernel o número de blocos lançados é igual ao número de partículas utilizadas no algoritmo e o número de threads lançadas para cada bloco é igual ao número de azimutes que o sonar retorna a cada medição. Essa etapa do algoritmo é a única que a implementação, mesmo que na CPU, é diferente entre as configurações de sensores estudadas. Como visto na seção 4.1, a diferença é que nessa etapa a implementação da configuração com o sonar de multi elementos possui um laço a mais já que esse sonar fornece mais de um dado de distancia por medição. Assim para o caso da configuração com o sonar de multi elementos, essa etapa possui um processo de redução no cálculo do peso de cada partícula como pode ser visto em 4.1 .

- Etapa de reamostragem: essa etapa possui o processamento de oito kernels que são responsável por gerar um novo conjunto de partículas por meio de uma amostragem ponderada com reposição.

- Somatória dos pesos das partículas: essa subetapa da etapa de reamostragem é responsável por calcular a soma dos pesos das partículas para que o peso de cada uma possa ser normalizado posteriormente. A normalização dos pesos das partículas é necessária para a execução da etapa de reamostragem. Nessa subetapa são utilizados dois kernels.

- Normalização das partículas: essa subetapa da etapa de reamostragem é responsável por normalizar as partículas. Nessa subetapa é utilizado apenas um kernel sendo que ele é lançado com um número de blocos igual ao número de partículas utilizadas no algoritmo e cada bloco é lançado com apenas uma thread.

- Calculo da soma acumulada dos pesos das partículas: essa subetapa da etapa de reamostragem é responsável por calcular a soma acumulada dos pesos das partículas para ela ela seja utilizada na subetapa de seleção das partículas. Nessa subetapa são utilizados três kernels. 
- Seleção das partículas: essa subetapa da etapa de reamostragem é responsável por executar a seleção das partículas com base na soma acumulada dos pesos das partículas e utilizando uma quantidade de números aleatórios, uniformemente distribuídos entre $[0,1]$, igual ao número de partículas. Nessa subetapa é utilizado apenas um kernel sendo que ele é lançado com um número de blocos igual ao número de partículas utilizadas no algoritmo e cada bloco é lançado com apenas uma thread.

- Calculo da estimativa: essa etapa é responsável por calcular o baricentro das partículas que corresponde a estimativa de estado. Essa etapa é equivalente a etapa de somatória dos pesos das partículas

No caso da configuração de sensor que possui o sonar de varredura mecânica, o kernel responsável pela propagação das partículas e o kernel responsável pelo cálculo dos pesos das partículas poderiam ser um único kernel. Como o sonar de multi elementos produz mais de uma informação de distância a cada iteração do algoritmo esses dois kernels tiveram que ser separados já que a execução do primeiro só depende do número de partículas e segundo além do número de partículas, também depende da quantidade de informações de distâncias fornecida pelo sonar a cada iteração. Outra característica da implementação paralela realizada neste trabalho é que tanto no kernel que faz a filtragem dos sonares que possui uma filtragem Gaussiana tanto no kernel que faz o ciclo de medição que possui o algoritmo de ray casting foram utilizadas memórias do tipo constate para acelerar esses dois processos. Outra característica é que todos os processamentos de redução envolvidos na implementação foram feitos utilizando a memória compartilhada. Uma última característica sobre a implementação paralela realizada neste trabalho é o kernel responsável pelo cálculo da soma acumulada dos pesos das partículas foi implementado segundo o algoritmo mostrado em [67]. Com essas características, a implementação realizada neste trabalho pode utilizar um número máximo de 32768 partículas. A implementação ficou com esse limite no número de partículas devido as operações de redução presentes no algoritmo que são a soma acumulativa e a soma dos elementos de um vetor. A forma como essas operações foram implementadas junto com o limite máximo de blocos e threads que um kernel pode lançar na GPU utilizada neste trabalho ( GT540M da NVIDIA ) são os motivos desse número máximo de partículas. O número máximo de partículas poderia ser aumentado por meio de modificações na implementação do algoritmo, porém na seção 6.2.4 será mostrada uma análise que indica que a quantidade de partículas necessárias para uma boa estimativa, considerando o problema estudado neste trabalho, está muito abaixo dessa limitação dessa implementação. A quantidade de memória global e compartilhada presente na placa utilizada neste trabalho não foi o limitante para o número máximo de partículas que pode ser utilizado no algoritmo. 
Tendo sido feita a explicação da implementação paralela do algoritmo, agora será feita a comparação de desempenho da execução da localização de Monte Carlo na GPU e na CPU. A GPU utilizada neste trabalho é a GT540M da NVIDIA e a CPU é um processador intel core i5 de 2.30GHz. A análise da comparação entre a execução da localização de Monte Carlo na GPU e na CPU será dividida em dois processos, um processo correspondendo a filtragem dos dados do sonar e o outro correspondendo ao algoritmo da localização de Monte Carlo em si, isso porque como o processo de filtragem dos dados dos sonar não dependem do número de partículas utilizados no algoritmo, é possível verificar se esse processo é mais eficiente na GPU ou na CPU independentemente do número de partículas. Caso a filtragem não seja mais eficiente na GPU, ela pode ser processada na CPU. No caso do algoritmo de localização de Monte Carlo, o aumento do número de partículas garante que a eficiência da GPU seja maior do que a da CPU.

Começando pela análise da filtragem dos dados do sonar, para o caso do sonar de varredura mecânica a filtragem leva em média $0.00236686 \mathrm{~ms}$ para ser executado na CPU e leva em média 0.061888 ms para ser executado na GPU o que mostra que não há ganho de se executar a filtragem desse tipo de sonar na GPU. Essa ineficiência da execução da filtragem desse tipo de sonar na GPU está relacionada com o baixo fluxo de dado gerado por esse sonar e que por isso a paralelização não consegue compensar a troca de dados necessária entre a CPU e a GPU que demanda bastante tempo. Já para o caso do sonar de multi elementos, a filtragem leva em média $2.11322 \mathrm{~ms}$ para ser executado na CPU e leva em média 0.752256 ms para ser executado na GPU. Nesse caso como o fluxo de dados é bem maior, compensa fazer a paralelização da filtragem desse tipo de sonar.

Tendo sido feita a comparação do tempo de execução das filtragens dos sonares na GPU e na CPU para os dois casos de configuração de sensores estudadas neste trabalho, agora será feita a comparação da execução do resto do algoritmo de localização para diferentes números de partículas. Como será visto na seção 6.2.4.2 que o número de partículas necessário para uma boa estimativa para o sistema de navegação proposto neste trabalho para o caso da configuração de sensores do sonar de varredura é por volta de 4000 partículas e, assim como na filtragem dos dados desse sonar, o algoritmo de localização dessa configuração apresenta um paralelização menor do que a configuração do sonar de multi elemento como visto na seção 4.1, o sistema de navegação formado pela configuração do sonar de varredura proposto neste trabalho pode ser processado na CPU atingindo ainda os requisitos de tempo real. Por isso a análise do tempo de execução do resto do algoritmo de localização para diferentes números de partículas na GPU e na CPU só será feita para o caso do sonar de multi elementos. Essa análise da configuração do sonar de multi elementos é mostrada na figura 5.14.

A figura 5.14 mostra que para todos os número de partículas analisados, a implementação na GPU para a localização de Monte Carlo para o caso da configuração do sonar de multi elementos é mais eficiente do que a implementação na CPU. Porém levando em 


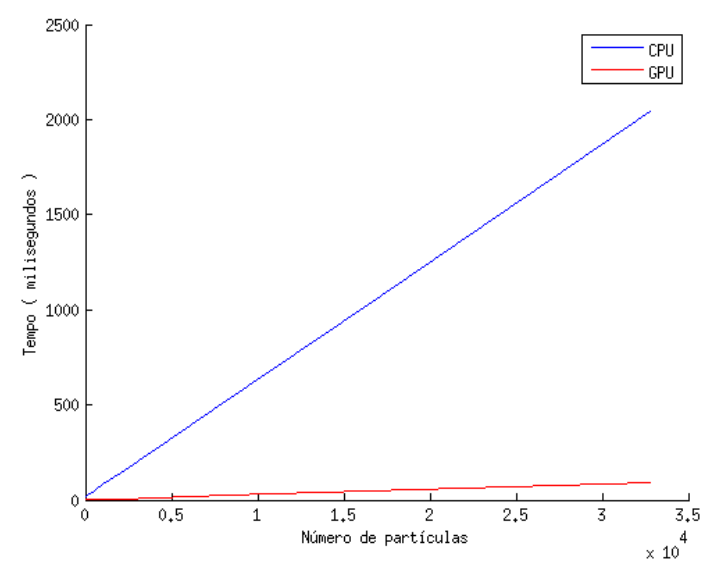

Figura 5.14 - Comparação entre o tempo de processamento do algoritmo de localização de Monte Carlo sem a parte de filtragem dos dados do sonar para o caso da configuração de sensor formada pelo sonar de multi elementos entre a CPU e a GPU

consideração que a frequência de aquisição do sonar de multi elementos é de $15 \mathrm{~Hz}$, se a CPU fosse inteiramente dedicada a realizar o algoritmo de localização e a filtragem do sonar, ela conseguiria atender os requisitos de tempo com até 775 partículas. Na seção 6.2.4 será mostrado que esse número de partículas está acima do número necessário para uma boa estimativa para o caso dessa configuração. Porém para processar esse número de partículas, a estação base de controle do ROV ficaria dedicada completamente ao processamento do sistema de navegação. Como isso não é um caso normal para uma estação de controle de um ROV e como o ganho da implementação paralela é muito grande, a utilização desse tipo de implementação é importante. O tempo total de execução do algoritmo pela implementação paralela em cada iteração utilizando 32768 partículas é de 88, 64 milisegundos. Para esse número de partículas a implementação paralela é 23 vezes mais rápida que a CPU. Porém com esse tempo de processamento para 32768 partículas não é possível atender os requisitos de tempo real já que a frequência de aquisição do sonar de multi elementos é de $15 \mathrm{~Hz}$. Para atender os requisitos de tempo real tem que ser utilizado 16384 partículas que resulta em um tempo de processamento de cada iteração do algoritmo de 44.4 milisegundos.

Essa comparação entre a execução do algoritmo na GPU e na CPU foi feita com base no sistema de navegação desenvolvido e com base nas características da GPU utilizada, assim alterando-se alguns fatores, o desempenho da execução do algoritmo na GPU pode mudar. Os fatores que podem influenciar o desempenho do algoritmo na GPU são: número de partículas necessárias para fazer a estimativa que depende da dimensão do vetor de estado, necessidade da localização global ( quanto maior o mapa maior o número de partículas necessárias ), tipo de mapa que está sendo utilizado, assim como a implementação do ray casting e qual a GPU que está sendo utilizada.

Como será visto na seção 6.2.4, o número de partículas necessário para uma boa 
estimativa para o caso da navegação estudada neste trabalho é muito menor do que 16384 . Como a quantidade de memória na GPU utilizada neste trabalho não é o limitante para a implementação do algoritmo, para trabalhos futuros, é possível aumentar o tamanho do vetor de estado para incluir outros estados de interesse e assim melhorar a estimativa do algoritmo já que o número de partículas que a implementação realizada neste trabalho permite suporta o aumento do número de partículas necessário para uma boa estimativa devido ao aumento do vetor de estado. 


\section{Resultados}

Nesta seção serão mostrados os resultados obtidos com os sistemas de navegação propostos neste trabalho que envolvem a localização de Monte Carlo para duas configurações de sensores, uma utilizando um sonar de varredura mecânica, um medidor de velocidades por efeito Doppler e um giroscópio e a outra utilizando apenas um sonar de multi elementos.

Para validar os resultados deste trabalho foi utilizado um sistema de captura de movimentos baseado em visão computacional da Qualisys [68]. Este sistema necessita de uma linha de visada direta com o objeto rastreado, e consequentemente não funciona embaixo d'água. Assim, os resultados foram gerados utilizando dados coletados dos sensores fixados a uma plataforma flutuante ao invés de dados coletados diretamente do ROV. Com o intuito de manter as mesmas condições se os dados fossem coletados pelo ROV, a plataforma flutuante foi construída de forma que ao ser manualmente deslocada na superfície da água, ela não sofresse grandes varições de arfagem e de rolagem. A figura 6.15 mostra um desenho técnico da plataforma flutuante e a figura 6.16 mostra uma foto dela. Na figura 6.15 é possível ter uma ideia da disposição dos sensores na plataforma. O giroscópio foi fixado na parte de cima da plataforma. Por precaução, como esse sensor não pode ter contato com a água, ele foi colocado dentro de um compartimento cilíndrico estanque. O giroscópio utilizado neste trabalho, na verdade, faz parte de um sensor mais completo conhecido como sistema de referência de atitude e rumo (AHRS) [69] que possui três acelerômetros, três giroscópios e três magnetômetros. Na parte da plataforma que fica submersa, que corresponde a parte formada por duas hastes, são fixados o sonar de varredura mecânica, o medidor de velocidades por efeito Doppler e o sonar de multi elementos. O sensor preso em apenas uma das hastes é o sonar de varredura, logo acima dele fica o medidor de velocidades por efeito Doppler e mais acima fica o sonar de multi elementos. O único cuidado que foi tomado na escolha do posicionamento desses sensores acústicos na plataforma, foi de que as ondas acústicas de cada um não fossem bloqueadas. Na figura 6.15 também é possível observar os quatro marcadores necessário para o funcionamento do sistema de rastreio visual [68] utilizado para validar os resultados deste trabalho. Esses marcadores correspondem às bolinhas na parte superior da plataforma.

Os resultados que serão apresentados neste trabalho foram gerados utilizando dados coletados de testes realizados no tanque retangular do Laboratório de Engenharia Naval e Oceânica (LENO) do departamento de engenharia Naval da escola politécnica da Universidade de São Paulo. Apesar desse tanque possuir 4, 8 metros de largura e 21, 50 metros de comprimento, devido a existência de uma prainha em uma das suas extermidades, foi considerado um valor menor de comprimento no mapa necessário para o funcionamento do sistema de navegação proposto neste trabalho. O comprimento utilizado foi o valor 

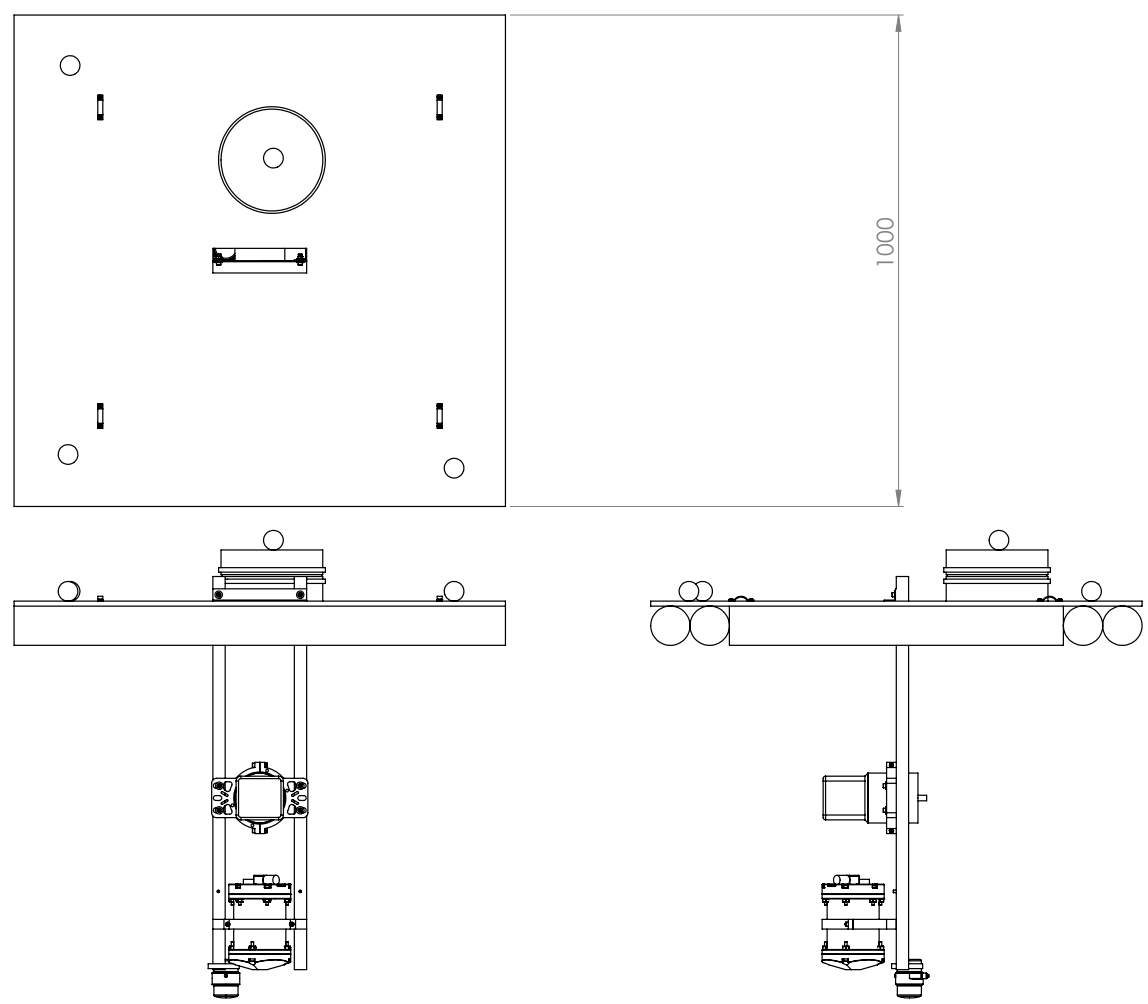

Figura 6.15 - Desenho técnico da plataforma flutuante utilizada nos testes

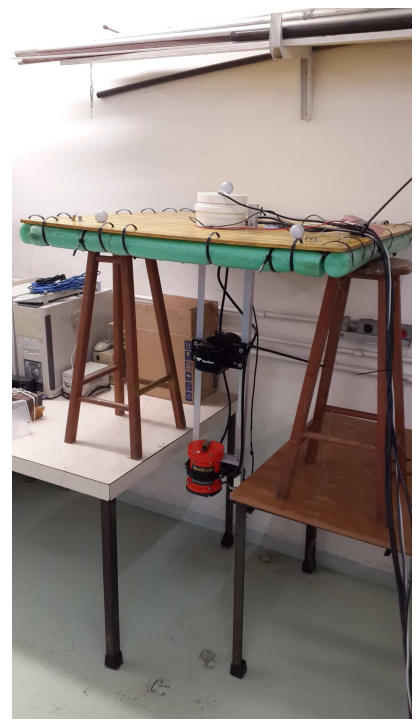

Figura 6.16 - Foto da plataforma flutuante utilizada nos testes 

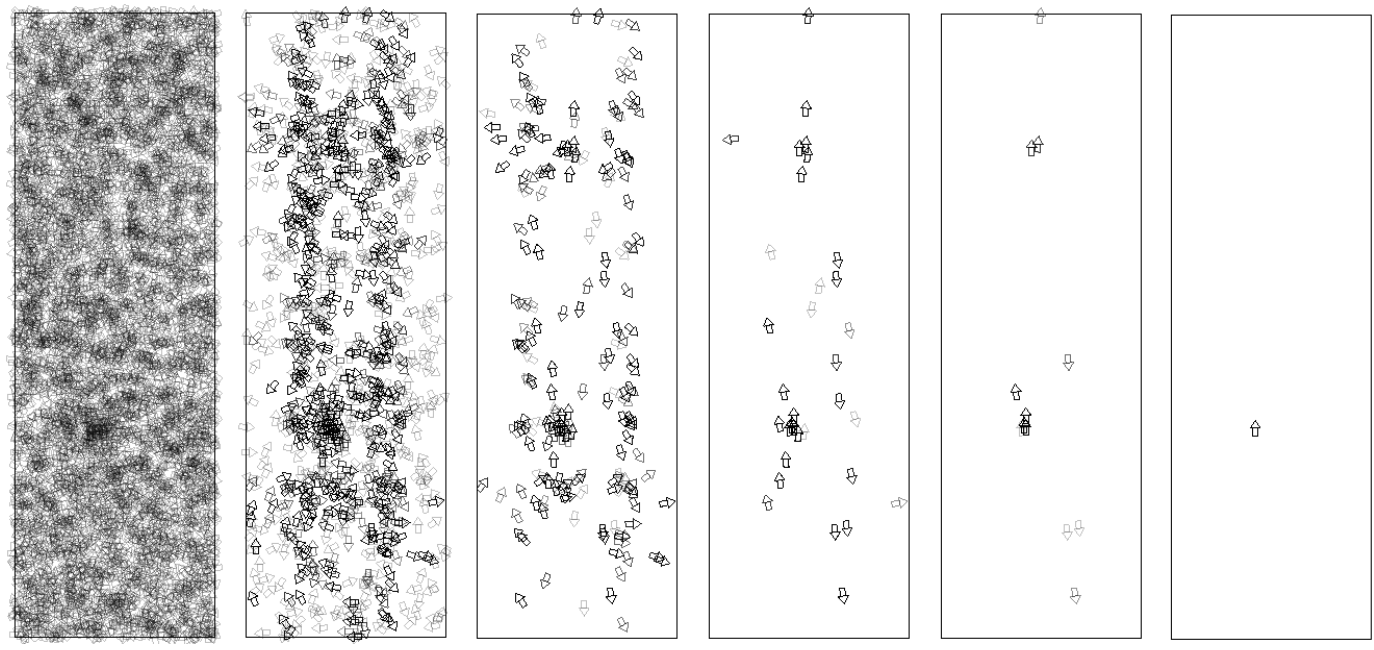

Figura 6.17 - Primeira forma de validação a localização de Monte Carlo foi verificar a sua convergência utilizando dados dos sensores para o caso em que a plataforma permaneceu parada (iterações do algoritmo estão da esquerda para a direita)

comprimento total do tanque menos o comprimento da prainha.

\subsection{Resultados qualitativos}

Nesta seção serão mostrados resultados obtidos durante desenvolvimento deste projeto que, por não terem uma comparação com nenhum sistema externo preciso para fazer a sua validação, são analisados apenas qualitativamente. Apesar de submetidos a uma análise meramente qualitativa, estes resultados trouxeram uma conclusão importante para o andamento do projeto. Os resultados mostrados nesta seção são resultados obtidos com a configuração de sensores que usa o sonar de varredura mecânica, o medidor de velocidades por efeito Doppler e o giroscópio.

O primeiro resultado obtido neste trabalho foi a verificação da convergência do algoritmo. Como na inicialização da localização de Monte Carlo pode ser considerado nenhum conhecimento sobre o estado inicial do robô dentro do ambiente, já que esse tipo de algoritmo consegue resolver tanto o problema de localização global, como o de rastreamento de posição, um primeiro resultado preliminar foi verificar se o algoritmo convergia para o estado do tanque em que a plataforma estava parada lendo os sensores. Quando a localização de Monte Carlo é inicializada sem nenhum conhecimento sobre o estado inicial, as partículas são distribuídas uniformemente ao longo de todo o espaço de estado, indicando que qualquer estado é candidato ao verdadeiro estado da plataforma. Se o algoritmo estiver funcionando corretamente, as partículas irão convergir para o estado da plataforma que se encontrava parada no tanque. O resultado deste teste é mostrado na figura 6.17. Na figura 6.17, pode ser visto que o algoritmo convergiu, após algumas iterações, para a posição em que a plataforma estava parada.

O segundo resultado obtido neste trabalho foi a verificação da estimativa de rumo pelo 


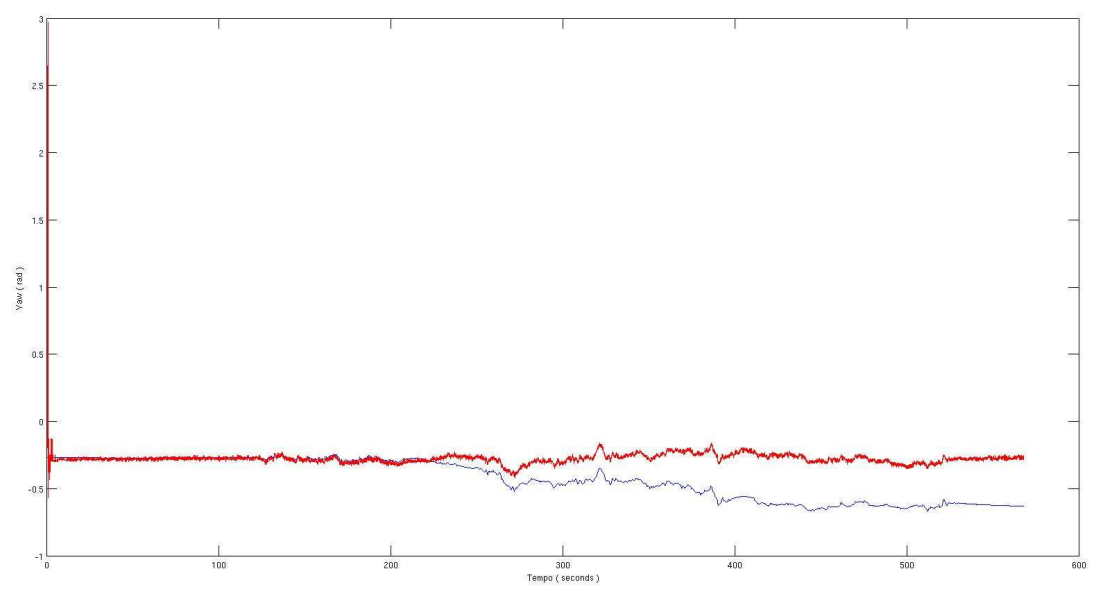

Figura 6.18 - Comparação entre o rumo obtido com o sistema de navegação proposto nesse trabalho (vermelho) e o rumo estimado por uma AHRS (azul) no primeiro teste

sistema de navegação. Como uma das motivações do trabalho é fazer a estimativa de rumo sem a utilização de magnetômetros já que ROVs podem ser usados em ambientes que possam conter materiais ferromagnéticos inviabilizando a utilização desse sensor, era necessário verificar se o sistema conseguiria estimar o rumo sem utilizar este sensor. No caso da configuração do sistema de navegação usando o sonar de varredura mecânica, a estimativa de rumo pelo sistema de navegação é feita pelo giroscópio e pelo sonar, no caso da configuração usando o sonar de multi elementos, a estimativa é feita apenas por esse sonar. Como, na época, o sistema de câmeras comercial utilizado para validar os resultados deste trabalho, não estava disponível, a estimativa de rumo pelo sistema de navegação foi validada de forma qualitativa. A forma escolhida para fazer essa validação foi fazer uma trajetória com a plataforma dentro do tanque sempre mantendo o rumo em torno do mesmo valor, assim a estimativa do rumo dada pelo sistema de navegação também teria que dar sempre em torno de um mesmo valor durante toda a trajetória. O resultado dessa validação é mostrada na figura 6.18. Para elucidar a escolha deste trabalho de não se utilizar magnetômetros para fazer a estimativa de rumo, na figura 6.18 também é mostrado a estimativa de rumo dada por um sensor de referência de atitude e rumo (AHRS) [69] que utiliza os dados desse tipo de sensor para estimar o rumo. Já comentado anteriormente, o sensor de referência de atitude e rumo é um sensor que estima a orientação por meio da fusão sensorial de três giroscópios, três acelerômetros e três magnetômetrosum utilizando um filtro de Kalman Estendido [70].

A figura 6.18 mostra que a estimativa de rumo dada pelo sistema de navegação proposto neste trabalho foi coerente com a metodologia do teste aplicado comprovando qualitativamente o funcionamento do algoritmo. Já a estimativa obtida pela AHRS apresentou uma deriva. Essa deriva pode ter sido causada por anomalias ferromagnéticos existentes em torno do tanque como, por exemplo, da estrutura de aço presente nas 


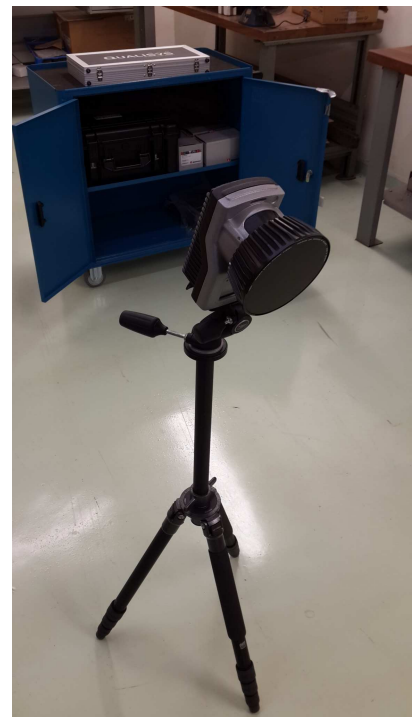

Figura 6.19 - Uma das câmeras utilizadas para validar os resultados deste trabalho

paredes do tanque, em seus magnetômetros, afetando assim a sua estimativa de rumo. Este resultado ilustra o motivo pelo qual optou-se por não utilizar uma bússola para se estimar o rumo, uma vez que não é garantido um bom funcionamento desse tipo de sensor em determinados lugares. Apesar dessa deriva da AHRS pode se observar que as estimativas exibem um mesmo comportamento.

\subsection{Resultados quantitativos com referência externa}

Após ter sido observado o funcionamento qualitativo da abordagem de navegação proposta neste trabalho, o próximo passo foi validar quantitativamente os resultados dos sistemas de navegação propostos neste trabalho. Neste trabalho, os resultados dos sistemas de navegação foram validados por meio da comparação com os resultados obtidos de um sistema de rastreamento por câmeras da Qualisys [68]. Esse sistema de rastreamento consegue estimar a posição e a orientação de objetos que estejam em seu campo de visão por meio da utilização de marcadores específicos que são fixados aos objetos. Neste trabalho o objeto que foi rastreado foi a plataforma flutuante utilizada na realização dos testes. Como a validação foi feita com base neste sistema de câmeras, o tamanho do deslocamento manual da plataforma flutuante dentro do tanque ficou limitado a área de cobertura das câmeras. A figura 6.19 mostra uma das três câmeras que formam esse sistema.

Para analisar a performance dos sistemas de navegação propostos neste trabalho, foram realizados três tipos de testes para cada configuração de sensor, um teste em que a plataforma foi deslocada manualmente formando uma trajetória retangular em que seu rumo foi mantido em torno do mesmo valor, outro em que a plataforma foi submetida a oscilações de rumo permanecendo em torno da mesma posição e o último em que plataforma foi deslocada manualmente formando uma trajetória retangular ao mesmo 
tempo em que sofria oscilando no seu rumo.

Os resultados que serão apresentados nesta seção foram obtidos por meio de um processamento offline (não em tempo real). Como o processamento foi feito dessa maneira, não se teve uma preocupação com o tempo de processamento do filtro e assim foram utilizados um número de partículas para cada configuração de sensor que necessariamente não atingia os requisito de tempo real. O número de partículas utilizada para cada caso foi escolhido de forma empírica com base no desempenho dos resultados e também de forma que o tempo de processamento de cada um fosse o mesmo levando em consideração o processamento na CPU. Os resultados com a configuração formada pelo sonar de multi elementos foram gerados utilizando 1000 partículas e os resultados gerados com a configuração do sonar de varredura foram gerados utilizando 5000 partículas.

\subsubsection{Configuração de cada sensor nos testes}

Antes de analisar os resultados é necessário relatar a forma como cada sensor foi configurado nos testes já que isso pode influenciar na performance dos sistemas de navegação.

Com o objetivo de cobrir todo o ambiente dos testes, os sonares foram configurados com um alcance de 15 metros. Além do alcance, o sonar de varredura mecânica também pode ter o seu valor de discretização de feixe modificado. Considerando um requisito de 10 centímetros na discretização no posicionamento do veículo, a discretização do sonar de varredura foi configurada para 100 divisões. Com essa configuração, esse sonar, nos testes, ficou com um período de varredura de aproximadamente de 8.6 segundos. Já o sonar de multi elementos, não pode ter sua discretização de feixe, que é de 597 divisões, modificada. A frequência de aquisição do sonar de multi elementos é de $13 \mathrm{~Hz}$.

Com relação ao medidor de velocidades por efeito Doppler e ao giroscópio, a única configuração modificada desses sensores foram as suas frequências de aquisição, que no medidor de velocidade por efeito Doppler foi de $2.5 \mathrm{~Hz}$ e no giroscópio foi de $25 \mathrm{~Hz}$.

Outras especificações desses sensores podem ser encontradas nos apêndices A, B, C e D.

\subsubsection{Resultados com o sonar de varredura mecânica}

Nesta seção serão mostrados os resultados obtidos com a configuração de sensores formada pelo sonar de varredura mecânica, pelo medidor de velocidades por efeito Doppler e pelo giroscópio para os três tipos de testes citados acima. Os resultados que serão mostrados nesta seção foram obtidos utilizando sempre 5000 partículas.

Para o caso dessa configuração de sensores, os resultados não serão apenas comparados com os resultados do sistema de câmeras. Nos gráficos que envolverem a estimação do rumo, serão comparados três resultados, o resultado do sistema de navegação, o resultado do sistema câmeras e o resultado do sensor AHRS (Attitude and heading reference system). 


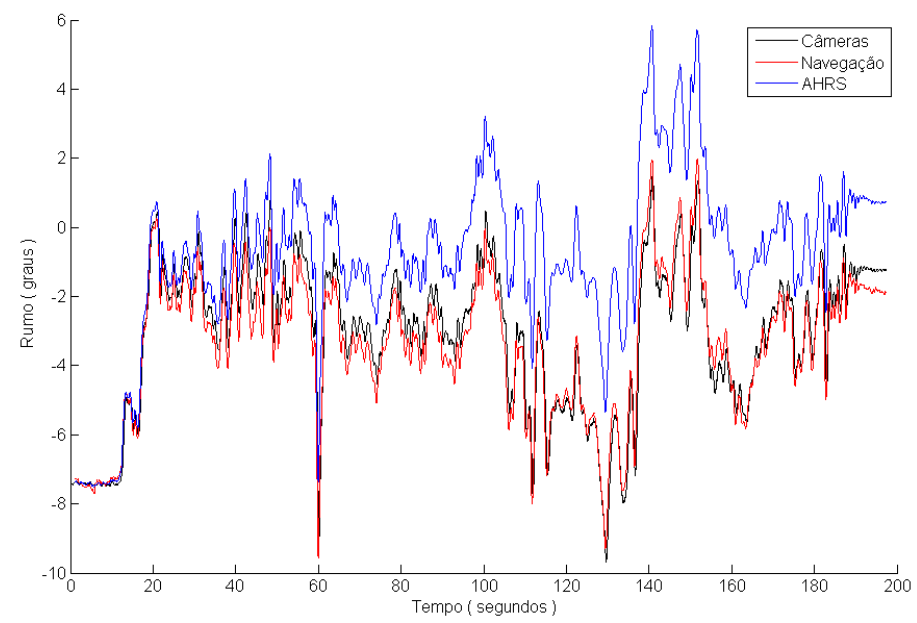

Figura 6.20 - Comparação entre a estimativa de rumo pelo sistema de câmeras (preto), pelo sistema de navegação ( vermelho ) e pelo sensor AHRS (azul) para o teste de trajetória retangular com pouca variação de rumo

Além do fato de ser outra fonte de comparação, o intuito de incluir os resultados da AHRS nas comparações de resultados, é mostrar a necessidade da restrição, que foi levada em consideração no desenvolvimento deste projeto, de se fazer a estimativa de rumo sem a utilização de magnetômetros. Como aplicações de ROVs podem envolver ambientes que podem conter materiais ferromagnéticos, sensores que utilizam magnetômetros terão sua estimativa de rumo prejudicada. A estimativa de rumo fornecida pela configuração de sensores estudada nessa seção se baseia apenas nos dados de giroscópios. Com relação aos gráficos que mostram a estimação da posição horizontal, também serão comparados três tipos de resultados, o resultado do sistema de navegação, o resultado do sistema de câmeras e o resultado da navegação estimada. A navegação estimada é o nome dado para a navegação que é baseada na integração direta dos dados dos sensores sem a utilização de nenhuma técnica de fusão sensorial. Essa navegação obtém a estimativa de posição por meio da integração direta das velocidades lineares obtidas por um sensor, junto com os dados de rumo obtido ou como leitura direta de um sensor ou pela integração dos giroscópios para fazer a transformada dessas velocidades do sistema de coordenadas do corpo para um sistema fixo. Como essa técnica se baseia na integração direta dos sensores, ela apresenta um erro, que aumenta com o tempo, nas suas estimativas. No caso deste trabalho os sensores utilizados na navegação estimada são o DVL (Doppler Velocity Log) e a AHRS. O intuito de comparar os resultados do sistema de navegação com a navegação estimada é mostrar a melhora na estimativa da posição por meio da fusão sensorial que o sistema de navegação faz entre o DVL e o sonar.

O primeiro resultado que será comentado é o resultado obtido no teste em que a plataforma foi deslocada manualmente formando uma trajetória retangular com pouca variação de rumo. A figura 6.20 mostra o resultado da estimativa de rumo para este caso. 
Observando a figura 6.20, pode ser concluído que o sistema de navegação apresentou uma boa estimativa de rumo já que a sua estimativa está próxima da estimativa dada pelo sistema de câmeras. A figura 6.20 também mostra a mesma conclusão comentada na seção 6.1, que a estimativa de rumo dada por um sensor que utiliza magnetômetros, que nesse caso é AHRS, fica prejudicada devido à presença de materiais ferromagnéticos presentes no ambiente, já que sua estimativa apresenta uma deriva. Para analisar melhor a estimativa de rumo feita pelo sistema de navegação para este teste, a figura 6.21 mostra o erro dessa estimativa junto com o seu histograma.

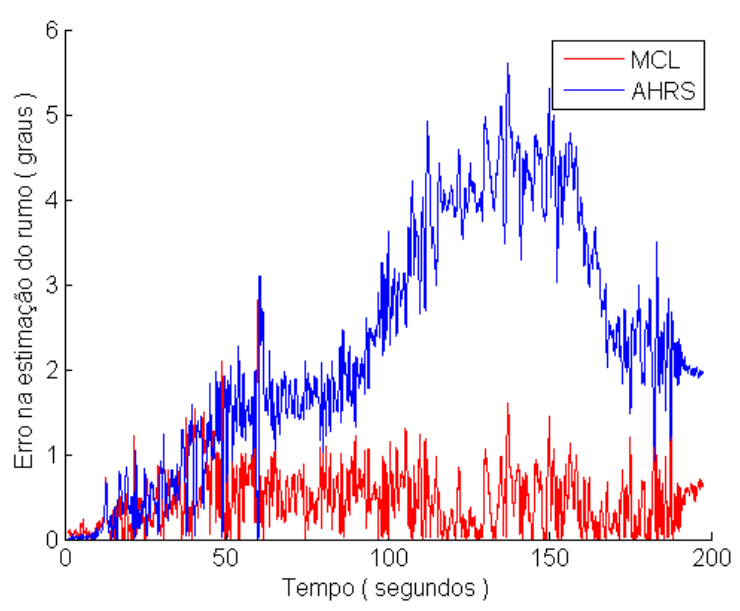

(a)

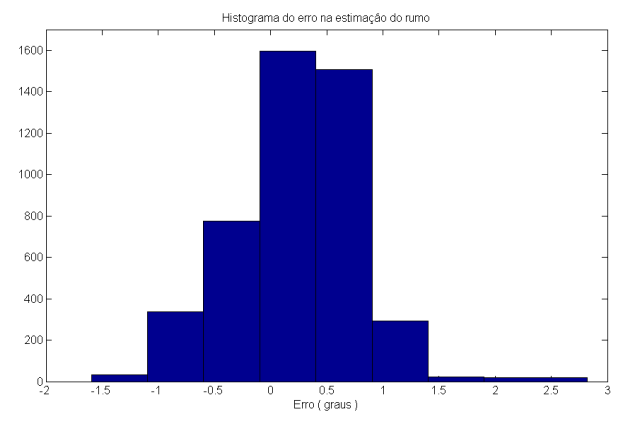

(b)

Figura 6.21 - Análise do erro da estimativa de rumo pelo sistema de navegação para o teste de trajetória retangular com pouca variação de rumo. (a) Série temporal do erro. (b) Histograma de erros.

Observando a figura 6.21, pode ser concluído que o modelo escolhido para o erro do giroscópio, apesar de ser simples, é suficiente para fazer a estimativa de rumo. A modelagem mais comum de giroscópios é utilizar um erro de random walk e um erro de viés. No caso deste trabalho apenas o erro de random walk foi considerado. Seria possível utilizar também o modelo do erro de viés, porém para isso seria necessário incluir mais uma dimensão no vetor de estados do sistema de navegação o que aumentaria consideravelmente o número de partículas necessárias para fazer a estimativa. Como foram obtidos bons resultados, a inclusão do modelo de viés ficou para trabalhos futuros. Esse aumento do número de partículas para incluir o erro de viés não traria uma mudança significativa no tempo de processamento do filtro para o caso de uma implementação na GPU, porém para o caso de uma implementação na CPU poderia deixar inviável o processamento do filtro em tempo real. Como foi visto na seção 5.4, para essa configuração de sensores é possível um processamento em tempo real apenas utilizado a CPU, no caso da configuração utilizando o sonar de multi elementos um processamento em tempo real utilizando apenas a CPU é inviável.

Do histograma da figura 6.21 pode-se perceber que a média do erro ficou um pouco 


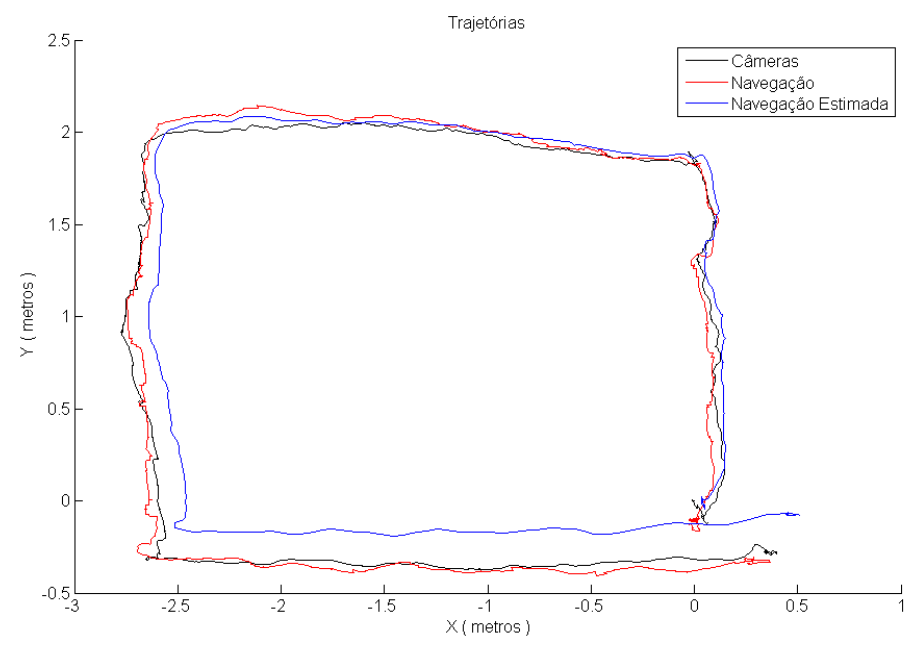

Figura 6.22 - Comparação entre a estimativa de posição dada pelo sistema de câmeras (preto), pelo sistema de navegação ( vermelho ) e pela navegação estimada (azul) para o teste de trajetória retangular com pouca variação de rumo

deslocada para a direita do zero, o que pode ser consequência de dois fatores, a aproximação da estimativa inerente ao filtro de partículas e a influência do viés no resultado. Para este teste, o erro máximo da estimativa de rumo foi de 1.92 graus, o erro médio foi de 0.44 graus e o desvio padrão do erro foi de 0.22 graus. Esses erros podem ser considerados admissíveis para o caso da navegação de um ROV. Tendo visto a estimativa do rumo pelo sistema de navegação para o caso da trajetória retangular com pouca variação de rumo, a figura 6.22 mostra a estimativa de posição para este caso.

A primeira conclusão do resultado apresentado na figura 6.22 é que o sistema de navegação apresentou uma boa estimativa de posição já que a sua estimativa está próxima da estimativa dada pelo sistema de câmeras. Da figura 6.22 pode-se observar que a estimativa dada pela navegação estimada apresenta um erro considerável, que aumenta com o tempo. Como já comentado anteriormente, a navegação estimada é a navegação que estima a posição por meio da integração direta das velocidades lineares referenciadas no corpo, utilizando informações de orientação para fazer a mudança de coordenadas para um sistema fixo. Com isso, o erro na estimativa de posição dada por esse sistema, tem duas possíveis fontes, ou erro está nos dados de velocidades ou o erro está nos dados de orientação. Como o tempo total do teste foi baixo e como o DVL é um sensor de alta exatidão, o erro da navegação estimada observado na figura 6.22 é em sua grande maioria devido ao erro de estimação de rumo da AHRS. Esse resultado da navegação estimada mostra que a fusão sensorial realizada pelo sistema de navegação traz uma melhora na estimativa. Para analisar melhor a estimativa de posição feita pelo sistema de navegação a figura 6.23 mostra o erro dessa estimativa junto com o seu histograma.

A figura 6.23 mostra pequenos erros da estimava de posição dada pelo sistema de navegação sendo que a média ficou em torno de zero. O erro máximo da estimativa de 


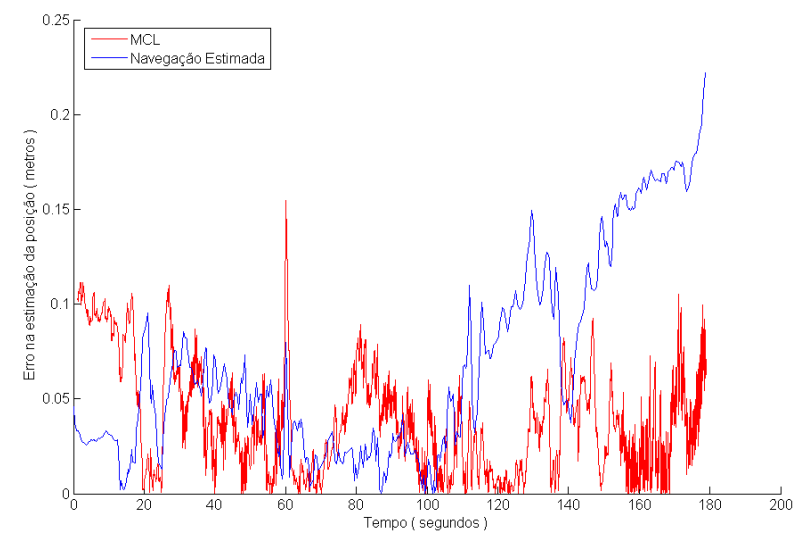

(a)

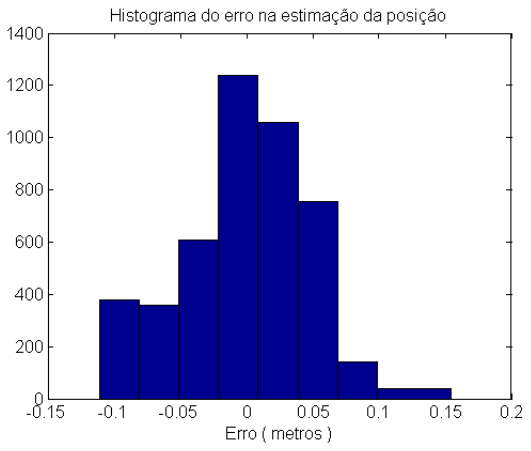

(b)

Figura 6.23 - Análise da estimativa de posição pelo sistema de navegação para trajetória retangular com pouca variação de rumo. (a) Série temporal do erro. (b) Histograma de erros

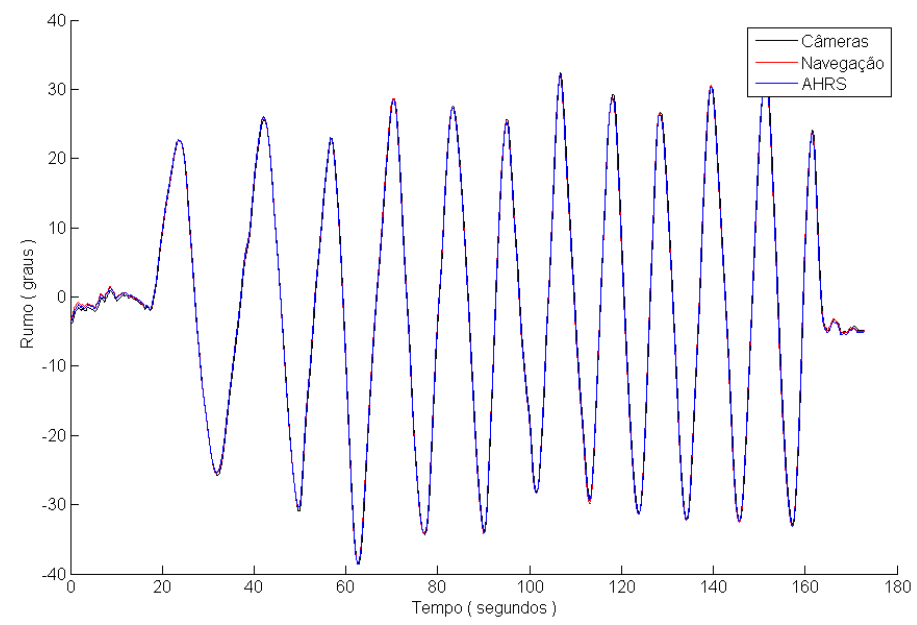

Figura 6.24 - Comparação entre a estimativa de rumo do sistema de câmeras (preto), do sistema de navegação (vermelho) e da AHRS (azul) para o teste em que a plataforma permaneceu em torno da mesma posição mas com oscilação no rumo

posição para esse teste foi de 0.43 metros, o erro médio foi de 0.03 metros e o desvio padrão do erro foi de 0.03 metros. Esses erros, assim como os de rumo, podem ser considerados admissíveis para o caso da navegação de um ROV. Tendo sido feita a análise de todos os resultados para o caso da trajetória retangular com pouca variação de rumo, a seguir será feita a análise dos resultados para o caso em que a plataforma foi submetida a oscilações de rumo permanecendo em torno da mesma posição. O intuito deste teste era verificar a estimativa de rumo do sistema de navegação para grandes velocidades angulares. Por isso para este caso só serão mostrados os resultados com relação a estimativa de rumo. As figuras 6.24 e 6.25 mostram a estimativa de rumo para este caso. 


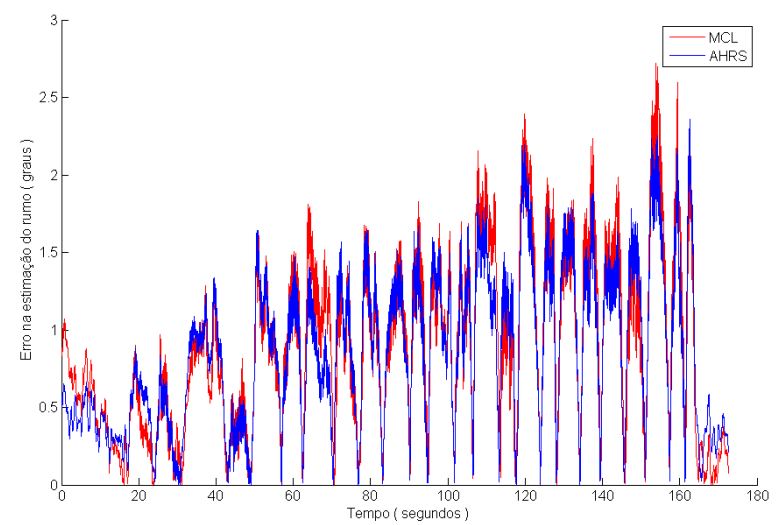

(a)

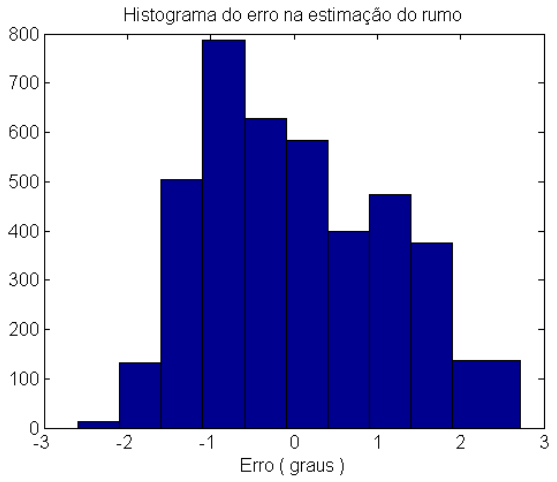

(b)

Figura 6.25 - Análise da estimativa de posição pelo sistema de navegação para plataforma oscilando em rumo na mesma posição. (a) Série temporal do erro. (b) Histograma de erros

Assim como a estimativa de rumo pelo sistema de navegação no primeiro teste mostrada na figura 6.20, a estimativa de rumo no segundo teste pelo sistema de navegação mostrada na figura 6.24 também apresentou bons resultados. Para este teste, o erro máximo da estimativa de rumo foi de 1.97 graus, o erro médio foi de 0.56 graus e o desvio padrão foi de 0.37 graus. Apesar deste segundo teste ter uma maior variação de rumo do que o primeiro ( $\Delta \psi_{2}=71$ e $\Delta \psi_{1}=11.2$ ), assim como uma maior velocidade angular média ( $\overline{w_{2}}=8$ graus $/ \mathrm{s}$ e $\overline{w_{1}}=1.5$ graus $/ \mathrm{s}$ ), os erros de rumo apresentados nos dois testes foram parecidos, o que mostra uma robustez do sistema de navegação para esta configuração de sensores.

Tendo sido feita a análise da estimativa de rumo para a plataforma permanecendo em torno da mesma posição mas com uma oscilação em seu rumo, a seguir será feita a análise para o caso em que a plataforma foi deslocada manualmente formando uma trajetória retangular ao mesmo tempo em que o seu rumo sofria oscilações. As figuras 6.26 e 6.27 mostram os resultados para a estimativa de rumo deste caso.

Das figuras 6.26 e 6.27 pode-se concluir que a estimativa de rumo obtida pelo sistema de navegação, assim como nos outros testes, também apresentou uma boa estimativa de rumo. Para este teste, o erro máximo da estimativa de rumo foi de 2.9 graus, o erro médio foi de 0.7 graus e o desvio padrão foi de 0.5 grau. Tendo sido visto a estimativa de rumo dada pelo sistema de navegação para o caso da trajetória retangular com oscilação de rumo, as figuras 6.28 e 6.29 mostram o resultado da estimativa de posição para este caso.

Assim como nos outros testes, as figuras 6.28 e 6.29 mostram bons resultados na estimativa de posição para o terceiro teste. Neste teste, o erro máximo da estimativa de posição foi de 0.15 metros , o erro médio foi de 0.04 metros e o desvio padrão foi de 0.03 metros.

Um fato importante a ser observado na figura 6.28 é que a estimativa de posição dada 


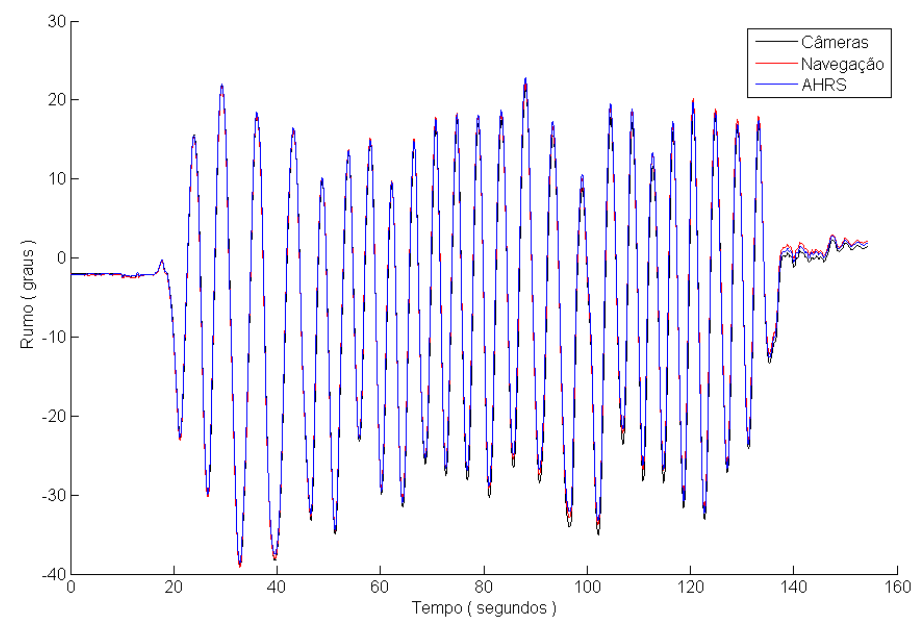

Figura 6.26 - Comparação entre a estimativa de rumo do sistema de câmeras (preto), do sistema de navegação ( vermelho ) e da AHRS (azul) para o teste de trajetória retangular com variação de rumo

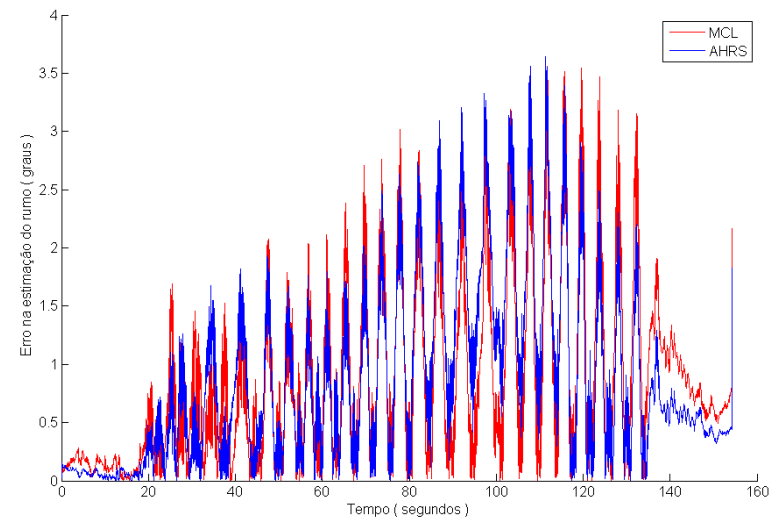

(a)

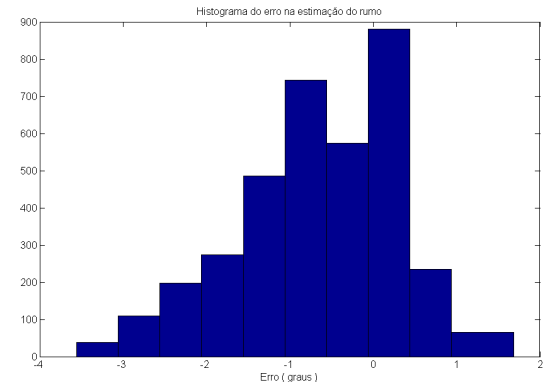

(b)

Figura 6.27 - Análise do erro da estimativa de rumo pelo sistema de navegação para trajetória retangular com variação de rumo. (a) Série temporal do erro. (b) Histograma de erros.

pela navegação estimada apresentou um erro muito maior do que o esperado. Como já comentado anteriormente, o erro da estimativa de posição dada pela navegação estimada pode ser causada por dois fatores, ou pelo ruído nos dados das velocidades ou por erros nos dados de orientação. Como o DVL apresenta uma precisão muito alta, para testes de curta duração, que é o caso deste terceiro teste, achava-se que poderia ser considerado que o erro da navegação estimada seria causado apenas pelos erros nos dados de orientação. Porém, como visto na figura 6.27, a estimativa de rumo dada pela AHRS foi bem precisa, mostrando que o erro da estimativa da navegação estimada está relacionado com erros do medidor de velocidades por efeito Doppler o que não é coerente com a especificação desse sensor. Assim conclui-se que esse terceiro teste acabou mostrando um erro que o DVL 


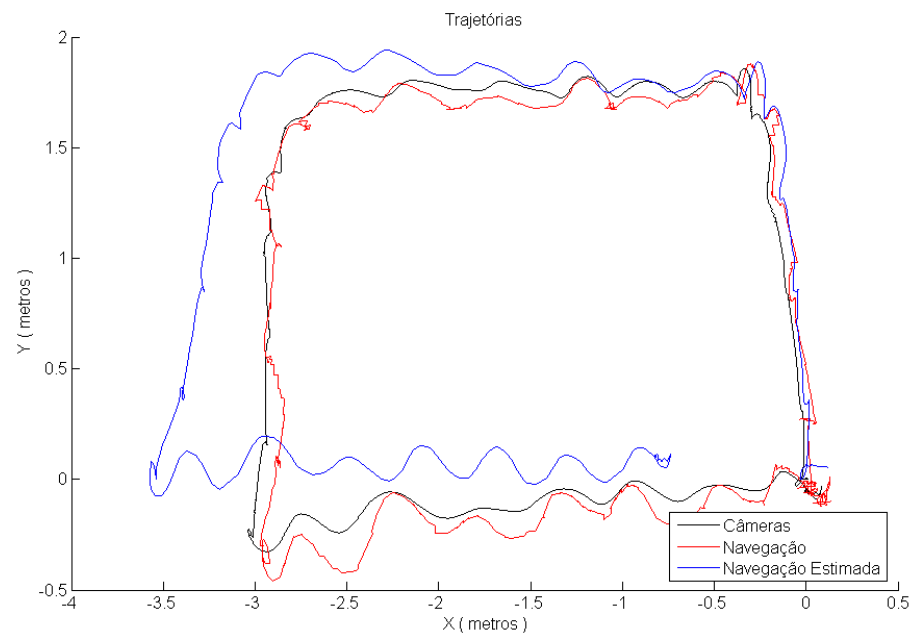

Figura 6.28 - Comparação entre a estimativa de posição do sistema de câmeras (preto), do sistema de navegação ( vermelho ) e da navegação estimada (azul) para o teste de trajetória retangular com variação de rumo

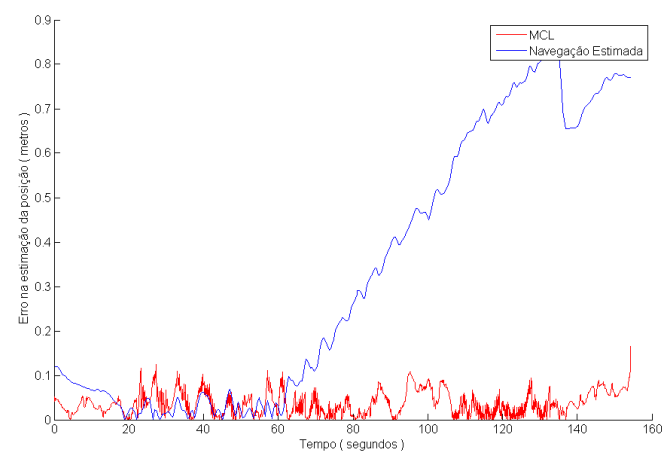

(a)

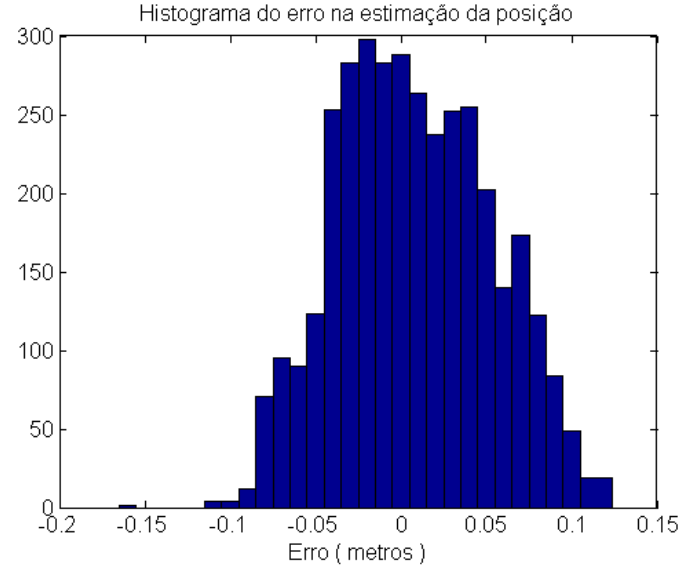

(b)

Figura 6.29 - Análise do erro da estimativa de posição pelo sistema de navegação para o teste de trajetória retangular com variação de rumo. (a) Série temporal do erro. (b) Histograma de erros.

apresenta quando submetido a oscilações. Esse erro foi comentado na seção 2.2.

Todos os resultados mostrados nesta seção mostraram um bom desempenho da localização de Monte Carlo para a configuração de sensores formada pelo sonar de varredura, pelo medidor de velocidades por efeito Doppler e pelo giroscópios. Todos os resultados apresentaram erros admissíveis para a aplicação da navegação de ROVs. Um fator que pode ter piorado os resultados apresentados nesta seção, foi que, como uma das extremidades do tanque, onde os testes foram realizados, apresenta uma prainha, que por ser de difícil modelagem, foi considerada como uma parede, isso pode ter prejudicado a associação de dados dessa extremidade com os dados do sonar e assim prejudicando tanto a estimativa de rumo como a de posição. 


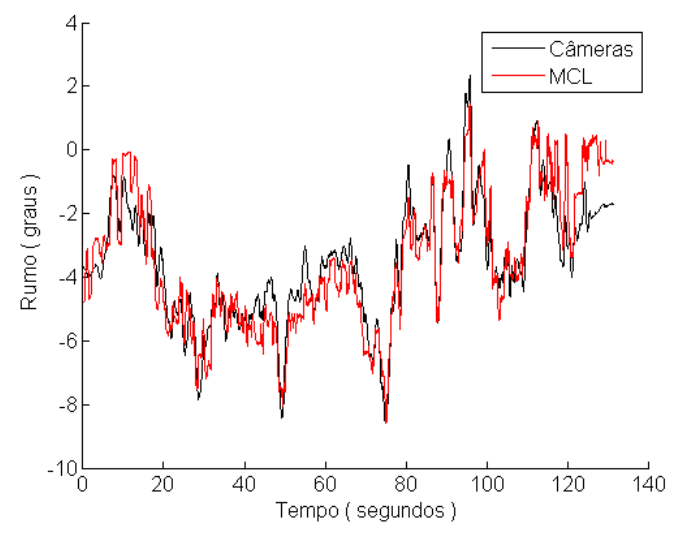

Figura 6.30 - Comparação entre a estimativa de rumo do sistema de câmeras (preto) e do sistema de navegação ( vermelho ) para o teste de trajetória retangular com pouca variação de rumo

\subsubsection{Resultados com o sonar de multi elementos}

Nesta seção serão mostrados os resultados obtidos com a configuração de sensores formada apenas pelo sonar de multi elementos para os três tipos de testes citados acima. Os resultados que serão mostrados nesta seção foram obtidos utilizando sempre 1000 partículas. O primeiro resultado que será comentado é o resultado obtido com a trajetória retangular com pouca variação de rumo. As figuras 6.30 e 6.31 mostram o resultado da estimativa de rumo para este caso.

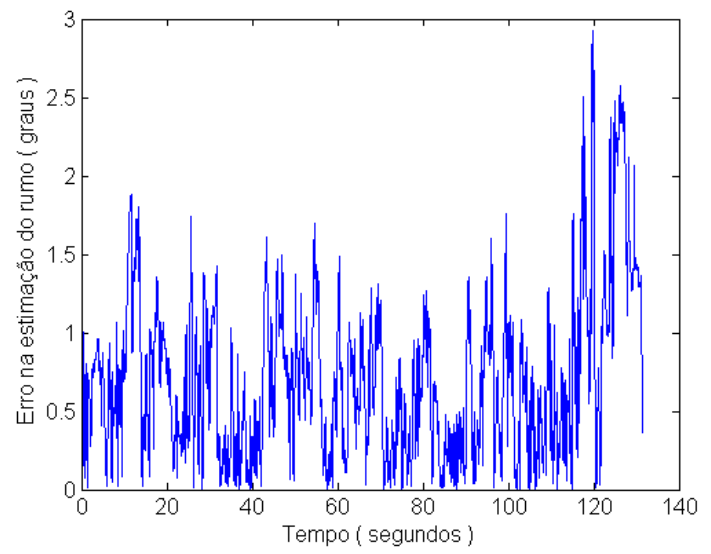

(a)

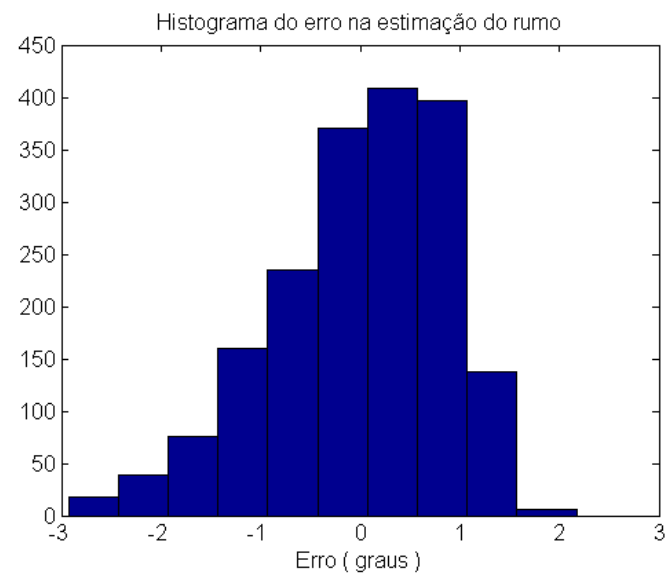

(b)

Figura 6.31 - Análise do erro da estimativa de rumo pelo sistema de navegação para o teste de trajetória retangular com pouca variação de rumo

Das figuras 6.30 e 6.31 pode-se concluir que a estimativa de rumo pelo sistema de navegação apresentou uma boa estimativa de rumo para este caso já que a sua estimativa está próxima da estimativa dada pelo sistema de câmeras que é um sistema bem preciso. Pelo histograma da figura 6.31 pode-se observar que os erros do rumo ficaram próximos do zero com um pequeno desvio para a direita que pode ser consequência da aproximação do 


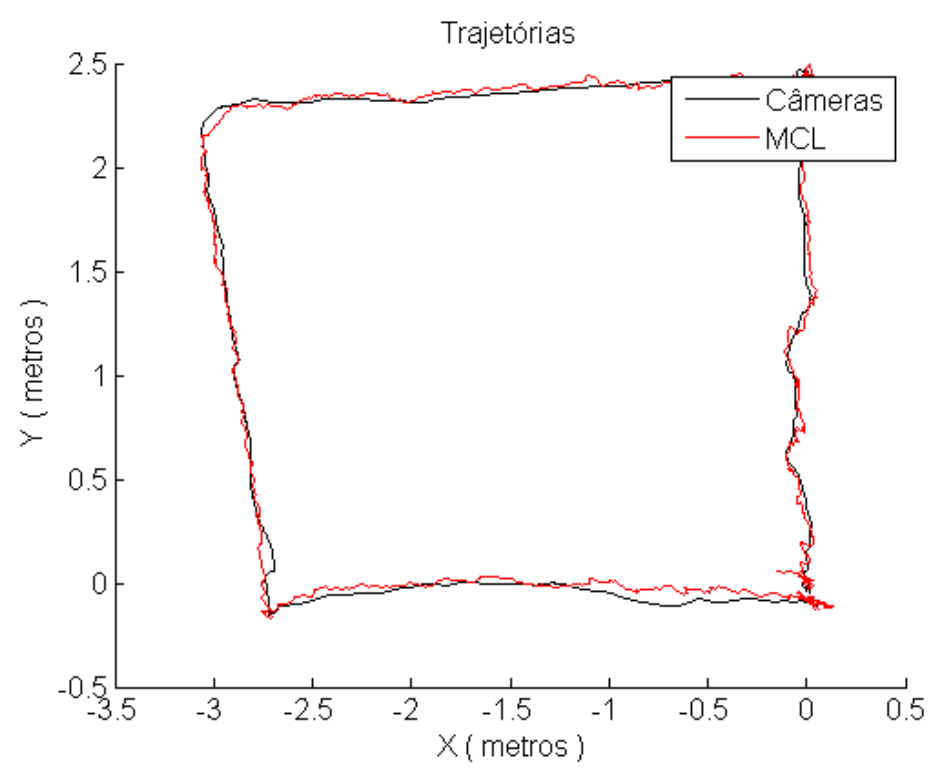

Figura 6.32 - Comparação entre a estimativa de posição do sistema de câmeras (preto) e do sistema de navegação ( vermelho ) para o teste de trajetória retangular com pouca variação de rumo

estado pelas partículas o que indicaria a necessidade da utilização de um número maior de partículas. Para este teste, o erro máximo da estimativa de rumo foi de 2.92 graus, o erro médio foi de 0.71graus e o desvio padrão foi de 0.52graus que podem ser considerados erros admissíveis para a navegação de um ROV. Tendo sido visto a estimativa do rumo pelo sistema de navegação para o caso da trajetória retangular com pouca variação de rumo, as figuras 6.32 e 6.33 mostram o resultado da estimativa de posição para este caso.
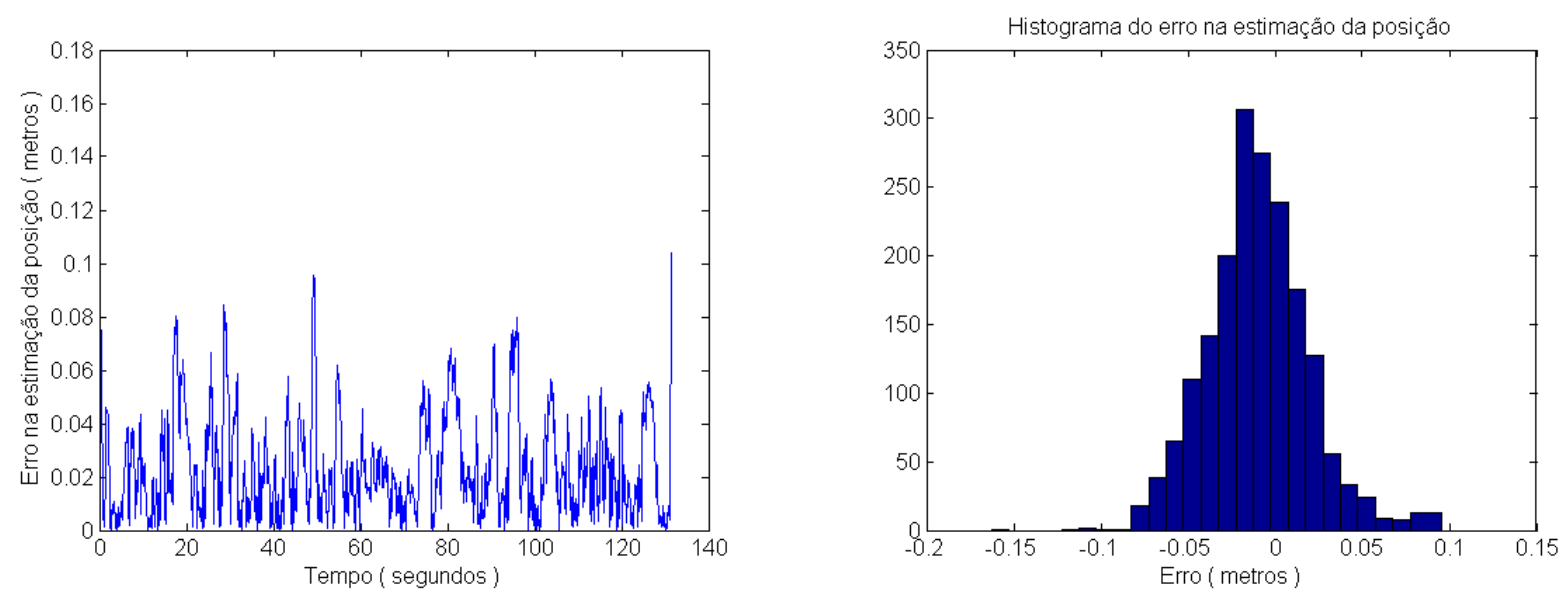

Figura 6.33 - Análise do erro da estimativa de posição pelo sistema de navegação para o teste de trajetória retangular com pouca variação de rumo

Das figuras 6.32 e 6.33 pode-se concluir que assim como a estimativa de rumo, a estimativa de posição pelo sistema de navegação apresentou um bom resultado. Assim como no histograma da figura 6.31, o histograma da figura 6.33 apresenta erros concentrados próximos do zero com um pequeno desvio. Para este teste, o erro máximo da estimativa 


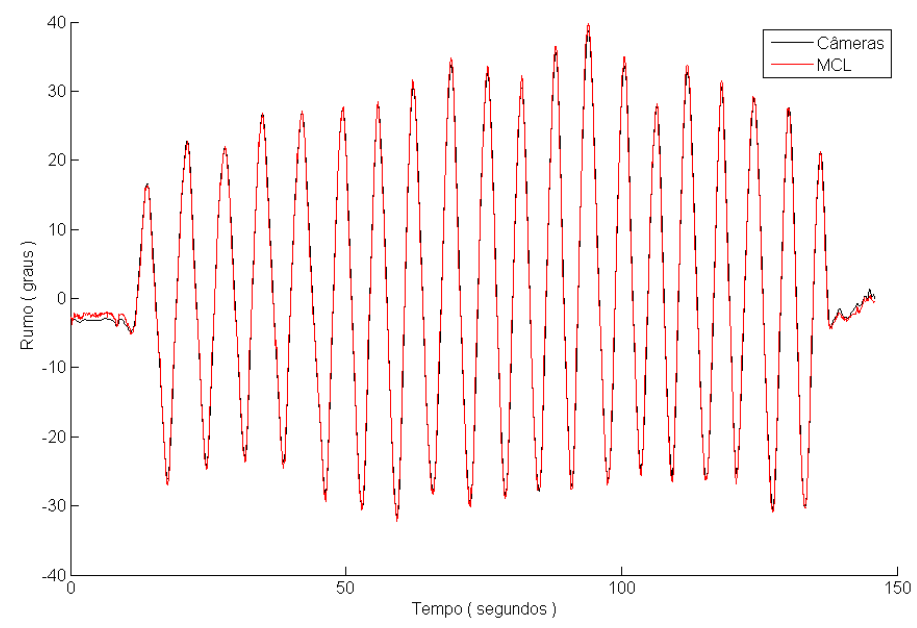

Figura 6.34 - Comparação entre a estimativa de rumo do sistema de câmeras (preto) e do sistema de navegação (vermelho) para o teste em que a plataforma permaneceu em torno da mesma posição mas com o rumo oscilando

de rumo foi de 0.14 metros , o erro médio foi de 0.02 metros e o desvio padrão foi de 0.02 metros que podem ser considerados erros admissíveis para a navegação de um ROV. Observando os resultados obtidos para esse primeiro teste pode-se concluir que a navegação utilizando apenas o sonar de multi elementos apresenta uma melhor estimativa da posição do que do rumo. Tendo sido feita a análise de todos os resultados para o caso da trajetória retangular com pouca variação de rumo, a seguir será feita a análise dos resultados para o caso em que a plataforma foi submetida a uma oscilação no rumo mantendo a mesma posição. Como já comentado na seção 6.2 .2 o intuito deste teste é verificar a estimativa de rumo pelo sistema de navegação para grandes velocidades angulares, por isso para este teste só serão mostrados os resultados com relação a estimativa de rumo. As figuras 6.34 e 6.35 mostram estes resultados.
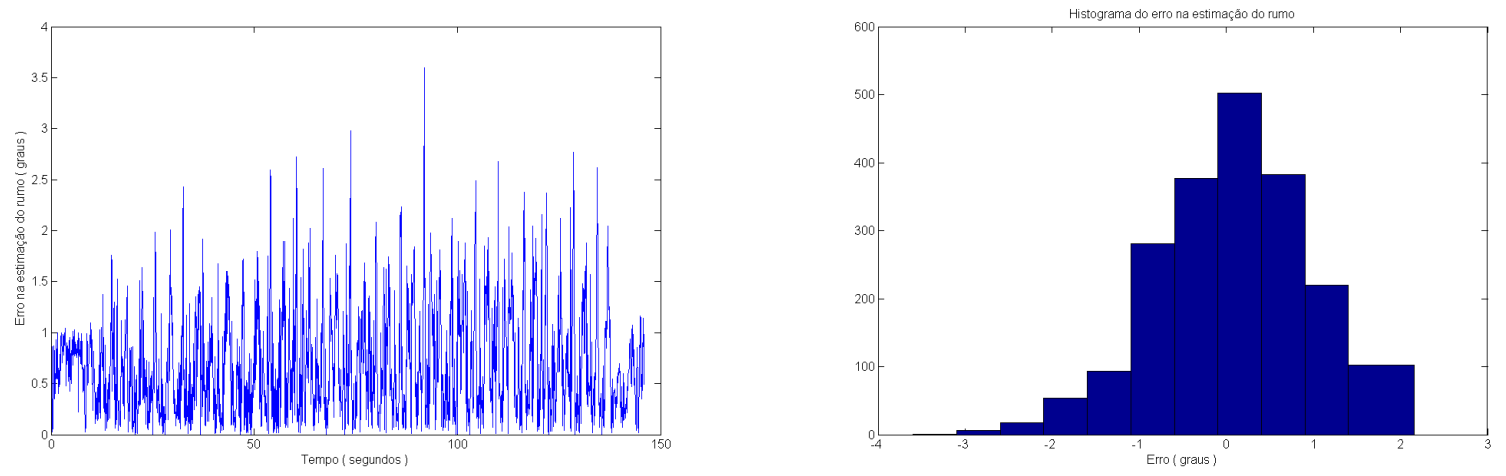

Figura 6.35 - Análise do erro da estimativa de rumo pelo sistema de navegação para o teste de trajetória retangular sem variação de rumo

Assim como no primeiro teste, a estimativa de rumo do segundo teste apresentou bons resultados. Para este teste, o erro máximo da estimativa de rumo foi de 3.6 graus, o erro 


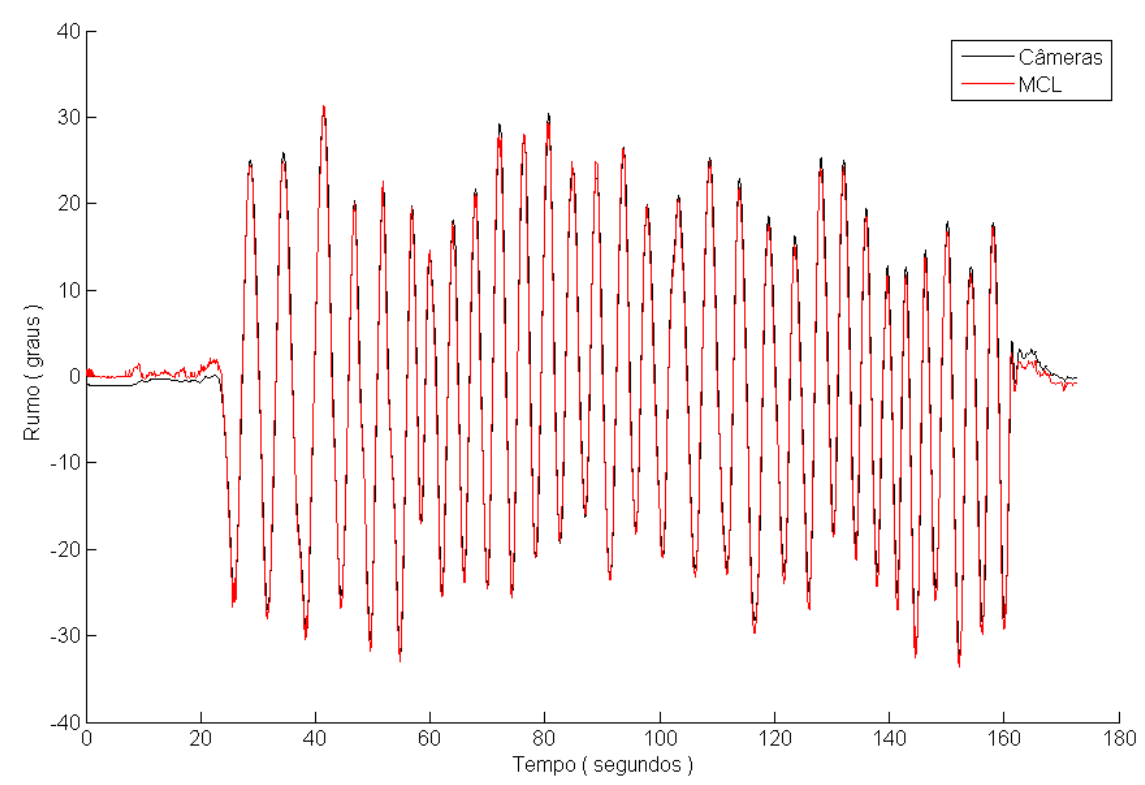

Figura 6.36 - Comparação entre a estimativa de rumo do sistema de câmeras (preto) e do sistema de navegação ( vermelho ) para o teste de trajetória retangular com oscilação no rumo

médio foi de 0.68graus e o desvio padrão foi de 0.52graus. Apesar deste segundo teste ter uma maior variação de rumo do que o primeiro ( $\Delta \psi_{2}=70.3$ e $\Delta \psi_{1}=10.9$ ) assim como uma maior velocidade angular média $\left(\overline{w_{2}}=15.16 \mathrm{graus} / \mathrm{s}\right.$ e $\left.\overline{w_{1}}=1.36 \mathrm{graus} / \mathrm{s}\right)$, os erros de rumo apresentados nos dois testes foram parecidos, o que mostra uma robustez do sistema de navegação utilizando apenas o sonar de multi elementos. Tendo sido feita a análise da estimativa de rumo para a plataforma permanecendo em torno da mesma posição mas com um oscilação em seu rumo, a seguir será feita a análise para o caso em que a plataforma foi deslocada manualmente formando uma trajetória retangular ao mesmo tempo em que o seu rumo sofria oscilações. As figuras 6.36 e 6.37 mostram os resultados para a estimativa de rumo deste caso.

Das figuras 6.36 e 6.37 pode-se concluir que a estimativa de rumo pelo sistema de navegação assim como nos outros teste também apresentou uma boa estimativa de rumo. Para este teste, o erro máximo da estimativa de rumo foi de 4.51graus, o erro médio foi de 1.09 graus e o desvio padrão foi de 0.75 graus. Dos resultados de estimativa de rumo, este foi o que apresentou maior desvio padrão o que pode ser observado pelo histograma da figura 6.37. Esse aumento no desvio padrão pode ter sido ocasionado pelo fato de que como todos os resultados foram obtidos utilizando o mesmo número de partículas, neste teste as partículas ficaram mais espalhadas pelo espaço de estado devido as características do teste em que se teve grandes variações de $\mathrm{x}$, y e $\psi$, o que aumentou o erro da estimativa do estado posteriori. Tendo sido visto a estimativa de rumo pelo sistema de navegação para o caso da trajetória retangular com oscilação de rumo, as figuras 6.38 e 6.39 mostram 

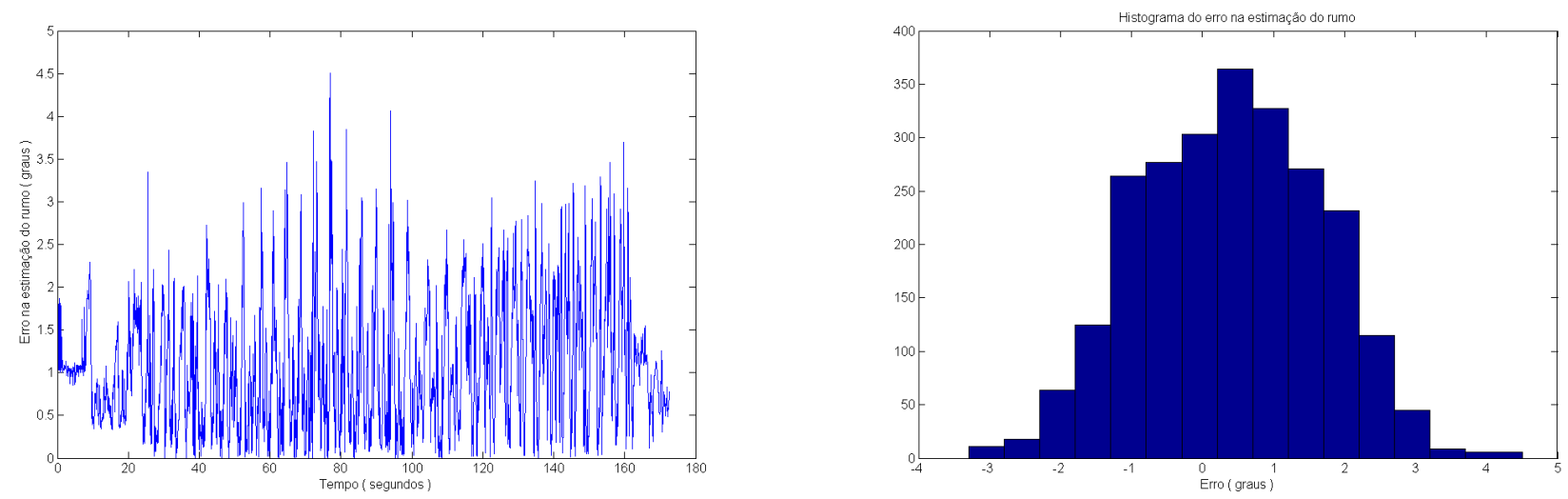

Figura 6.37 - Análise do erro da estimativa de rumo pelo sistema de navegação para o teste de trajetória retangular com oscilação no rumo

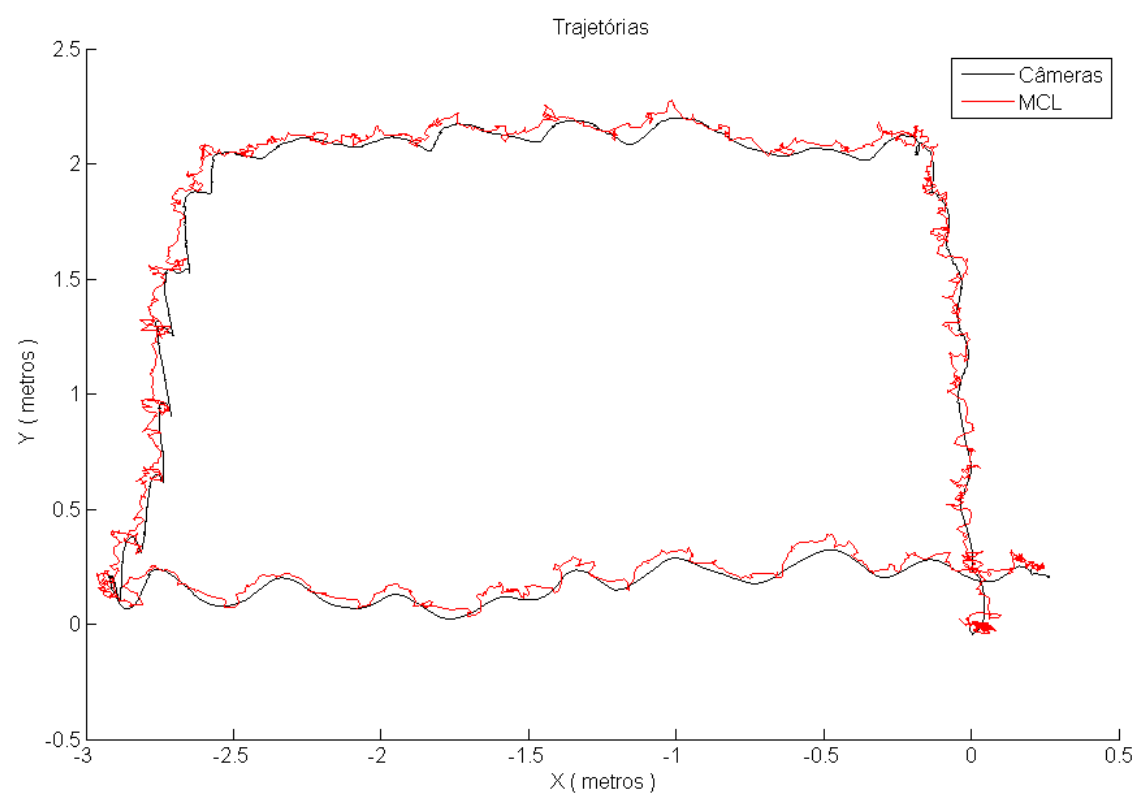

Figura 6.38 - Comparação entre a estimativa de posição do sistema de câmeras (preto) e do sistema de navegação ( vermelho ) para o teste de trajetória retangular com oscilação no rumo

o resultado da estimativa de posição para este caso.

Assim como nos outros testes, as figuras 6.38 e 6.39 mostram bons resultados na estimativa de posição para o terceiro teste.Para este teste, o erro máximo da estimativa de rumo foi de 0.33 metros, o erro médio foi de 0.07 metros e o desvio padrão foi de 0.08 metros.

De todos os testes, o que apresentou pior resultado foi o teste em que a plataforma foi deslocada manualmente em uma trajetória de formato retangular com oscilação no rumo, o que era de se esperar já que é o caso em que a variação na dinâmica da plataforma é maior. Mesmo neste pior resultado os valores dos erros observados são aceitáveis para aplicação de operação de ROVs. 

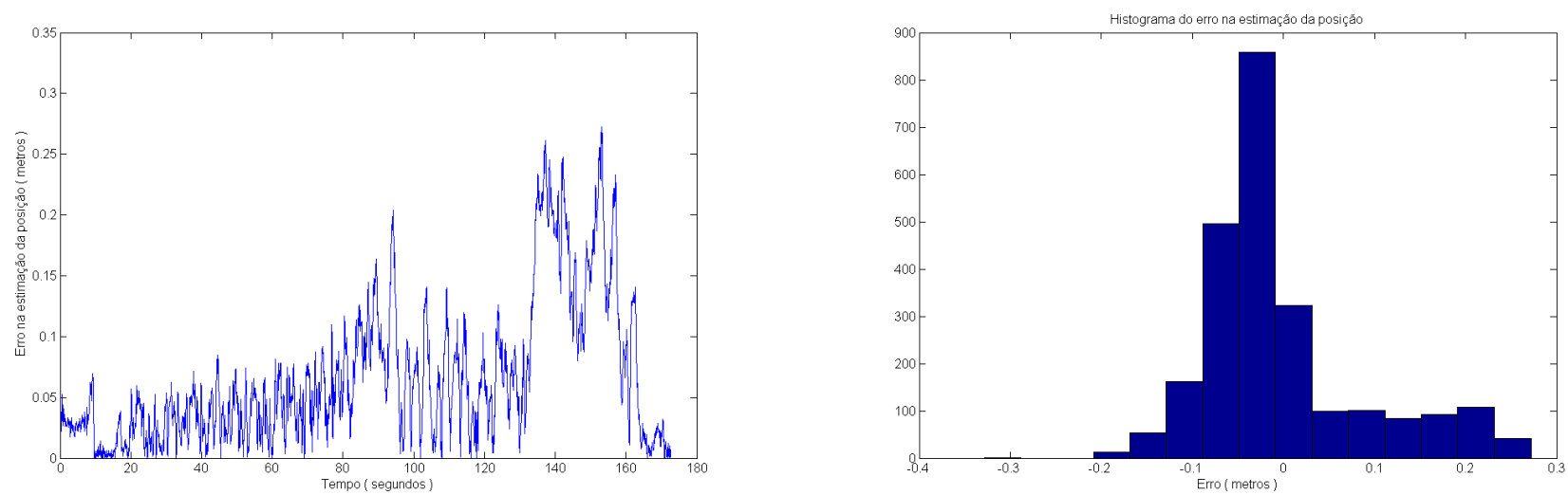

Figura 6.39 - Análise do erro da estimativa de posição pelo sistema de navegação para o teste de trajetória retangular com oscilação no rumo

Comparando os resultados obtidos com a configuração que utiliza o sonar de varredura mecânica, o medidor de velocidades por efeito Doppler e o giroscópio e com a configuração que utiliza apenas o sonar de multi elementos conclui-se que as duas configurações apresentaram resultados bons e parecidos sendo que a configuração que usa apenas o sonar de multi elementos apresentou resultados ligeiramente melhores.

\subsubsection{Influência do tamanho do conjunto de partículas}

A performance da localização de Monte Carlo está relacionada com o número de partículas utilizadas, quanto maior o número mais exata será a aproximação pelo filtro. Porém quanto maior o número de partículas utilizadas, maior será o custo computacional do filtro. Para situações em que não é necessário um processamento em tempo real, a questão do tempo de processamento não é restritiva com isso pode ser utilizado um número grande partículas para que a aproximação seja a melhor possível, mas para aplicação de tempo real isso não é possível já que é necessário fazer a estimação em um tempo limitado. Assim no desenvolvimento de aplicações utilizando o filtro de partículas com requisitos de tempo real é necessário descobrir qual o número de partículas necessário para que a aproximação seja satisfatória e verificar a viabilidade da implementação do filtro em tempo real com o custo computacional envolvido. Como este trabalho envolve a navegação de um robô submarino, a aplicação o filtro de partículas neste trabalho precisa atender requisitos de tempo real já que a estimativa da posição e da orientação do robô precisa ser feita em uma frequência em que permita que ele seja controlado, assim essa análise do número de partículas com relação ao desempenho do filtro versus o custo computacional é necessária. Como o trabalho estuda a utilização de duas configurações de sensores diferentes no sistema de navegação de um robô submarino, serão feitas duas análises, uma para cada configuração.

Pelo fato da localização proposta neste trabalho ser baseada no filtro de partículas 
que é uma implementação não paramétrica de filtragem Bayesiana e também por exigir o conhecimento previu das dimensões do ambiente, ela consegue resolver tanto o problema da localização global como a de rastreamento de posição. Na localização de Monte Carlo não é necessário ter conhecimento algum sobre o estado inicial do robô. Se nenhum conhecimento sobre o estado inicial do robô for dado à localização de Monte Carlo, ela começará a tentar localizar o robô globalmente e, uma vez que o veículo é localizado dentro do ambiente, o filtro passa a ter só que rastrear a sua posição. A maior parte do tempo o filtro fica rastreando a posição. O fato da localização de Monte Carlo conseguir resolver esses dois tipos de problemas está relacionado com o número de partículas. O número de partículas necessário para resolver cada um desses problemas é muito diferente um do outro, o problema de localização global necessita de um número muito maior de partículas do que o de rastreamento ([15] por meio de alguns experimentos mostra que o número de partículas cai para 1\% do total na transição entre a localização global e o rastreamento). Assim como essa diferença é muito grande e como o problema da localização global não é essencial em algumas aplicações de navegação robótica, nas análises sobre o número de partículas necessário no algoritmo de localização de Monte Carlo para os casos deste trabalho, que serão feitas a seguir, apenas o caso de rastreamento de posição foi levado em consideração.

A análise do número de partículas necessário para uma estimativa satisfatória na localização de Monte Carlo, para cada uma das duas configurações de sensores estudadas neste trabalho será feita de forma empírica e quantitativa. Para cada uma das duas configurações de sensores, será feita uma comparação dos resultados gerados pela localização de Monte Carlo para diferentes números de partículas utilizando um mesmo conjunto de dados coletados dos respectivos sensores. O conjunto de dados utilizados para cada uma das duas análises foi escolhido dentre os conjuntos que serão utilizados na seção 6.2 para validar as implementações da localização de Monte Carlo propostas neste trabalho. O conjunto escolhido para cada configuração foi coletado de um mesmo tipo de teste que corresponde ao teste em que os sensores de cada configuração foram submetidos a um deslocamento de formato retangular sendo que durante esse deslocamento os sensores foram submetidos a variações de rumo. As figuras 6.26 e 6.28 mostram as características do conjunto de dados para a configuração do sonar de varredura e as figuras 6.36 e 6.38 mostram as características do conjunto de dados para a configuração do sonar de multi elementos. Para quantificar essa análise do número de partículas foram escolhidos dois tipos de parâmetros, o valor quadrático médio (RMS) e a entropia relativa. Esses dois parâmetros foram escolhidos com intuito de fazer a análise de dois âmbitos diferentes, o RMS irá investigar a influência do número de partículas com relação ao valor do estado estimado e a entropia relativa irá investigar sob a influência da distribuição estimada. Assim nesse capítulo serão feitas duas análise quantitativas para cada uma das configurações de sensores, uma utilizando o RMS e a outra utilizando a entropia relativa. 
O escopo da navegação deste trabalho trata da estimativa da posição horizontal $(x, y)$ e da estimativa de rumo $\psi$ do robô, assim a análise da influência do número de partículas na estimativa deveria levar em consideração esses três graus de liberdade, porém como a estimada de rumo, para ambos os casos de configuração de sensores, estava muito próxima da estimativa dada pelo sistema de rastreio visual, que foi o sistema utilizado para validar os resultados dos sistemas de navegação propostos neste trabalho mostrados na seção 6.2 , o grau de liberdade referente ao rumo estava atrapalhando a análise da entropia relativa, na parte do condicionamento da estimativa da função densidade de probabilidade pelo conjunto de partículas devido a erros de trucamento. Por isso optou-se por realizar as análises apenas consideração a posição $(x, y)$.

\subsubsection{Efeito do número de partículas no erro RMS da estimativa de posição}

Nesta seção será feita a análise da influência do número de partículas na estimativa de posição dada pela localização de Monte Carlo para as duas configurações de sensores estudadas neste trabalho por meio do valor quadrático médio (RMS).

A medida de erro RMS capta a distância física entre o estimado e o real e ela pode ser calculada segundo a equação 6.1 .

$$
R M S=\sqrt{E\left((\text { real }- \text { estimado })^{2}\right)}
$$

Neste trabalho, o valor utilizado para representar o valor real será a estimativa dada por um sistema de câmeras comercial que foi o sistema utilizado para validar os resultados dos sistemas de navegação propostos neste trabalho mostrados na seção 6.2. A análise do RMS para os diferentes números de partículas será feita utilizando um conjunto de dados dos sensores coletados em um dos testes, que representa uma trajetória retangular, assim cada número de partícula terá um valor correspondente a somatória dos resultados da equação 6.1 calculada para cada estimativa do sistema de navegação dentro dessa trajetória. Como o filtro de partículas é um filtro estocástico, esse cálculo para cada número de partículas será repetido por dez vez e o resultado final será a média desses resultados. Nesse análise o número de partículas foi avaliado utilizando variações de potência de 2. A figura 6.40 mostra o resultado do calculo do RMS para a configuração do sonar de varredura e a figura 6.41 mostra o resultado do calculo do RMS para a configuração do sonar de multi elementos.

As figuras 6.40 e 6.41 mostram resultados coerentes já que o valor de RMS diminui com o aumento do número de partículas. Para o caso da configuração do sonar de multi elementos, o valor de RMS apresenta uma saturação a partir de 256 partículas, mostrando que não é necessário se utilizar um número maior de partículas para esse caso de configuração. Para o caso da configuração do sonar de varredura, o valor de RMS não apresenta uma saturação, mas a partir do número 256 partículas, a queda nesse valor é muito menor. Uma última observação das figuras 6.40 e 6.41 é que para um mesmo número 


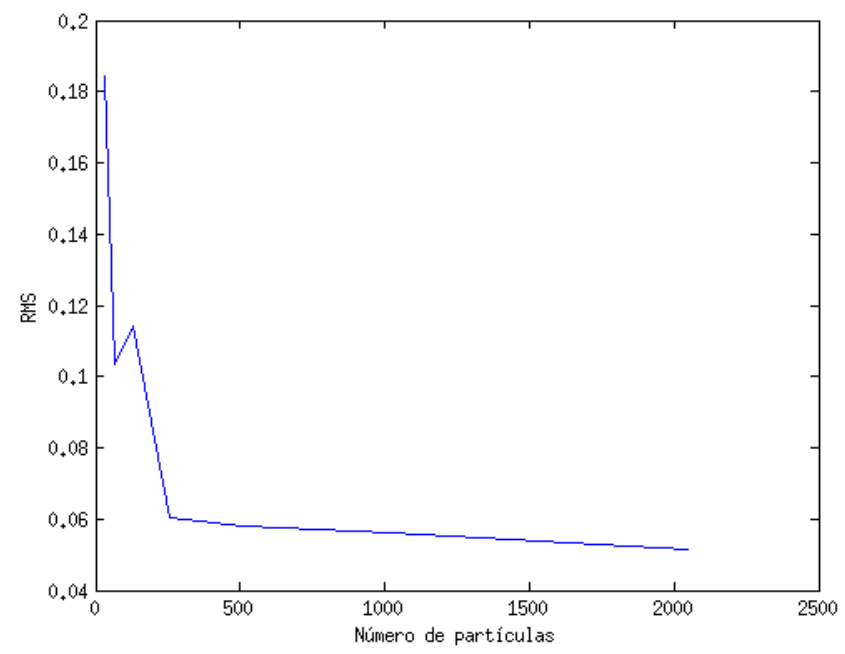

Figura 6.40 - Resultado do cálculo do RMS para diferentes números de partículas para a configuração de sensores que utiliza o sonar de varredura mecânica

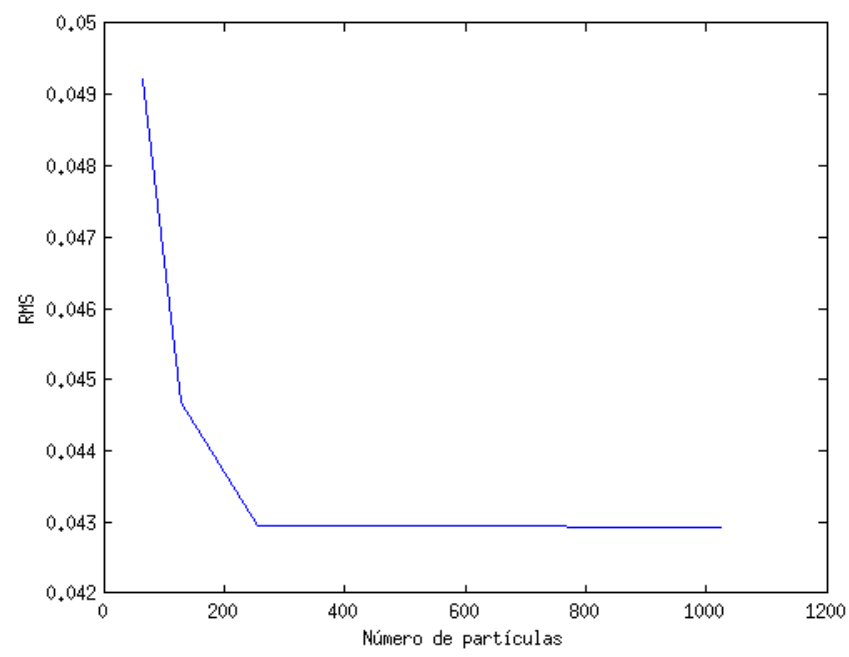

Figura 6.41 - Resultado do cálculo do RMS para diferentes números de partículas para a configuração de sensores que utiliza o sonar de multi elementos

de partículas a configuração com o sonar de multi elementos apresenta um menor valor de RMS do que a configuração com o sonar de varredura o que significa que a estimativa dada pela configuração com o sonar de multi elementos é mais precisa.

\subsubsection{Efeito do número de partículas na entropia relativa da posição}

A medida de erro RMS total capta a métrica mais tangível de erro da estimativa de navegação, ou seja, a distância física entre o estimado e o real. Ela no entanto despreza a maior parte da informação produzida pelo algoritmo de navegação. De fato, o produto do algoritmo não é uma mera estimativa singular de posição do veículo, mas uma distribuição de probabilidades completa do mesmo, representada na forma de uma amostra (vide seção 
3.2). Assim, ao considerar somente a estimativa de posição, a métrica RMS despreza a importante informação de incerteza produzida pelo algoritmo. Deste modo, é interessante empregar uma métrica de desempenho que leve em conta toda a informação produzida pelo algoritmo.

A métrica aqui proposta será derivada da entropia relativa da sequência de configurações reais do veículo, dadas as distribuições estimadas pelo algoritmo. Ela é definida como:

$$
I=-\sum \log (P(\boldsymbol{x}))
$$

Onde $\boldsymbol{x}$ é a posição de referência (obtida por alguma medida externa exata) e $P(\boldsymbol{x})$ é a densidade de probabilidade desta configuração, conforme estimada pelo algoritmo de navegação. A métrica é totalizada para todos os pontos amostrados da trajetória do veículo.

Esta métrica é derivada da entropia relativa ou divergência de Kullback-Leibler [71] entre duas estimativas da localização, uma obtida pelo algoritmo de navegação e outra por um referencial externo mais exato. A divergência de Kullback-Leibler é uma medida da diferença entre duas funções densidade de probabilidade $Q$ e $P$. A divergência pode ser entendida como uma medida da perda de informação, quando $P$ é utilizada para aproximar $Q$. Geralmente, ou a função densidade de probabilidade $Q$ é a distribuição verdadeira ou é uma distribuição precisamente calculada. Já a $P$, geralmente representa um modelo ou uma aproximação de $Q$. No caso das análises que serão feitas neste trabalho, $P$ será a função densidade de probabilidade estimada a partir do conjunto de partículas do filtro que corresponde a estimativa do estado e a $Q$ será a função densidade de probabilidade obtida utilizando a estimativa dada por um sistema de câmeras externo [68] que consegue estimar a posição e a orientação de objetos que estejam em seu campo de visão por meio da utilização de marcadores específicos que são fixados aos objetos. Esse sistema de câmeras foi o mesmo utilizado para validar os resultados do sistema de navegação que foram apresentados na seção 6.2. A divergência de Kullback-Leibler é definida segundo a equação 6.3 .

$$
K(Q, P)=\int Q(\boldsymbol{x}) \log \left(\frac{Q(\boldsymbol{x})}{P(\boldsymbol{x})}\right) \mathrm{d} \boldsymbol{x}
$$

A integral em (6.3) é feita sobre todo o domínio de $P$ e $Q$. Separando a divisão dentro do logaritmo na equação 6.3 é obtida a equação 6.4 .

$$
K(Q, P)=\int Q(\boldsymbol{x}) \log (Q(\boldsymbol{x})) \mathrm{d} \boldsymbol{x}-\int Q(\boldsymbol{x}) \log (P(\boldsymbol{x})) \mathrm{d} \boldsymbol{x}
$$

O primeiro termo de (6.4) corresponde à entropia diferencial de $Q$. Lembrando que $Q$ é a distribuição de posição do veículo obtida com o sistema de referência externo, nota-se que o primeiro termo independe da estimativa $P$, e consequentemente é irrelevante para a 


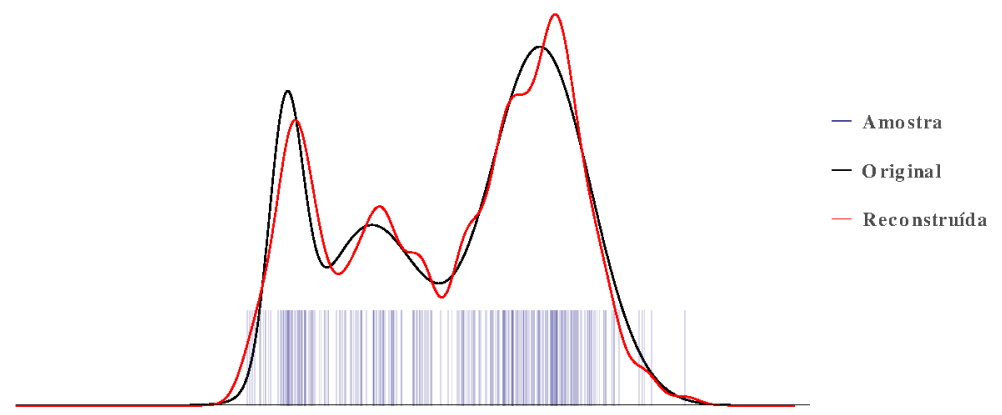

Figura 6.42 - Método escolhido para extrapolar uma função de densidade de probabilidade de um conjunto de pontos.

nossa métrica de informação. Assim, introduzimos para um dado instante a informação relativa obtida com a leitura externa de posição $Q$ dada uma estimativa $P$ :

$$
I(Q, P)=-\int Q(\boldsymbol{x}) \log (P(\boldsymbol{x})) \mathrm{d} \boldsymbol{x}
$$

Partindo da hipótese de que o sistema de referências externo é bem mais exato do que o sistema de navegação pelo sonar, podemos fazer a aproximação de que $Q(\boldsymbol{x}) \approx \delta\left(\boldsymbol{x}-\boldsymbol{x}_{m}\right)$, onde $\boldsymbol{x}_{m}$ é a posição estimada pelo sistema externo e $\delta$ é a função delta de Dirac. Assim, a equação (6.5) resume-se a:

$$
I\left(\boldsymbol{x}_{m}, Q\right)=-\log \left(P\left(\boldsymbol{x}_{m}\right)\right)
$$

Totalizando-se (6.6) para todas as posições do veículo, chega-se à métrica (6.2). Esta métrica pode ser interpretada como o ganho de informaçấo quando adiciona-se às estimativas produzidas pelo sistema de navegação as medidas de posição externa. Naturalmente, quanto menor este ganho, melhor a estimativa original do sistema de navegação. Neste sentido, esta métrica se comporta de forma similar ao erro RMS.

Para que seja possível fazer essa análise é necessário obter uma função densidade de probabilidade a partir de um conjunto de partículas do filtro para possibilitar o cálculo de $Q(x)$. Existem algumas maneiras de se aproximar um conjunto de pontos em um função densidade de probabilidade [15], a escolhida neste trabalho foi a que utiliza kernels para fazer essa aproximação. Nesse método, cada ponto do conjunto é usado como sendo um centro de um kernel e assim a densidade global é calculada por meio de uma mistura das densidades de cada um dos kernels. A vantagem de se utilizar esse método é uma suavização na aproximação da função densidade de probabilidade, além de ter uma implementação simples. O kernel pode ser qualquer função densidade de probabilidade simétrica e que tenha a integra no espaço igual a um. O kernel utilizado neste trabalho foi a distribuição Gaussiana. A figura 6.42 ilustra esse processo de estimação da função densidade de probabilidade a partir de um conjunto de pontos. 
Como a análise do número de partículas necessárias para uma estimativa satisfatória será feita de forma empírica utilizando dados coletados dos sensores, e como o filtro de partículas é um filtro estocástico, o cálculo da entropia relativa da posição para cada número de partículas será feito utilizando dez resultados de estimativas, ou seja para cada número de partículas a localização de Monte Carlo foi executada dez vezes. A figura 6.43 mostra os dez resultados obtidos da estimativa de posição horizontal para três diferentes números partículas ( 128, 1024 e 8192 ) para a configuração de sensor que utiliza o sonar de varredura mecânica, já a figura 6.43 mostra dez resultados obtidos da estimativa de posição horizontal para três diferentes números partículas ( 64, 512 e 4096 ) para a configuração de sensor que utiliza o sonar de multi elementos. Para a configuração que utiliza o sonar de varredura mecânica a análise foi feita com o número de partículas variando entre 32 partículas até 8192 partículas, já para a configuração que utiliza o sonar de multi elementos a análise foi feita com o número de partículas variando entre 64 partículas até 4096 partículas. Para ambas as configurações de sensores, o número de partículas foi avaliado utilizando variações de potência de 2 .

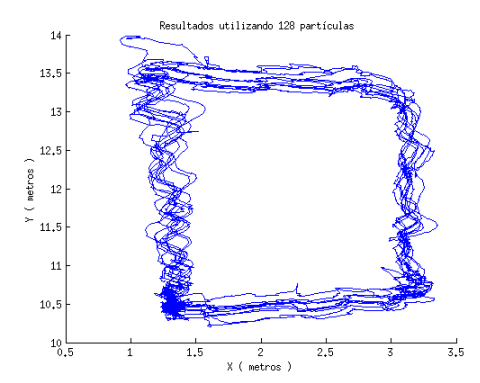

(a) 128 partículas

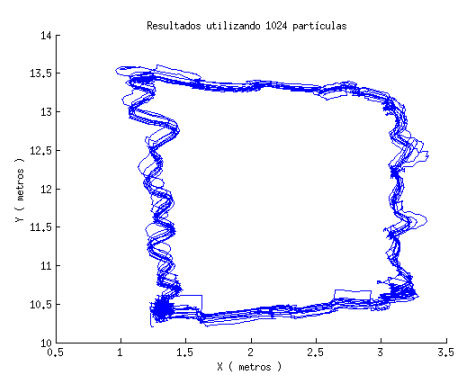

(b) 1024 partículas

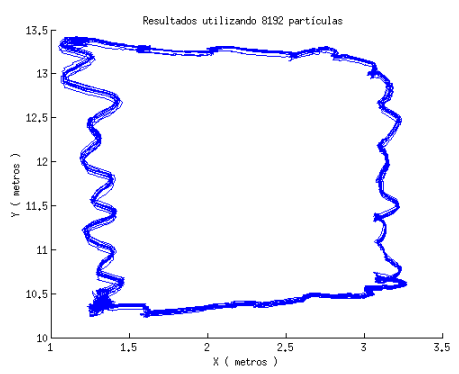

(c) 8192 partículas

Figura 6.43 - Comparação da variância na estimativa de posição dada pelo algoritmo de navegação utilizando sonar de varredura mecânica, o medidor de velocidades por efeito Doppler e o giroscópio para 128, 1024 e 8192 partículas. Para cada um desses números de partículas, o algoritmo foi executado dez vezes, todos a partir de um mesmo conjunto de dados coletados dos sensores.

Das figuras 6.43 e 6.44 é possível verificar visivelmente uma melhora na estimativa com o aumento do número de partículas. Pode ser observado também das figuras 6.43 e 6.44 que a estimativa feita pela configuração que possui o sonar de multi elementos, aparentemente possui uma estimativa melhor do que a estimativa feita pela configuração que possui o sonar de varredura mecânica já que o resultado da configuração que utiliza o sonar de multi elementos para 4096 partículas apresentou uma variância menor do que o resultado da configuração que utiliza o sonar de varredura mecânica para 8192 partículas.

Tendo-se os dez resultados de estimativa de posição horizontal para cada um dos número de partículas que estão sendo avaliados e para cada uma das duas configurações de sensores, foram calculados os valores de entropia relativa. A figura 6.45 mostra o resultado para a configuração de sensores que utiliza o sonar de varredura mecânica e a figura 6.46 


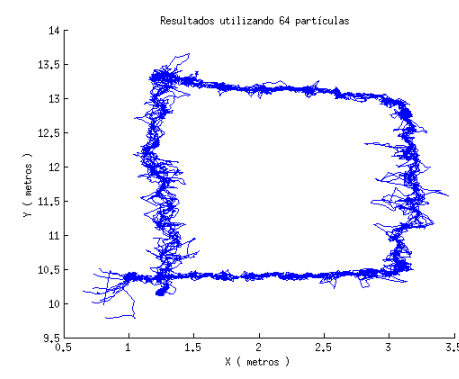

(a) 64 partículas

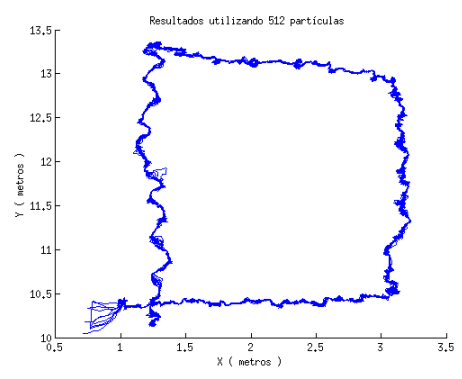

(b) 512 partículas

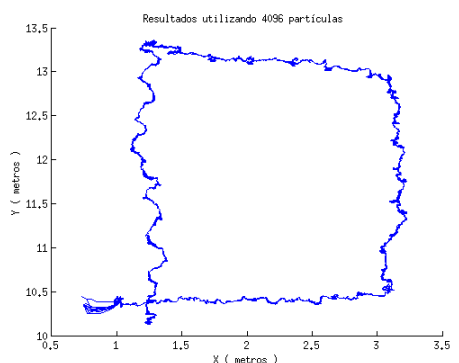

(c) 4096 partículas

Figura 6.44 - Comparação da variância na estimativa de posição dada pelo algoritmo de navegação utilizando 64, 512 e 4096 partículas para configuração de sensores formada pelo sonar de multi elementos. Para cada um desses números de partículas, o algoritmo foi executado dez vezes, todos a partir de um mesmo conjunto de dados coletados dos sensores.

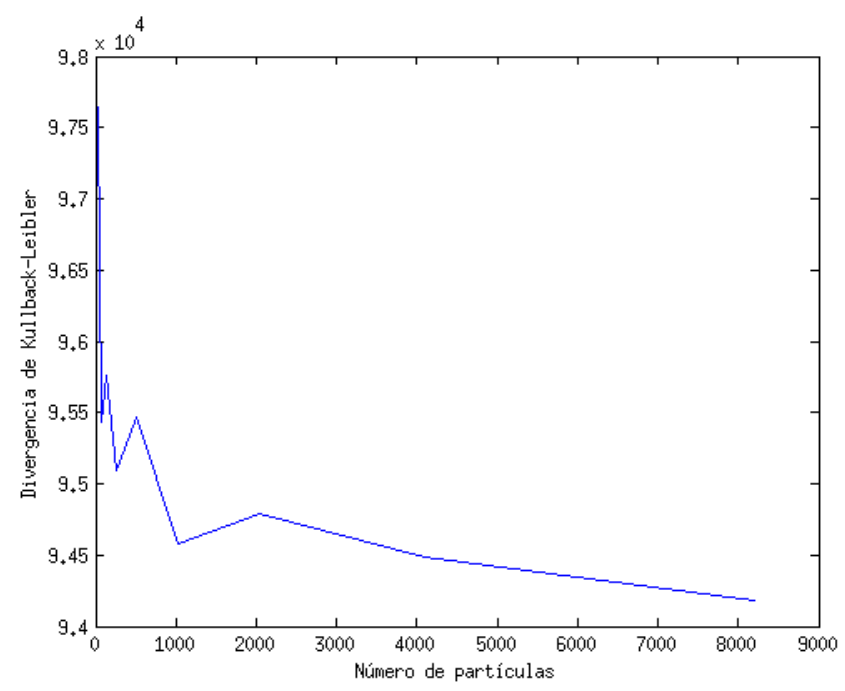

Figura 6.45 - Resultado do cálculo da entropia relativa para diferentes números de partículas para a configuração de sensores que utiliza o sonar de varredura mecânica

mostra o resultado para a configuração de sensores que utiliza o sonar de multi elementos.

As figuras 6.45 e 6.46 mostram um resultado esperado já que a entropia relativa diminui com o aumento do número de partículas, na figura 6.46 essa queda da divergência apresenta uma saturação indicando que a partir de 512 partículas, o ganho com o aumento do número de partículas é pequeno. A figura 6.45 não apresenta uma saturação, mas a partir do número 4000 partículas essa queda é muito menor. Uma última observação das figuras 6.45 e 6.46 é que para um mesmo número de partículas a configuração com o sonar de multi elementos apresenta um menor valor de divergência do que a configuração com o sonar de varredura o que significa que a estimativa dada pela configuração com o sonar de multi elementos é mais precisa. 


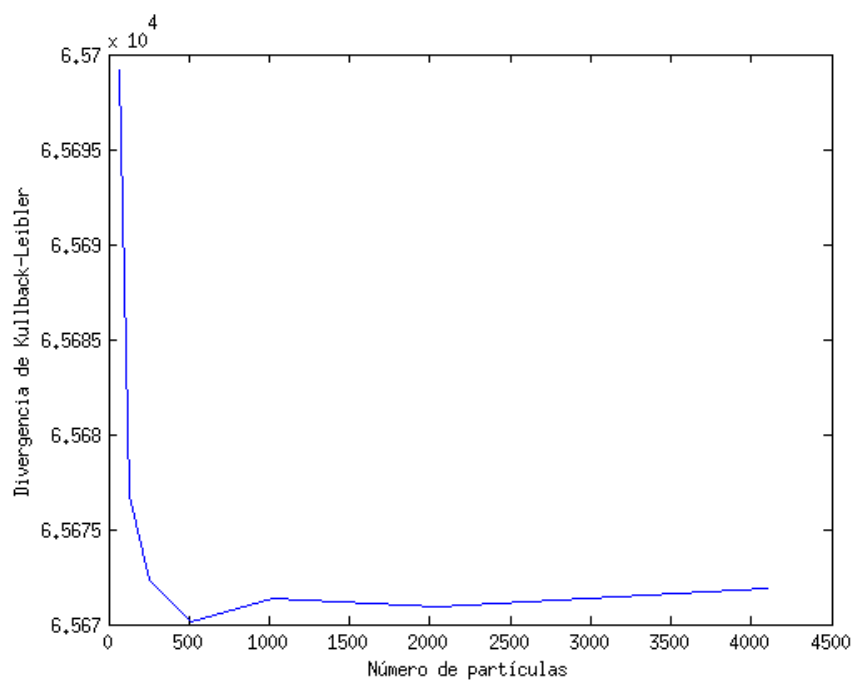

Figura 6.46 - Resultado do cálculo da entropia relativa para diferentes números de partículas para a configuração de sensores que utiliza o sonar de multi elementos 


\section{Conclusões}

Neste trabalho foi proposto um sistema de navegação para robôs submarinos baseado na localização de Monte Carlo, que é uma aplicação do filtro de partículas e que necessita do conhecimento previu das dimensões do ambiente, com o qual foram obtidos resultados que mostraram a capacidade desse tipo de localização para essa aplicação. Para esse tipo de localização foram testadas duas configurações de sensores, uma contendo um sonar de varredura mecânica, um medidor de velocidades por efeito Doppler e um giroscópio e outra configuração formada apenas por um sonar de multi elementos. Os resultados obtidos neste trabalho mostraram uma robustez do algoritmo de navegação proposto já que apesar da modelagem dos erros dos sensores ter sido simplificada, como é o caso do giroscópio que teve seu erro modelado apenas considerando um erro de random walk, os resultados obtidos foram satisfatórios. As duas configurações de sensores foram testadas em diversas condições diferentes, mesmo assim, o pior resultado obtido com a configuração de sensores com o sonar de varredura mecânica foi uma estimativa de rumo com erro médio de 0.7 graus e uma estimativa de posição com erro médio de 0.04 metros. Já o pior resultado para a configuração com o sonar de multi elementos foi uma estimativa de rumo com erro médio de 1 grau e uma estimativa de posição com erro médio de 0.07 metros. Além de se verificar a utilização da localização de Monte Carlo para o caso de robôs submarinos, os resultados obtidos neste trabalho também mostraram a possibilidade do desenvolvimento de um sistema de navegação baseado em apenas um único sensor que no caso é o sonar de multi elementos.

A desvantagem do sistema de navegação baseado no sonar de varredura mecânica é o fato dela precisar de três sensores o que deixa a sua implementação mais complexa devido a necessidade de se modelar um número maior de erros de sensores. Essa configuração de sensores também apresenta a desvantagem de que a sua estimativa pode ser afetada por erros de alinhamentos físico dos sensores. Já a desvantagem da configuração formada apenas pelo sonar de multi elementos é a dependência do sistema com relação a precisão do mapa conhecido a priori, necessário para o funcionamento do algoritmo de localização proposto neste trabalho. Se o mapa utilizado não for preciso, a correlação dos dados do sonar será prejudicada e como essa configuração não possui nenhum outro sensor que possa amenizar esse prejuízo, como é o caso da configuração do sonar de varredura, os erros causados são maiores para essa configuração.

Além disso, como algumas aplicações de ROVs envolvem ambientes que podem apresentar anomalias ferromagnéticos, inviabilizando a utilização de magnetômetros para estimar o rumo, neste trabalho foram propostas duas configurações de sensores que não utilizam esse tipo de sensor para estimar o rumo. Os resultados, além de mostraram que é possível fazer a estimativa do rumo sem a utilização de magnetômetros, também 
mostraram o erro causado neste tipo de sensor quando utilizando em ambientes com anomalias ferromagnéticas.

Como a localização de Monte Carlo é um algoritmo altamente paralelizável, neste trabalho foram mostrados os ganhos de se implementar esse algoritmo na GPU, ao invés da CPU, para deixar a sua execução muito mais rápida. O aumento na velocidade de execução do algoritmo de localização na GPU com relação a CPU depende do número de partículas utilizado no filtro. Além do algoritmo ser altamente paralelizado, uma das duas configurações de sensores estudadas neste trabalho utilizava um sonar de multi elementos que apresenta um fluxo de dados muito grande o que torna o algoritmo de localização ainda mais paralelizável como mostrado na seção 4.1. Além de sonar aumentar a paralelização do algoritmo de localização, a filtragem dos seus dados também foi paralelizada. Então na configuração de sensores baseado no sonar de multi elementos a paralelização foi muito maior e com isso o ganho de sua implementação na GPU também foi muito maior.

Como o sistema de localização proposto neste trabalho é baseado no filtro de partículas que tem sua performance relacionada ao número de partículas utilizado, ou seja, quanto maior o número melhor a estimativa, mas que também tem seu custo computacional aumentado com o aumento do número de partículas, neste trabalho foi proposto uma maneira de se determinar um número de partículas ótimo baseado no conceito de entropia relativa para balancear o custo computacional e a performance do filtro.

\subsection{Trabalhos futuros}

Apesar dos bons resultados apresentados neste trabalho para as duas configurações de sensores estudadas, existem algumas melhorias que ainda podem ser feitas.

Uma melhoria que ajudaria ambas as configurações de sensores é o estudo de um modelo de sonar adaptativo que leve em consideração a influência do ângulo de incidência da onda emitida pelo sonar nos contornos do ambiente. Quando a onda emitida pelo sonar atinge o contorno do ambiente com um ângulo de incidência grande, pouca energia dessa onda é refletida de volta para o sonar, assim o sonar pode não detecta esse contorno, prejudicando a correlação do seu dado com o mapa conhecido a priori necessário para o funcionamento do algoritmo de localização proposto neste trabalho. Como o sonar é responsável pelo ciclo de atualização do algoritmo de localização, isso acaba prejudicando a estimativa do algoritmo. Na modelagem do sonar neste trabalho foi considerado um tipo de erro para tratar erros randômicos, com isso esse erro do sonar devido ao ângulo de incidência foi incorporado nesse tratamento. Porém essa parte da modelagem do sonar considera um valor de erro randômico constante e o erro causado pelo ângulo de incidência muda dependendo do ângulo, assim se na modelagem do sonar no algoritmo de localização for levado em conta o ângulo de incidência da onda, o seu desempenho pode ser melhorado. Alternativas para incorporar a influência do ângulo de incidência foram 
encontradas em [72] e [73]. Em [72] a influência do ângulo de incidência é incorporada de forma adaptativa nos $z_{\text {hit }}$, $z_{\text {rand }}$ e $z_{\text {max }}$ comentados na seção 4.2.2.3, assim dependendo do ângulo de incidência são atribuídos valores diferentes para $z_{\text {hit }}$, $z_{\text {rand }}$ e $z_{\text {max }}$. Já em [73] a influência do ângulo de incidência é incorporada levando em consideração o feixe inteiro do sonar e não apenas considerar o feixe até ele encontra o primeiro obstáculo, como é feito neste trabalho. Assim a modelagem do sonar em [73] leva em consideração todos os obstáculos que a onda emitida pelo sonar encontra. Nessa modelagem ao invés de ser utilizado o algoritmo de ray casting é utilizado o algoritmo de ray tracing.

No caso da configuração de sensores do sonar de varredura, como essa configuração possui um giroscópio, uma possível melhoria consiste em aumentar a dimensão do vetor de estado para incluir um erro de bias para esse sensor. Como foi visto que o número de partículas necessário nas aplicações da localização de Monte Carlo neste trabalho não foram muito altas, é possível fazer esse aumento na dimensão do vetor de estado que fará com que seja necessário um número muito maior de partículas para se fazer a estimativa.

Outro possível trabalho futuro para tentar verificar uma melhoria na estimativa de localização seria fazer uma ańalise do desempenho do algoritmo de localização proposto neste trabalho com diferentes etapas de reamostragem. Os resultados apresentados neste trabalho foram obtidos utilizando apenas a reamostragem sistemática, mas como visto na seção 3.2.4 existem outros tipos e assim uma análise poderia ser feita para se verificar qual das etapas apresenta um melhor desempenho.

Por último, como o escopo do trabalho era desenvolver um sistema de navegação para um ROV, um assunto que não foi estudado neste trabalho foi a utilização dos comandos enviados para o robô pelo joystick como ações de controle no ciclo de propagação da localização de Monte Carlo, que por ser uma fonte de informação a mais pode trazer melhoria no algoritmo. 


\section{A Especificações do medidor de veloci- dade por efeito Doppler}

\section{A.1 Descrição}

As especificações a seguir, foram extraídas do manual do fabricante LinkQuest.

Tabela 1 - Especificações do NavQuest 600 Micro Model P

Frequência acústica de operação entre $600 \mathrm{kHz}$

Acurácia

$0.2 \% \pm 1 \mathrm{~mm} / \mathrm{s}$

Máxima altitude

$110 m$

Mínima altitude

$0.3 m$

Máxima velocidade

\pm 20 knots

Máxima frequência de aquisição

$5 \mathrm{~Hz}$

Número de transdutores

4

Ângulo de feixe do transdutor

$22^{\circ}$ 


\section{B Especificações do giroscópio}

\section{B.1 Descrição}

As especificações a seguir, foram extraídas do manual do fabricante SBG systems.

Tabela 1 - Especificações dos giroscópios da AHRS IG-500A

$\begin{array}{lc}\text { Máxima frequência de aquisição } & 100 \mathrm{~Hz} \\ \text { Intervalo de medição } & \pm 300^{\circ} / \mathrm{s} \\ \text { Viés } & \pm 1^{\circ} / \mathrm{s} \\ \text { Densidade de rudo } & 0.05^{\circ} / \mathrm{s} / \sqrt{\mathrm{Hz}}\end{array}$




\section{Especificações do sonar de varredura mecânica}

\section{C.1 Descrição}

As especificações a seguir, foram extraídas do manual do fabricante Tritech.

Tabela 1 - Especificações do Micro DST sonar

Frequência acústica de operação entre $650 \mathrm{kHz}$ a $750 \mathrm{kHz}$

Largura vertical do feixe $35^{\circ}$

Largura horizontal do feixe

$3^{\circ}$

Intervalo de alcance

2 a 75 metros

Campo de varredura

$360^{\circ}$

Potência 12V-50V@4VA

Comunicação

RS232

Diâmetro máximo

$56 \mathrm{~mm}$

Comprimento máximo

$78.5 \mathrm{~mm}$

Peso no ar

$324 \mathrm{~g}$

Peso na água

$180 \mathrm{~g}$

Máxima profundidade de operação

$750 \mathrm{~m}$ 


\section{Especificações do sonar de multi ele- mentos}

\section{D.1 Descrição}

As especificações a seguir, foram extraídas do manual do fabricante BlueView.

Tabela 1 - Especificações do M900-130

Frequência acústica de operação

$900 \mathrm{kHz}$

Largura vertical do feixe

$20^{\circ}$

Espaçamento dos feixes

$0.18^{\circ}$

Resolução do alcance

0.0254 metros

Intervalo de alcance

0.6 a 100 metros

Campo de visão

$130^{\circ}$

Potência

13-19W

Comunicação

Ethernet/VDSL

Diâmetro máximo

$101.6 \mathrm{~mm}$

Comprimento máximo

$192 \mathrm{~mm}$

Peso no ar

$2268 \mathrm{~g}$

Peso na água

$500 \mathrm{~g}$

Máxima profundidade de operação

$1000 \mathrm{~m}$ 


\section{Referências}

1 CHRIST, R.; WERNLI, R. The ROV Manual: A User Guide for Observation Class Remotely Operated Vehicles. [S.l.]: Elsevier Science, 2011. ISBN 9780080550169. Citado 2 vezes nas páginas 10 e 22 .

2 BARROS, E. et al. New aspects in the pirajuba AUV project. 21st Brazilian Congress of Mechanical Engineering, v. 21, 2011. Citado na página 10.

3 DANTAS, J. L. D. et al. Experimental research on underwater vehicle manoeuvrability using the auv pirajuba. International Congress of Mechanical Engineering (COBEM), 2013. Citado na página 10.

4 LEONARD, J. J. et al. Autonomous underwater vehicle navigation. In: MIT Marine Robotics Laboratory Technical Memorandum. [S.1.: s.n.], 1998. Citado na página 10.

5 STUTTERS, L. et al. Navigation technologies for autonomous underwater vehicles. IEEE Systems, Man, and Cybernetics Society, Part C: Applications and Reviews, v. 38, p. 581-589, 2008. Citado na página 10.

6 PAULL, L. et al. Auv navigation and localization: A review. Oceanic Engineering, IEEE Journal of, v. 39, n. 1, p. 131-149, 2014. ISSN 0364-9059. Citado na página 11.

7 JALVING, B. et al. Dvl velocity aiding in the hugin 1000 integrated inertial navigation system. Modeling, Identification and Control, v. 25, p. 223-236, 2004. Citado 2 vezes nas páginas 12 e 23.

8 MATOS, A. et al. Development and implementation of a low-cost lbl navigation system for an auv. In: OCEANS Conference. [S.l.: s.n.], 1999. v. 2, p. 774-779. Citado na página 12 .

9 ZANONI, F. Modelagem e implementação do sistema de navegação para um $A U V$. Tese (Doutorado) — Universidade de São Paulo, 2012. Disponível em: <http://www.teses.usp.br/teses/disponiveis/3/3152/tde-23032012-114741/en.php>. Citado na página 12 .

10 RIBAS, D.; RIDAO, P.; NEIRA, J. Underwater Slam for Structured Environments Using an Imaging Sonar. [S.1.]: Springer, 2010. (Springer Tracts in Advanced Robotics (Book 65)). Citado 2 vezes nas páginas 13 e 43.

11 GORDOn, N. J.; SAlmOND, D. J.; SMITH, A. F. M. Novel approach to nonlinear/non-gaussian bayesian state estimation. IEE Proceedings F, Radar and Signal Processing, v. 140, p. 107-113, 1993. Citado 2 vezes nas páginas 13 e 27.

12 RISTIC, B.; ARUlampalAm, S.; GORDON, N. Beyond the Kalman Filter: Particle Filters for Tracking Applications. [S.l.]: Artech Print on Demand, 2004. Citado 2 vezes nas páginas 13 e 29.

13 GUSTAFSSON, F. et al. Particle filters for positioning, navigation, and tracking. IEEE Transactions on Signal Processing, v. 50, p. 425-437, 2002. ISSN 1053-587X. Citado na página 13. 
14 GUSTAFSSON, F.; GUSTAFSSON, F.; MEMBER, S. Particle filter theory and practice with positioning applications. IEEE Aerospace and Electronic Systems Magazine, p. 53-82, 2010. Citado na página 13.

15 THRUN, S.; BURGARD, W.; FOX, D. Probabilistic Robotics (Intelligent Robotics and Autonomous Agents). [S.l.]: The MIT Press, 2005. ISBN 0262201623. Citado 8 vezes nas páginas 13, 26, 30, 45, 46, 47, 81 e 85.

16 CEN, G. et al. Effective application of monte carlo localization for service robot. In: International Conference on Intelligent RObots and Systems - IROS. [S.l.: s.n.], 2007. p. 1914-1919. Citado 2 vezes nas páginas 13 e 36.

17 RöFER, T.; JüNGEL, M. Vision-based fast and reactive monte-carlo localization. IEEE International Conference on Robotics and Automation (ICRA), v. 1, p. 856-861, 2003. Disponível em: < https://www.cs.utexas.edu/ pstone/Courses/393Rfall11/readings/ german \_localize \_icra03.pdf $>$. Citado 2 vezes nas páginas 13 e 36 .

18 ZHANG, L.; ZAPATA, R.; LéPINAY, P. Self-adaptive monte carlo localization for mobile robots using range finders. Robotica, v. 30, p. 229-244, 3 2012. ISSN 1469-8668. Disponível em: < http://journals.cambridge.org/article_S0263574711000567>. Citado 2 vezes nas páginas 13 e 36 .

19 BISWAS, J.; VELOSO, M. Wifi localization and navigation for autonomous indoor mobile robots. In: Robotics and Automation (ICRA), 2010 IEEE International Conference on. [S.l.: s.n.], 2010. p. 4379-4384. Citado 2 vezes nas páginas 13 e 36.

20 KARLSSON, R.; GUSTAFSSON, F. Bayesian surface and underwater navigation. IEEE Transactions on Signal Processing, v. 54, p. 4204-4213, 2006. Citado na página 14.

21 RIGBY, P.; WILLIAMS, S. Adaptive Sensing for Localisation of an Autonomous Underwater Vehicle. 2006. Citado na página 14.

22 KO, N. Y.; KIM, T. G.; NOH, S. W. Monte Carlo Localization of underwater robot using internal and external information. 2011. Citado na página 14.

$23 \mathrm{KONDO}, \mathrm{H}$. et al. Auv navigation based on multi-sensor fusion for breakwater observation. The 23rd International Symposium on Automation and Robotics in Construction (ISARC), 2006. Citado na página 14.

24 VALE, R.; BARROS, E.; MARTINS, T. de C. Rov navigation with mechanically scanned sonar and inertial sensors. 9th IFAC Conference on Control Applications in Marine Systems, v. 9, p. 221-226, 2013. Citado na página 14.

25 TEXEIRA, F.; PASCOAL, A. Terrain-Aided Navigation and Geophysical Navigation of Autonomous Underwater Vehicles. Tese (Doutorado) - Instituto Superior Técnico, 2007. Citado na página 14.

$26 \mathrm{KONDO}, \mathrm{H}$. et al. Relative navigation of an auv using image and acoustic based profiling systems. IEEE OCEANS, 2004. Citado na página 14.

27 MAURELLI, F.; PETILLOT, Y. Particle diversity reduction for auv's active localisation. IEEE OCEANS, p. 1-8, 2010. Citado na página 14. 
28 MAURELLI, F. et al. A particle filter approach for auv localization. OCEANS, p. 1-7, 2008. Citado na página 14.

29 LAMMAS, A. K.; SAMMUT, K.; HE, F. A 6 dof navigation algorithm for autonomous underwater vehicles. IEEE OCEANS, 2007. Citado na página 14.

30 DOUCET, A. et al. Rao-blackwellised particle filtering for dynamic bayesian networks. In: Proceedings of the 16th Conference on Uncertainty in Artificial Intelligence. San Francisco, CA, USA: Morgan Kaufmann Publishers Inc., 2000. (UAI '00), p. 176-183. ISBN 1-55860-709-9. Citado na página 14.

31 VERNAZA, P.; LEE, D. D. Rao-blackwellized particle filtering for 6-dof estimation of attitude and position via gps and inertial sensors. In: . [S.l.: s.n.], 2006. p. 1571-1578. Citado na página 14.

32 SCHONEFELD, J.; MOLLER, D. P. F. Mathematical aspects of the implementation of particle filters on fpga. Yth Vienna International Conference on Mathematical Modelling, v. 7 , p. 1243-1248, 2012. Citado 2 vezes nas páginas 14 e 51.

33 MAZZOTTI, B. F. Co-projeto de Hardware/Software do Filtro de Partículas para Localização em Tempo Real de Robôs Móveis. Tese (Doutorado) — Universidade de São Paulo, 2009. Disponível em: <http://www.teses.usp.br/teses/disponiveis/55/55134/ tde-14052010-164204/pt-br.php>. Citado na página 14.

34 TIEMI, P. et al. An Analysis of Parallel Approaches for a Mobile Robotic Self-localization Algorithm. International Journal of Future Generation Communication and Networking, v. 2, n. 4, p. 49-64, 2009. Citado 2 vezes nas páginas 14 e 51.

35 HENDEBY, G.; KARLSSON, R.; GUSTAFSSON, F. Particle filtering: The need for speed. EURASIP Journal on Advances in Signal Process, 2010. Citado 3 vezes nas páginas 14, 52 e 55.

36 CHAO, M. et al. Efficient parallelized particle filter design on cuda. IEEE Workshop on Signal Processing Systems (SIPS), p. 299-304, 2010. Citado 2 vezes nas páginas 14 e 51.

37 RUAS, A.; CAMPOS, M.; CHAIMOWICZ, L. Implementação paralela da localização de monte carlo para robos móveis em gpus comerciais. XVIII Congresso Brasileiro de Automática (CBA), 2010. Citado na página 15.

38 YIGIT, H.; YILMAZ, G. Development of a gpu accelerated terrain referenced uav localization and navigation algorithm. Journal of Intelligent and Robotic Systems, v. 70, n. 1-4, p. 477-489, 2013. ISSN 0921-0296. Citado na página 15.

39 LEONARD, J.; DURRANT-WHYTE, H. Directed Sonar Sensing for Mobile Robot Navigation. [S.1.]: Springer, 1992. ISBN 9780792392422. Citado 2 vezes nas páginas 22 e 44 .

40 BROKLOFF, N. A. Matrix algorithm for doppler sonar navigation. OCEANS '94. 'Oceans Engineering for Today's Technology and Tomorrow's Preservation.' Proceedings (Volume:3), p. III/378 - III/383 vol.3, 1994. Citado na página 23. 
41 TITTERTON, D.; WESTON, J.; ENGINEERS, I. of E. Strapdown Inertial Navigation Technology, 2nd Edition. 2. ed. [S.l.]: Institution of Engineering and Technology, 2004. (IEE radar, sonar, navigation, and avionics series). ISBN 9780863413582. Citado na página 24.

42 DOUCET, A.; FREITAS, N. de; GORDOn, N. Sequential Monte Carlo Methods in Practice. [S.1.]: Springer, 2001. (Information Science and Statistics). ISBN 9780387951461. Citado na página 27.

43 CANDY, J. V. Bayesian Signal Processing: Classical, Modern and Particle Filtering Methods. [S.1.]: Wiley-Interscience, 2009. ISBN 978-0-470-18094-5. Citado na página 27.

44 KALMAN, R. E. A new approach to linear filtering and prediction problems. ASME Journal of Basic Engineering, 1960. Citado na página 28.

45 THRUN, S. Particle filters in robotics. In: Proceedings of the 17th Annual Conference on Uncertainty in AI (UAI). [S.l.: s.n.], 2002. Citado na página 28.

46 WASSERMAN, L. All of Statistics: A Concise Course in Statistical Inference. [S.1.]: Springer, 2004. (Springer Texts in Statistics). ISBN 9780387402727. Citado na página 30.

47 HOL, J.; SCHON, T.; GUSTAFSSON, F. On resampling algorithms for particle filters. IEEE Nonlinear Statistical Signal Processing Workshop, 2006. Citado na página 34.

48 BOLIC, M.; DJURIC, P.; HONG, S. New resampling algorithms for particle filters. IEEE International Conference on Acoustics, Speech, and Signal Processing, v. 2, p. II 589-92 vol.2, 2003. Citado na página 34.

49 FRANCISCO, T. Magnetic navigation and tracking of underwater vehicles. 9th IFAC Conference on Control Applications in Marine Systems, p. 239-244, 2013. Disponível em: $<$ http://www.ifac-papersonline.net/Detailed/64481.html>. Citado na página 38.

50 SNAME. Nomenclature for Treating the Motion of a Submerged Body Through a Fluid. [S.l.], 1950. Citado na página 39.

51 FOSSEN, T. I. Handbook of Marine Craft Hydrodynamics and Motion Control. 1. ed. [S.1.]: Wiley, 2011. ISBN 9781119991496. Citado 3 vezes nas páginas 39, 40 e 41.

52 KEMPE, V. Inertial MEMS: Principles and Practice. [S.l.]: Cambridge University Press, 2011. ISBN 9781139494823. Citado na página 42.

53 VALE, R.; BARROS, E.; MARTINS, T. de C. Rov navigation with mechanically scanned sonar, dvl and gyroscope. COBEM 2013 - International Congress of Mechanical Engineering, 2013. Citado na página 45.

54 NIXON, M.; AGUADO, A. S. Feature Extraction and Image Processing for Computer Vision. 3nd. ed. [S.1.]: Academic Press, 2012. Citado na página 45.

55 MADHAV, S. Game Programming Algorithms and Techniques: A Platform-Agnostic Approach. 1nd. ed. [S.l.]: Addison-Wesley Professional, 2013. (Game Design). Citado na página 47.

56 COUTO, L. N. Sistema para localização robótica de veículos autônomos baseado em visão computacional por pontos de referência. Tese (Doutorado) - Universidade de São Paulo, 2012. Citado na página 47. 
57 ZHANG, H.; MARTIN, F. Cuda accelerated robot localization and mapping. IEEE International Conference on Technologies for Practical Robot Applications (TePRA), p. 1-6, 2013. Citado na página 51.

58 RUAS, A. Implementação paralela de algoritmos para localização e Mapeamento Simultâneos com uma única câmera. Tese (Doutorado) - Universidade Federal de Minas Gerais, 2011. Disponível em: < http://hdl.handle.net/1843/SLSS-8KDQJJ>. Citado na página 51.

59 FARBER, R. CUDA Application Design and Development. 1st. ed. [S.1.]: Morgan Kaufmann Publishers Inc., 2011. ISBN 9780123884268. Citado na página 52.

60 SANDERS, J.; KANDROT, E. CUDA by Example: An Introduction to GeneralPurpose GPU Programming. 1st. ed. [S.l.]: Addison-Wesley Professional, 2010. ISBN 0131387685, 9780131387683. Citado 2 vezes nas páginas 52 e 55.

61 PAPOULIS, A.; PILLAI, S. Probability, random variables, and stochastic processes. 4. ed. [S.l.]: McGraw-Hill, 2002. (McGraw-Hill electrical and electronic engineering series). ISBN 9780073660110. Citado na página 54.

62 GONG, P.; BASCIFTCI, Y. O.; OZGUNER, F. A parallel resampling algorithm for particle filtering on shared-memory architectures. In: Proceedings of the 2012 IEEE 26th International Parallel and Distributed Processing Symposium Workshops 8 PhD Forum. [S.1.]: IEEE Computer Society, 2012. (IPDPSW '12), p. 1477-1483. ISBN 978-0-7695-4676-6. Citado na página 54.

63 NVIDIA. CURAND LIBRARY Programming Guide. 2013. Citado 2 vezes nas páginas 55 e 56.

64 NANDAPALAN, N. et al. High-performance pseudo-random number generation on graphics processing units. In: Proceedings of the 9th International Conference on Parallel Processing and Applied Mathematics - Volume Part I. [S.l.]: Springer-Verlag, 2012. (PPAM'11), p. 609-618. ISBN 978-3-642-31463-6. Citado na página 55.

65 MEEL, J. A. van et al. Harvesting graphics power for MD simulations. Molecular Simulation, v. 34, p. 259-266, 2008. Citado na página 55.

66 GAO, S.; PETERSON, G. Gasprng: Gpu accelerated scalable parallel random number generators. Computer Physics Communications, p. 1241-1249, 2013. Citado na página 55.

67 NGUYEN, H. Gpu Gems 3. First. [S.1.]: Addison-Wesley Professional, 2007. ISBN 780321515261. Citado na página 58.

68 QUALISYS. QTM Qualisys Track Manager USER MANUAL. 2011. Citado 3 vezes nas páginas 62,66 e 84 .

69 BEKIR, E. Introduction to modern navigation systems. [S.l.]: World Scientific Publishing Company, 2007. ISBN 9789812707659. Citado 2 vezes nas páginas 62 e 65.

70 BROWN, R.; HWANG, P. Introduction to Random Signals and Applied Kalman Filtering with Matlab Exercises. 4. ed. [S.l.]: Wiley, 2012. (CourseSmart Series). ISBN 9780470609699. Citado na página 65. 
71 COVER, T. M.; THOMAS, J. A. Elements of Information Theory. 2. ed. [S.1.]: Wiley-Interscience, 2006. ISBN 0471241954. Citado na página 84.

72 BENNEWITZ, M. et al. Utilizing reflection properties of surfaces to improve mobile robot localization. IEEE International Conference on Robotics and Automation (ICRA), p. 4287 - 4292, 2009. Citado na página 91.

73 WHITE, C. et al. C.: The malta cistern mapping project: Underwater robot mapping and localization within ancient tunnel systems. Journal of Field Robotics, 2010. Citado na página 91. 